Universidad Nacional de La Plata

Facultad de Ciencias Jurídicas y Sociales

Maestría en Ciencia Política

\title{
TESIS
}

\section{LIDERAZGO: EVOLUCIÓN Y FUNCIONES}

Alumno: Hugo Cao

Directora de Tesis: Dra. María Cristina Linchetta

Lugar y Fecha: La Plata, 2017 


\section{$\underline{\text { INDICE }}$}

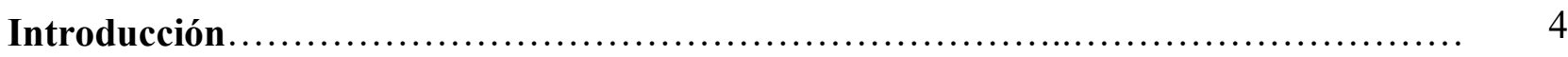
A. Hipótesis
B. Metodología.
C. Estado del arte y marco teórico
D. Desarrollo

\section{Capítulo I. Introducción al liderazgo}

I.1. Consideraciones preliminares............................................... 9

I.2. Lo que distingue al liderazgo.................................................. 11

I.3. Evolución de las teorías de liderazgo................................................................. 13

I.4. Marcos de referencia del liderazgo.............................................. 15

\section{Capítulo II. El poder en el ámbito de lo político y en el ámbito de las organizaciones}

II.1. Introducción al liderazgo político................................................ 18

II.2. El ámbito de lo político y el liderazgo.........................................

II.3. El poder en el ámbito de la política............................................. 26

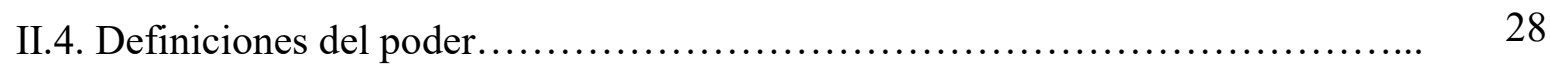

II.5. El rol de las percepciones sociales y de las expectativas......................... 31

II.6. Formas en la que el poder es ejercido............................................ 31

II.7. Autoridad............................................................... 32

II.8. Autoritarismo ........................................................ 35

II.9. El poder en el ámbito de las organizaciones................................. 36

II.10. Los cinco tipos de poder del líder............................................ 36

II.11. Respuestas al uso del poder por posición y al uso del poder personal............ 38

II.12. La dependencia.......................................................... 39

II.13. Incrementar el poder por intermedio de actividades políticas.................... 40

II.14. Tácticas que mejoran la influencia del líder..................................... 41

\section{Capítulo III. El individuo. Rasgos, valores y actitudes}

III.1. Liderazgo y personalidad.................................................... 43

III.2. Énfasis sobre la personalidad............................................... 44

III.3. Valores y actitudes................................................. 45

III.4. Liderazgo carismático y transformacional......................................... 47 
Capítulo IV. La teoría del comportamiento y la teoría de la contingencia

IV.1. La teoría del comportamiento......................................... 51

IV.2. La teoría de la contingencia............................................ 55

Capítulo V. La importancia de las cuestiones humanas

V.1. Modelos mentales................................................... 57

V.2. Inteligencia emocional................................................. 60

V.3. La conveniencia de dirigir con amor en lugar de con miedo...................... 65

\section{Capítulo VI. EI liderazgo moral y los seguidores}

VI.1. El liderazgo moral.................................................... 67

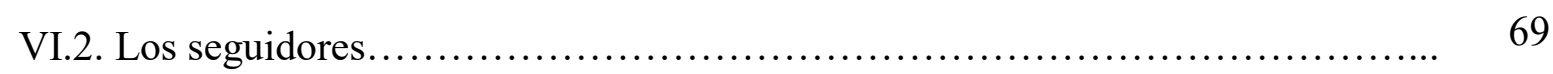

\section{Capítulo VII. La Motivación}

VII.1. Premios intrínsecos y extrínsecos.................................. 71

VII.2. Necesidades de orden superior y de orden inferior....................... 71

VII.3. Teoría de la motivación basada en las necesidades.......................... 71

\section{Capítulo VIII. La comunicación}

VIII.1. Relatos y metáforas............................................... 78

VIII.2. Comunicación informal............................................. 78

\section{Capítulo IX. El equipo y la diversidad}

IX.1. El equipo....................................................... 80

IX.2. Cómo lideran las mujeres........................................ 81

IX.3. El entorno sociocultural........................................... 84

IX.4. Las diferencias...................................................... 86

\section{Capítulo X. Crear una visión y desarrollar la estrategia para conseguirla}

X.1. El liderazgo estratégico.......................................... 88

X.1.1. La visión..................................................... 89

X.1.2. La misión................................................. 90

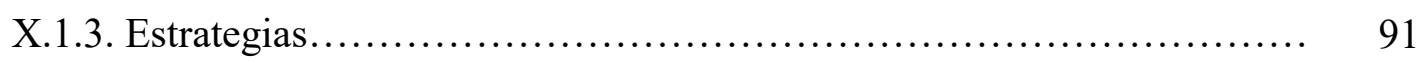

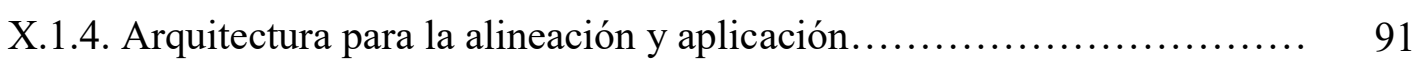




\section{Capítulo XI. La cultura empresarial}

XI.1. Introducción a la cultura empresarial................................... 91

XI.2. Definición de cultura empresarial...................................... 92

XI.3. Niveles de cultura.................................................... 95

XI.4. La necesidad de comprender mejor la cultura............................... 98

XI.5. Fortaleza de la cultura.................................................. 106

XI.6. Cómo se configura la cultura............................................ 107

XI.7. Qué son los valores de la organización................................... 109

XI.8. Liderazgo basado en valores............................................ 109

\section{Capítulo XII. Lo trascendente de la cultura}

XII.1. Las funciones de la cultura............................................. 110

XII.2. Los problemas de adaptación externa.................................. 112

XII.3. Cuestiones de integración interna...................................... 114

XII.4. La función de reducir la ansiedad...................................... 119

\section{Capítulo XIII. La evolución del liderazgo}

XIII.1. El líder de aprendizaje............................................ 121

XIII.1.1. Estructura organizacional................................ 122

XIII.1.2. El desafío del líder de la organización que aprende................ 127

\section{Capítulo XIV. Cómo se crea la cultura}

XIV.1. Teoría sociodinámica de grupos..................................... 128

XIV.2. Teoría del liderazgo................................................. 132

XIV.3. La ansiedad y los tipos de ansiedad................................... 133

XIV.4. El cambio........................................................ 135

XIV.5. Resistencia al cambio............................................... 138

XIV.6. La cara negativa del cambio......................................... 140

\section{Capítulo XV. Configuración e implantación de la cultura}

XV.1. Cómo los fundadores de empresas logran configurar la cultura................ 140

XV.2. Cómo los líderes implantan y transmiten la cultura........................... 141 


\section{Introducción}

Lograr que una estructura social sea más eficaz no resulta una tarea fácil debido a que existen numerosos inconvenientes con los que es imprescindible enfrentarse. Sin embargo, pareciera correcto decir que la organización que cuente con un buen líder que haga las veces de un arquitecto de su propia estructura social y sea capaz de configurar una cultura que se adapte a los requerimientos y a los veloces cambios del entorno, teniendo en cuenta como mínimo las variables más destacadas del liderazgo (líder, seguidores y situación), habrá resuelto gran parte de los problemas esenciales.

Así, la elección de la investigación tiene como fundamento la necesidad de evaluar diversas soluciones para modificar situaciones problemáticas que conllevan no sólo razones sociales sino también políticas y económicas. Principalmente, lo que se pretende, es concientizar de los grandes beneficios que podrían conseguirse si se comprende la importancia que tiene en toda organización, el hecho de contar con un líder sumamente capacitado que ejerza un liderazgo fuerte y comprometido para alcanzar el éxito, sin olvidar el diálogo.

El estudio del concepto de liderazgo, como es sabido, puede ser estudiado utilizando diversos análisis de ciencia política, psicología y sociología; pero, si lo que se pretende es comprender cabalmente cómo los líderes pueden ser arquitectos de una estructura social determinada en la actualidad, resultará imprescindible amalgamar los diversos enfoques.

Para ello, será necesario examinar distintos términos que son la base del tema en cuestión, tales como poder (Bobbio, 2008) y cultura (Schein, 1988), aplicados no sólo al ámbito político sino también al de las organizaciones. Luego, aumentando el nivel de detalle, la concentración se dirigirá hacia el desarrollo de conceptos más específicos, como por ejemplo, la importancia que tienen las personas y las relaciones interpersonales en el liderazgo haciendo hincapié en las distintas personalidades, en los valores y en las emociones. Se enfatizará en los beneficios que otorga el hecho de que la persona se conozca y se comprenda a sí misma para conseguir desarrollar y equilibrar las dos mentes que existen en los individuos: la racional y la emocional.

Una vez descriptas las características personales fundamentales, se pasará a exponer no sólo sobre los tipos de liderazgo como el carismático y el transformacional, sino también sobre ciertas teorías fundamentales como la teoría del comportamiento y la teoría de la contingencia que son dos caminos importantes estudiados por los investigadores para hacer más exitoso el liderazgo. Aquí, se podrá establecer el valor del rol de los líderes estimando el papel elemental que juegan los 
seguidores en la relación de liderazgo, lo que conducirá a precisar cómo es posible conseguir lo mejor de estos últimos mediante una buena motivación. En este sentido, será clave saber cómo lograr una buena comunicación, tanto verbal como gestual, y construir buenas relaciones interpersonales para convencerlos de la necesidad de luchar por el cambio deseado. Así, los líderes podrán determinar cuáles son los valores culturales importantes y utilizar herramientas tales como ceremonias, anécdotas, símbolos, lenguaje especializado, selección, socialización y especialmente por medio de sus actos diarios a fin de influir en los seguidores, configurar la cultura y lograr el futuro deseado.

Sin embargo, se verá que si se quiere enfrentar con eficacia los desafíos planteados, será menester contar con coraje, moral y habilidad para seleccionar los seguidores más adecuados a la función a realizar y a la situación que se presenta teniendo siempre presente la diversidad del mundo actual y las culturas locales. Por ejemplo, se puede pensar en el caso de las mujeres en un país como la Argentina y notar que son tratadas de forma sexista, aunque de la misma forma, se pueden considerar otras minorías que soportan similar discriminación y que deben tener las mismas oportunidades que el resto. De esta forma resultará sencillo darse cuenta que, en estos casos, es fundamental la capacidad de liderazgo para unir a las personas en torno a un propósito común permitiendo y aprovechando las diferencias individuales y ejerciendo adecuadamente el poder y la influencia. Esto permite comprender cómo -en la creciente diversidad cultural- el liderazgo resulta el componente más importante para cambiar la cultura y valorar la diversidad. Una de las funciones sustanciales que tiene que realizar el líder es la de proporcionar una visión convincente de un futuro mejor, que esté bien articulada y que sea comunicada apropiadamente, generando en la sociedad civil la motivación y la energía para acceder a dicho futuro.

En definitiva, quedará evidenciado que para llegar a ser un buen líder se requiere analizar el concepto de cultura en la organización a fin de comprender con más profundidad lo que sucede, por lo que podría sostenerse que una de sus funciones principales sería la creación, la conducción e incluso hasta la destrucción de la cultura del lugar si fuera necesario.

\section{A. Hipótesis}

Pensamos que, las organizaciones y/o instituciones que cuenten en la actualidad con un líder que posea habilidades específicas para ejercer el liderazgo y que utilice adecuadamente el poder y la influencia -entendiendo que las relaciones humanas constituyen un complejo entramado de poder, jerarquía y dominación- lograrán resultados más eficientes y eficaces y, en consecuencia, una evolución de la organización y de sus componentes debido a que conseguirán que los individuos den lo mejor de sí. 
Se demostrará que el liderazgo es un factor estratégico y que todas aquellas organizaciones argentinas que propicien el desarrollo de los líderes en todos los niveles, enseñándoles no sólo la importancia de las funciones del liderazgo sino también la necesidad de realizar un análisis profundo de la situación a fin de ser capaces de poder tomar una decisión y ejecutarla, estarán más cerca de alcanzar el éxito. En este sentido, y de acuerdo a la revisión efectuada, asumimos que la solidez del liderazgo será mayor para quienes logren comprender la relación entre las diversas variables y los distintos estilos de liderazgo debido a que encontramos que existen variables vinculadas con los seguidores y con los líderes (como por ejemplo características personales de ambos, motivaciones o compromiso con la organización) y con el contexto. Esto último será determinante en la correspondencia que habrá entre el buen líder, la satisfacción de las personas y la calidad de una organización.

\section{Objetivos}

El presente trabajo persigue como:

a) Objetivo general: promover y profundizar los conocimientos sobre el liderazgo y sus funciones utilizando una perspectiva multidisciplinaria a fin de desarrollar estrategias para ejercerlo adecuadamente realizando una evaluación acertada del contexto y demostrando cómo todas aquellas organizaciones, ya sean públicas o privadas -que logren aplicar lo expresado previamente- podrán lograr grandes beneficios y, así, alcanzar un futuro mejor.

\section{b) Objetivos específicos:}

1) Identificar la importancia del líder y de su relación directa con la obtención del éxito en la organización.

2) Comprender la importancia del poder y de la influencia en los diversos marcos de referencia.

3) Valorar las características de cada individuo en particular y evaluar su importancia junto con la de los seguidores en su conjunto, el líder y la situación.

4) Determinar la importancia de la cultura organizacional en el liderazgo y demostrar que la cultura y el liderazgo son dos caras de la misma moneda que no pueden ser estudiados por separado.

\section{B. Metodología}

El método elegido para alcanzar los objetivos planteados es el hipotético-deductivo que, en síntesis, determina el procedimiento racional a seguir y está compuesto de varios pasos fundamentales: 
1) La observación del fenómeno a estudiar: este aspecto es inductivo, ya que intenta ordenar lo observado mediante el análisis tratando de extraer conclusiones de carácter universal desde la acumulación de datos particulares.

2) La creación de una hipótesis para explicar el por qué de ese fenómeno detectado.

3) La verificación de la verdad de los enunciados deducidos comparándolos con la experiencia. Este es el momento deductivo del método, donde a partir de principios generales, y con ayuda de la inferencia, se demuestran los supuestos. Un diseño experimental se basa siempre en un razonamiento, en una deducción de las siguientes características: si la hipótesis "p" es correcta entonces se encontrará el efecto observable “q”. Entonces, si se encuentra "q" seguro que “p” es correcta, por lo que la hipótesis recibe un apoyo experimental. Así, el método explicado obliga a combinar la reflexión racional (la formación de hipótesis y la deducción) con la observación de la realidad o momento empírico (la observación y la verificación).

Para nosotros, éste método resulta ser el más adecuado para comprender el liderazgo especialmente el político-, distinguiéndose por tener como pilares la observación objetiva y la observación subjetiva, la comprensión de la situación, la información y los estudios bases. Luego, aparece el análisis y la síntesis y, finalmente, la resolución con la generación de un plan, la ejecución y el control con su posterior verificación.

En otras palabras y en definitiva, tomando los conceptos de Hernández Sampieri, Fernández Collado y Baptista (Hernández Sampieri - Fernández Collado - Baptista, 1997: capítulo 4), la metodología comienza revisando la literatura sobre el tema de investigación seleccionado, teniendo en cuenta el enfoque y los objetivos planteados, para conocer con profundidad el problema (recurriendo a la búsqueda de antecedentes históricos y lingüísticos, entre otros). Luego, se procede a describir los conceptos fundamentales (variables que pueden medirse) cómo es y cómo se manifiesta el fenómeno y sus componentes sometiendo todo al análisis. Por último, se explora la manera en la que se relacionan las diversas variables en un contexto particular (construcción de un escenario acotado témporo-espacialmente) explicando el por qué, es decir, las causas y las razones que las provocan. El estudio ofrece, asimismo, la posibilidad de cierto grado de predicción, posibilitando proyecciones a futuro.

\section{Estado del arte y marco teórico}

Para ubicar el problema descripto, se hará una síntesis seleccionando lo relevante -debido a que los enunciados que aparezcan serán explicados en los capítulos siguientes- a fin de describir cómo ha sido tratada la categoría conceptual de liderazgo hasta la actualidad, de forma que permita determinar su vigencia. 
En ese orden de ideas diremos que, a través de la evolución humana, puede apreciarse cuan frecuente es observar cómo han sido resaltadas las acciones realizadas por líderes de gobiernos, militares, religiosos, de empresas, de equipos deportivos, etcétera. Tal es así que a estos individuos se les ofrece un reconocimiento especial por ser capaces de lograr un propósito trabajando e influyendo en un grupo. Por lo tanto, efectuar un recorrido por la historia haciendo un análisis de la evolución, permitirá identificar ciertas características de los líderes que permiten mejorar la calidad de vida al conjunto de personas que guían debido a que, los recursos humanos -sin olvidar que son seres humanos-, son un recurso que determinará el éxito futuro de una organización.

Los grandes líderes ya aparecen en las civilizaciones antiguas como Sumeria, Egipto, Babilonia, China, Grecia, Roma en carácter de organizadores de regiones, de exploradores o encabezando guerras; es de destacar que el liderazgo recibe una gran contribución de militares y religiosos. Luego, el desarrollo del concepto llega a la edad media con el sistema feudal y continúa posteriormente con la Revolución Industrial. Es por ello que, si bien existen muchas etapas, las citadas son tomadas por su relevancia en el desarrollo de los pueblos, por su impacto y por su influencia en las organizaciones actuales.

De acuerdo con Castaño Sánchez (Castaño, 2013: 24-25), pensadores de China como Confucio y Sun Tzu moldean la cultura China y sientan las bases del pensamiento del mando y la obediencia, explicando que la autoridad la tenía el amo, ya que disponía de la vida y la muerte: se creía que había hombres que habían nacido para mandar y otros para obedecer. Griegos como Platón (Platón, 2008), y Aristóteles (Aristóteles, 2005), realizan aportes en cuanto a formas de gobierno; escritores militares como Von Clausewitz Karl (Von Clausewitz, 2005) colaboran desde el punto de vista militar ofreciendo enfoques distintos; luego, llegan autores del pensamiento en el marco de las teorías de las organizaciones como Frederick Taylor (Castaño, 2013: 27): a mayor motivación recompensas y castigos- mayor rendimiento; Henri Fayol (Koontz - Weihrich, 1998: 17-20) con su enfoque integral de la administración, formuló el proceso administrativo y catorce principios de la administración como los referidos a la autoridad y responsabilidad, la unidad de mando, la cadena escalar (jerarquía) y el espíritu de cuerpo; Max Weber (Weber, 2009: 51) con sus tres tipos puros dominación; Elton Mayo (Castaño, 2013: 27) concepto del hombre social en busca de relaciones sociales dentro del trabajo (líder orientado a la producción y a los empleados). Siguiendo con Maslow Abraham (Koontz - Weihrich, 1998: 506-507) quién explicó que el líder debe conocer las necesidades individuales para motivar a sus empleados; McGregor Douglas (Koontz - Weihrich, 1998: 504-505) y su teoría X: las personas son por naturaleza perezosas e irresponsables -necesidad de control; y su teoría Y: a las personas les gusta asumir responsabilidades; Robert Blake y Jane Mouton (Koontz - Weihrich, 1998: 540-542) idearon la grilla de estilos de liderazgos en función del 
interés del líder hacia los objetivos o hacia las personas; Kurt Lewin (Castaño, 2013: 31-34) relaciona el estilo de liderazgo con el tipo de personas a liderar; Drucker Peter (Castaño, 2013: 36) explica que el líder ofrece más autonomía a los trabajadores del conocimiento; aparición de nuevos conceptos como cultura de las empresas, aprendizaje organizacional. Hollander Edwin (Castaño, 2013: 37) dice que el líder efectivo detecta las necesidades y expectativas de sus subordinados y responde a ellas en consecuencia; Burns James (Castaño, 2013: 38) agrega el sentido de innovación y colaboración, fomento del trabajo en equipo, cuidado de los recursos: confianza y compromiso; Bass Bernard (Castaño, 2013: 38) escribe que el desarrollo de los grupos y las organizaciones elevan los deseos de logro y de autodesarrollo, el optimismo y el entusiasmo; Goleman Daniel acuña al líder con inteligencia emocional (Goleman, 2000). Éstos autores, entre otros, han hecho grandes aportes a la evolución desde distintos enfoques.

Sin embargo, debido a que el tema ha sido bastamente tratado, como además se desprende de la Bibliografía, para investigar la evolución del concepto de liderazgo hemos seguido las conceptuaciones dadas por Norberto Bobbio (Bobbio, 2008) y por Richard Daft (Daft, 2006), por considerar que son las que, a nuestro criterio, mejor se ajustan a la interpretación del fenómeno que nos ocupa.

\section{Desarrollo}

\section{Capítulo I. Introducción al liderazgo}

\section{I.1. Consideraciones preliminares}

De la revisión literaria puede establecerse que el liderazgo es un tema que ha despertado el interés de historiadores y filósofos desde la antigüedad. Los autores han presentado gran cantidad de definiciones del término liderazgo, y se ha llegado a la conclusión de que es uno de los fenómenos más observados en la Tierra y uno de los menos comprendidos. Definir el liderazgo ha sido siempre un problema complejo, en gran parte, porque su esencia misma es compleja: la verdadera esencia del liderazgo es una influencia real y poderosa, tanto en las organizaciones como en las sociedades.

En la actualidad, se entiende normalmente al liderazgo en un sentido muy distinto del de sus orígenes, ya que los estudios sobre liderazgo son una disciplina joven y su estudio científico empezó apenas en el siglo XX, lo que significa que el concepto continuará evolucionando. Como ejemplo de una formulación moderna del concepto tradicional se pude citar la definición que dan R. M. MacIver y C. H. Page (1937) quienes lo consideran como "la capacidad de persuadir o dirigir a los hombres que se deriva de cualidades personales independientemente del oficio" (Bobbio, 2008: 914). Aquí el liderazgo es la resultante de las actitudes del líder en cuanto tal. El 
concepto permanece íntimamente ligado a la idea de una biología particular del líder: y éste es una concepción del líder como "héroe" carismático que ha entrado en crisis.

Es en cambio más realista, como dice Bobbio,

(...) considerar el liderazgo como un papel: que a) se desempeña en un contexto especifico de interacción y refleja en sí mismo la "situación" de este contexto.; b) manifiesta ciertas motivaciones del lider y requiere ciertos atributos de personalidad y habilidad, además de ciertos recursos en general, que son todos (motivaciones, atributos y recursos) variables del papel en función de su contexto; c) está ligado a las expectativas de sus seguidores, con sus recursos, sus demandas y sus actitudes. (Bobbio, 2008: 914).

En este sentido, se observa que la personalidad del líder es uno de los factores que influyen en la determinación del liderazgo, lo que no significa, excluir que el líder pueda por sí mismo elaborar su papel, de una forma más o menos importante, y hasta generar el contexto en el que se coloca como líder. Se trata de precisar la distinción entre liderazgo determinado por el papel y el líder que determina el papel. Es decisivo comprender el hecho de que el liderazgo se relaciona siempre con la situación del contexto en que se consolida. Así, las funciones y los objetivos del liderazgo no pueden considerarse como si reflejaran solamente las motivaciones y los intereses del líder, ya que deben considerarse relacionados con la finalidad otorgada al liderazgo por el contexto que expresa.

Ahora bien, según Daft (Daft, 2006: 5) el liderazgo implica hacer cambios y no conservar el status quo, aunque los cambios pretendidos, en realidad reflejen los propósitos que comparten los líderes y también sus seguidores. En este sentido el liderazgo también busca influir en otros con el propósito de que se agrupen en torno a una visión común y así propiciar el cambio que llevará hacia un futuro deseable. Por lo tanto, como el líder y sus seguidores participan voluntaria y activamente en la persecución del cambio, asumen su responsabilidad personal para llegar a ese futuro. Entonces, a los efectos de este trabajo, se considerará especialmente la siguiente definición de liderazgo que delinea los elementos esenciales de su proceso: "es una relación de influencia que ocurre entre los líderes y sus seguidores, mediante la cual las dos partes pretenden llegar a cambios y resultados reales que reflejen los propósitos que comparten".

En esta introducción al liderazgo, es importante hacer notar que en la actualidad existen veloces cambios del contexto, los cuales provocan transformaciones esenciales que repercuten notablemente en las organizaciones. Estas transformaciones representan la transición de un paradigma tradicional a otro nuevo (entendiendo paradigma como una mentalidad compartida que representa una forma fundamental de percibir y comprender el mundo). A modo de ejemplo, se dirá que el nuevo paradigma apunta a la colaboración, a la diversidad, al fin superior (sobre el fin personal) y a la humildad; motivos por los cuales, los líderes más destacados aceptan que el 
cambio y las crisis son inevitables, sin dejar de reconocer que son posibles fuentes de energía y renovación, y piensan que en vez de darse por vencidos, es preferible desarrollar las habilidades que les sirvan para manejar las crisis y ayudar a sus organizaciones a superar los inconvenientes y avanzar hacia algo mejor.

Además, hay que resaltar que el éxito depende de la capacidad intelectual de todos $\mathrm{y}$, los líderes de hoy, tienen que admitir de una vez y para siempre la terrible realidad: los edificios y las máquinas son posesiones, pero las personas no lo son. De forma tal que una de las tareas más destacadas del líder es guiar a los trabajadores para que utilicen su poder con eficacia y responsabilidad y lo conseguirá si genera un clima de respeto, así como posibilidades de desarrollo para todos los empleados.

\section{I.2. Lo que distingue al liderazgo}

Como es sabido, existen modernos análisis de psicología, sociología y ciencia política que estudian el liderazgo. Por ello, durante la presente tesis, se tratará de amalgamar los diversos enfoques para lograr la idea más precisa posible de lo que significa este concepto.

Entonces, para empezar, se puede decir junto con Bobbio que son líderes los que " $a$ ) dentro de un grupo b) detentan tal posición de poder que influyen en forma determinante en las decisiones de carácter estratégico, c) poder que se ejerce activamente, d) y que encuentra una legitimación en su correspondencia con las expectativas del grupo.” (Bobbio, 2008: 917).

A lo que se puede agregar que entre las tareas del líder, como explica Daft (Daft, 2006: 20-24) se encuentran la de crear una visión que logre convencer sobre el futuro y la de formular estrategias de largo plazo que procure los cambios necesarios para cumplir esa visión. Luego, se encargan de comunicar la visión, de generar una cultura compartida y una serie de valores centrales que puedan ser utilizados como guía para llegar al objetivo deseado. Lógicamente, esto involucra también a otros actores, por lo que los líderes se concentran en alinear a todos en la misma dirección, motivando e inspirando a las personas y fomentando así un sentimiento de pertenencia en todos ellos. Es necesario decir que si bien la visión describe el destino, la cultura y los valores ayudan a definir el camino para alcanzarlo.

El liderazgo se basa principalmente en la influencia por lo que es menos probable que recurra a la coacción. Intenta que el trabajo resulte estimulante e intenta atraer a la gente hacia las metas, en lugar de empujarlas hacia ellas. El objetivo es inyectarles energía, motivándolas porque se sienten identificadas y no por medio de premios o castigos. El poder del liderazgo se deriva del carácter personal del líder, ya que depende de la persona y no de la posición que ocupa o el título que ostenta. Es mucho más que un conjunto de habilidades; depende de una serie de 
sutiles cualidades personales que incluye elementos como el entusiasmo, la integridad, el valor y la humildad. Así, en primer término, el buen liderazgo surge de una verdadera pasión por el trabajo y de un auténtico interés por las otras personas; los mejores líderes son quienes están enamorados de lo que hacen por lo que desean compartir ese amor con otros. Esto significa que están vinculados emocionalmente con los demás, por lo que no fomentan la distancia emocional. Donde el liderazgo se hace presente, las personas se vuelven parte de una comunidad y sienten que están aportando a algo bueno.

El liderazgo requiere además valor para aceptar errores y dudas, para correr riesgos, escuchar, confiar y aprender de otros. Por ello, precisa de una serie de fuerzas sutiles que llevan en su interior los líderes, como por ejemplo, una mentalidad abierta que reciba con agrado ideas nuevas y no las critique; una disposición a no conformarse, a disentir y a decir no cuando no cree que es bueno para la mayoría, y una capacidad para aceptar inconformidades de otros y no intentar obligar a todos a pensar como ellos.

El liderazgo crea el cambio, a veces radical, dentro de una cultura que colabora con la organización a fin de que mejore a largo plazo. Aquí, es donde se necesita valor para tomar decisiones difíciles $\mathrm{y}$, tal vez poco convencionales, que en ocasiones pueden traer resultados negativos a corto plazo. Entonces, el concepto significa cuestionar y desafiar el status quo de modo que las normas que sean antiguas, socialmente irresponsables o incluso improductivas puedan ser remplazadas por otras mejores. Por lo tanto, a diferencia de una buena administración que es necesaria para que las organizaciones puedan cumplir los compromisos actuales, el buen liderazgo es necesario para que la organización pueda avanzar al futuro. Sin embargo, este accionar trae ciertas consecuencias, ya que el liderazgo desgasta a las personas porque los líderes son vulnerables, corren riesgos e inician el cambio que, generalmente, ofrece resistencia.

Para finalizar este parágrafo, se citará una lección ofrecida por el general Colin Powell ${ }^{1}$, en la que de una manera muy clara explica refiriéndose al ámbito militar (pero que es aplicable la idea a otros ámbitos) que el día en que los soldados dejen de transmitirle los problemas a su líder, ése será el día en el cual se dejará de ser el líder. Ello significará que han dejado de pensar que puede ayudarles o que han razonado que lo que exponen no es de su interés. Aquí, el liderazgo ha fallado.

Esta falla, puede ser consecuencia de la gran cantidad de barreras que existen para la comunicación hacia arriba, por lo cual resulta complicado que una persona ubicada en una posición baja de la jerarquía se dirija al líder en busca de ayuda. Por otra parte, la cultura empresarial fomentada también suele establecer que solicitar ayuda es una debilidad o un fracaso,

\footnotetext{
${ }^{1}$ Lección número 2 del general Colin Powell. Secretario de Estado, A Leadership Primer. (Citado por Daft, Richard (2006): La experiencia del liderazgo, México D.F.: International Thomson Editores, P.21.
} 
dando como resultado que las personas oculten los problemas y que la organización sufra las consecuencias. La realidad indica que un buen líder está disponible y es accesible, demostrando preocupación por los seguidores. Por lo tanto, probablemente lo ideal sea la generación de un ambiente donde el análisis de problemas reemplace a la asignación de culpas.

\section{I.2.1. Liderazgo y Administración no son lo mismo}

En palabras de Koontz y Weihrich (Koontz - Weihrich, 1998: 498 y 534), administrar implica planificar cuidadosamente, establecer la mejor estructura organizacional que contribuya al cumplimiento de lo planificado y dotar a dicha estructura del personal más competente posible. La medición y corrección de los individuos a través del control también corresponde a la administración. No obstante, todo ello sería insuficiente si los administradores no supieran como conducir a la gente ni comprendieran a las personas y a los factores humanos para obtener el resultado deseado. El líder genera las condiciones adecuadas para que sus subordinados trabajen en conjunto en favor del cumplimiento de los objetivos de la organización y de los objetivos grupales. Preocuparse por los individuos (por su dignidad personal) y saber cómo motivarlos es muy importante, lo que no significa, convertirse en un psiquiatra aficionado. Es por lo cual, uno de los principios fundamentales del liderazgo, dice que los individuos tienden a seguir a quienes, en su opinión, les ofrezcan la manera de satisfacer sus objetivos personales.

\section{I.3. Evolución de las teorías de liderazgo}

El concepto de liderazgo ha ido evolucionado con el transcurso del tiempo ya que normalmente es un reflejo de la sociedad. Las teorías evolucionan a medida que las normas, el ánimo y las concepciones del mundo cambian. Por ello, a modo de síntesis histórica de los más destacados planteamientos, es posible recorrer y clasificar, según Daft (Daft, 2006: 24-26), las distintas teorías de liderazgo dentro de planteamientos básicos, los cuales se describirán a continuación en orden cronológico.

\section{I.3.1. Teorías del gran hombre}

En sus orígenes, los estudios de liderazgo decían que los líderes, que se pensaba eran hombres, nacían con ciertos rasgos de un liderazgo heroico, así como con capacidad para ejercer el poder y la influencia. El liderazgo estaba compuesto por un solo "gran hombre" que, con la fuerza de sus rasgos y capacidades innatas, influía en otros para que le siguieran.

\section{I.3.2. Teorías de los rasgos}

Luego, los estudios sobre el "gran hombre" llevaron la investigación a intentar averiguar cuáles eran los distintos rasgos que definían al líder. En la década de 1920, se dieron inicio a las investigaciones que trataban de descubrir si los grandes líderes poseían rasgos o características 
especiales, como por ejemplo la inteligencia, la estatura o la energía. Se creía que si se lograban identificar estos rasgos entonces podrían predecir quienes eran líderes o incluso podrían formarlos. Finalmente no se produjo una lista de rasgos que pudiera asegurar siempre el éxito de los líderes, aunque el interés en las características del liderazgo aún perdura.

\section{I.3.3. Teorías del comportamiento}

En la década de 1950, como no se consiguió identificar una serie de rasgos universales, se comenzó a estudiar qué hace un líder en lugar de cómo es. Se investigó lo que los líderes hacen en su trabajo (contenido de las actividades de los administradores, funciones y obligaciones). Posteriormente, se ampliaron los estudios para determinar las diferencias de comportamiento entre los líderes eficaces y los que no lo son, investigando cómo se comportaba un líder con sus seguidores, por ejemplo, si eran autocráticos o democráticos, y la relación que ello guardaba con la eficacia del liderazgo.

\section{I.3.4. Teorías de la contingencia}

Seguidamente, aparecieron las teorías de la contingencia, a veces llamadas teorías situacionales, que explican que es imposible comprender el liderazgo independientemente de las distintas variables del contexto y de la situación que influyen en los comportamientos de liderazgo eficaces. Las variables más importantes de la situación son las características de los seguidores, las del entorno laboral y las tareas de los seguidores, así como las del entorno exterior. La idea es que los líderes estudian la situación y adaptan su comportamiento para mejorar su eficacia.

\section{I.3.5. Teorías de la influencia}

Son las teorías que analizan los procesos de influencia entre líderes y seguidores. Una de las teorías principales es la teoría del liderazgo carismático, que se refiere a la influencia del liderazgo que no se basa en la posición ni en la autoridad formal, sino en las cualidades y la personalidad carismática del líder. Tratan de identificar cómo se comportan los líderes carismáticos y las condiciones que pueden dar lugar al liderazgo carismático. La visión del futuro del líder sirve de inspiración e influye en el cambio de las personas.

\section{I.3.6. Teorías de las relaciones}

Al término de la década de 1970, surgen teorías que consideran que las relaciones interpersonales son el aspecto más importante de la eficacia del liderazgo. Dicho liderazgo empieza a no ser visto como algo que el líder hace a un seguidor sino como un proceso de relaciones, que consiste en la forma en que los líderes y sus seguidores interactúan, influyendo unos en otros, y que permite que cada persona colabore para alcanzar la visión. Por ejemplo, una teoría básica de las relaciones es la del liderazgo transformacional, que estimula a los seguidores para que se vuelvan líderes y eleva los estándares morales y la motivación de los líderes y los 
seguidores. La teoría del liderazgo de servicio enfatiza que el líder es una persona que sirve a los otros y no una que los controla, por lo tanto coloca las necesidades y los intereses de los otros por encima de los suyos.

\section{I.3.7. Teorías emergentes del liderazgo}

Es importante observar que algunos de los elementos de las teorías anteriores todavía se aplican al liderazgo actual y a las teorías que son abordadas desde la perspectiva de un nuevo paradigma. No obstante, el entender al mundo como un lugar confuso, siempre cambiante, arriesgado que presenta constantes desafíos, da origen a nuevos conceptos de liderazgo. De esta manera, al haber un entorno impredecible, aparecen cuestiones tales como la de facilitar el cambio que terminan siendo una parte fundamental del líder. Y, si bien iniciar un cambio siempre fue una función del liderazgo, muchas teorías anteriores no se enfocaron plenamente en el cambio. Ante este contexto la atención apunta a la manera en que los líderes generan cambios tanto en sus seguidores como en la organización, respondiendo a la transformación del entorno. Los líderes, intentan realizar cambios para adaptarse al mundo turbulento, razón por la cual se esfuerzan para crear organizaciones que aprendan, en las que todas las personas participan en identificar y solucionar los problemas. Así, en vez de dirigir y controlar, trabajan con los seguidores para crear una visión compartida y para dar forma a los valores culturales necesarios para realizarla; los líderes construyen entonces organizaciones enteras en formas de comunidades con un propósito y un curso que comparten.

Ahora bien, sólo resta decir que a lo largo de la tesis se irán cubriendo en diversos pasajes éstos y otros temas relevantes vinculados a las teorías mencionadas, tal es el caso de las cualidades personales que deben tener los líderes para crear relaciones eficaces, como por ejemplo la inteligencia emocional, la integridad y las elevadas normas morales y el coraje personal. Además, se verá que los líderes crean relaciones por medio de la motivación, la atribución de facultades, la comunicación del liderazgo, el liderazgo en equipo y la aceptación de la diversidad.

\section{I.4. Marcos de referencia del liderazgo}

Para finalizar el capítulo, es necesario introducirse en los marcos de referencia, pudiendo básicamente definir la palabra marco como la perspectiva utilizada para ver y entender al mundo. Por ello, el concepto de los marcos de referencia es muy importante y comprende principalmente la manera en la que las personas recaban información, toman decisiones y ejercen el poder. Richard Daft (Daft, 2006: 484-487) explica que existen cuatro marcos de referencia: el marco estructural, el de recursos humanos, el político y el simbólico. Estos marcos determinan el modo 
en que los líderes entienden las situaciones y consecuentemente establecen las medidas que tomarán.

De esta manera, debido a que cada marco de referencia presenta ventajas y desventajas, los líderes eficaces se esfuerzan para lograr una perspectiva equilibrada, teniendo en cuenta los cuatro marcos de referencia, ya que mientras más marcos usen mejor podrán entender las necesidades y los problemas de la organización. Entonces, a continuación se realizará un breve resumen de los cuatro marcos de referencia citados.

\section{I.4.1. El marco estructural}

La imagen que representa este marco es ver a la organización como una máquina. Se trata de conseguir una eficiencia mecánica y de tomar decisiones basadas en la eficiencia económica. Las herramientas esenciales de la administración son los planes y las metas y, los líderes, recurren al poder y a la autoridad conferidas por la posición que ocupan para influir en otros. Este marco enfatiza en establecer las metas y esclarecer las expectativas de trabajo para conseguir orden, eficacia y continuidad. Por ello, al preferir descripciones claras de las tareas, las políticas y los procedimientos, se ve a la organización como un sistema racional. Así, los líderes dan valor a los datos y al análisis, buscan la observancia y el respeto de las normas aceptadas y realzan los sistemas administrativos para dar orden y lógica a la organización; el rumbo y el control de los resultados son características apreciadas.

Se puede decir que los estilos de liderazgo orientados hacia las tareas son los que pertenecen al marco de referencia estructural. El liderazgo transaccional, por ejemplo, también recurre al marco estructural. Sin embargo, es necesario aclarar que la estructura, los planes y la racionalidad son requeridos en todas las organizaciones, pero no a expensas de los otros marcos. El marco estructural, llevado al extremo, produce rigidez e incluso la tiranía de los líderes, quienes mencionarán e insistirán que las reglas sean siempre cumplidas.

\section{I.4.2. El marco de los recursos humanos}

En este marco se definen los problemas y los asuntos en términos interpersonales. Aquí, las personas son el recurso más importante de la organización, por lo cual, se busca siempre la forma para que las necesidades humanas sean satisfechas modificando inclusive la organización. Los líderes no recurren exclusivamente al poder de su posición para ejercer la influencia, se centran en las relaciones y los sentimientos (atendiendo al análisis de inteligencia emocional) y lideran atribuyendo facultades y brindando apoyo. Los líderes también fomentan la comunicación abierta y el trabajo en equipo.

La perspectiva de los recursos humanos propicia la participación y brinda oportunidades para el desarrollo personal y profesional de las personas. Los líderes valoran a las personas, están 
siempre visibles, son accesibles y sirven a otros. Las imágenes de este marco son el sentimiento de conformar una familia, de pertenencia y de la organización como un clan. Sin embargo, este planteamiento puede llevar a la ineficacia si los líderes ceden siempre a los caprichos de otros, sobre todo si usan el afecto y la participación como excusa para evitar la responsabilidad del liderazgo.

\section{I.4.3. El marco simbólico}

Los líderes simbólicos ven a la organización como un sistema de valores compartidos. En lugar de recurrir solamente al poder formal y a la política, se concentran en la visión, la cultura y los valores compartidos para influir y liderar. Algunos liderazgos que recurren a este marco son, por ejemplo, el liderazgo carismático y el transformacional. Estos líderes usan los relatos y los símbolos para crear valores compartidos, cambiando de ser necesario los valores culturales para apoyar la diversidad.

Los líderes simbólicos son eficaces cuando articulan una visión compartida, y cuando apoyan las inquietudes y los valores más profundos de los seguidores. Les preocupa el estado de ánimo de las personas y se concentran en aprovechar los sueños y los deseos de las mismas para beneficio de todos y de la organización. Sin embargo, si dependen demasiado del marco en cuestión, pueden generar distintos problemas. Uno de los peligros es que los líderes pueden llegar a desarrollar un complejo de "mesías" donde el líder se vuelve el centro en lugar de la organización y todos sus miembros (parte negra del carisma). Pueden llegar a usar los símbolos para propósitos falaces, poco éticos y egoístas.

\section{I.4.4. El marco político}

El marco político "ve las organizaciones como campos de tensión o de conflictos permanentes por la asignación de recursos escasos." (Daft, 2006: 486). Los líderes crean redes y alianzas y coaliciones para influir; luchan por construir una base de poder y, generalmente, ejercen su poder personal y organizacional para obtener los resultados. Este marco de referencia conducido a un extremo, puede llevar al engaño y a la falta de honradez con el fin de servir a intereses individuales. Sin embargo, los líderes políticos eficaces usan sus habilidades para negociar y crear alianzas con el objeto de servir a los intereses de la organización.

El marco político concibe la organización como una jungla donde el poder y la política son una parte importante de la misma. El poder es una realidad y las maquinaciones políticas están en la vida de la organización. Una parte importante del liderazgo eficaz en muchas organizaciones consiste en adoptar este marco pero no al grado de excluir a los otros marcos.

En definitiva, se puede concluir que cada uno de los cuatro marcos mencionados ofrece posibilidades de mejorar la eficacia del liderazgo, pero cada uno por sí solo es incompleto. Los 
líderes pueden entender su propio marco natural de referencia y reconocer sus limitaciones, y aunque no todos pueden desarrollar capacidades en todos los campos, pueden también aprender a integrar varios marcos y así aprovechar más su potencial de liderazgo. Los líderes eficaces comprenden sus fortalezas, se esfuerzan por ampliarlas y se rodean de seguidores para formar equipos que puedan ayudar a ver a la organización desde muchas perspectivas, idealmente, en sus cuatro formas.

\section{Capítulo II. El poder en el ámbito de lo político y en el ámbito de las organizaciones}

\section{II.1. Introducción al Liderazgo político}

El término liderazgo tiene múltiples acepciones que pertenecen en su mayoría al ámbito privado. Pero, en sentido general puede referirse a diversas actividades, es decir, es aplicable tanto a grupos pequeños como al gobierno de naciones enteras, a las actividades de un supervisor en una empresa como a las de un estadista y a la administración rutinaria como a la creación de organizaciones. Sin embargo, en la esfera de la ciencia política no abundan los textos referentes a éste fenómeno, hecho que resulta extraño ya que es lógico pensar que el liderazgo es uno de los atributos básicos de la política. Entonces, podría decirse que el liderazgo político no es un concepto fácil de precisar y que, su tratamiento, parece no haber sido operacionalizado de forma clara.

El liderazgo de los gobernantes es indispensable para todo sistema político. Sus inicios, podrían remontarse hasta Platón y Aristóteles.

3.1. En La República, Platón detalla un esquema según el cual la dirección política debe ser ejercida por gobernantes que fueran sabios filósofos, ya que ellos serían los únicos capaces de llevar adelante un gobierno justo y deliberar sabiamente sobre los asuntos de la polis. En este contexto, la educación de los hombres aseguraría el buen funcionamiento del gobierno.

Diferente es el planteo realizado por Aristóteles. En Política, este autor postula la necesidad de que la voluntad de los individuos se encuentre subordinada al régimen político al cual pertenecen. De esta manera, haciendo referencia a tres regímenes políticos (monarquía, aristocracia y república), Aristóteles presenta a la república como el más deseable de todos, ya que la considera como el único de los tres que busca continuamente el bien común. Por el contrario, en la monarquía y en la aristocracia, los gobernantes están en condiciones de priorizar sus propios intereses por sobre los de la comunidad. En consecuencia, el planteo combina el cumplimiento de las leyes con el reconocimiento del lugar del líder, que perseguirá el bien común y la felicidad de los ciudadanos. 
3.2. Posteriormente, fue Santo Tomás de Aquino quien plantea que el hombre debía ser comprendido como un ser político y social, comparando a la sociedad con la imagen de una familia, de la cual el rey sería el padre.

3.3. Luego, aparece el pensamiento que presenta Nicolás Maquiavelo en el que distingue principalmente dos clases de Estados: los principados y las repúblicas, donde en cada uno de ellos existirá un liderazgo característico. Los principados nuevos se mantienen a partir de la "virtud"2, debido a que requieren una gran capacidad de mando. Esto significa que el líder de una comunidad debe adaptarse a los cambios e interpretar las diferentes circunstancias que vayan surgiendo utilizando toda su capacidad y recursos disponibles con el propósito principal de conseguir la permanencia de su gobierno aunque, para lograr dicho objetivo, no alcanzan solamente las cualidades de liderazgo si a la vez no cuentan con la eventual posibilidad de emplear la fuerza.

Seguramente, la contribución más importante de Maquiavelo fue escindir de forma concluyente las pautas morales del arte de gobernar, definiendo que la meta fundamental de un príncipe es la de permanecer en el poder; por lo tanto, la capacidad de mantenerse al tanto de las circunstancias, de entender el contexto y de dominar las diferentes situaciones (combinando actos de bondad con el uso de la fuerza), será lo que determine la continuidad del líder. Pero, como los hombres tienden por naturaleza al bien particular, las repúblicas ofrecen un régimen que pretende el bien común de la sociedad. Sin embargo, el líder tendrá también un papel fundamental, en tanto que deberá contribuir y orientar al pueblo para que aspire en su conjunto al bien común presentándose como ejemplo a seguir. Además, en el desempeño de sus funciones, el líder contará siempre con el poder de las leyes como medio para obligar a los otros a actuar de manera adecuada.

3.4. Es preciso destacar el aporte sobre liderazgo conseguido por los autores contractualistas ante la necesidad de obtener protección frente a la violencia. Aquí, el gobierno se concibe como un dispositivo constituido por la resultante de la sumatoria del poder individual, creando en consecuencia una especie de nuevo gran soberano al cual todos deben obedecer por igual. Éste régimen busca impedir el ejercicio abusivo y arbitrario del poder por parte del líder, estableciendo obligatoria la preferencia del interés general por sobre el interés particular; de esta manera, empieza a concebirse la preeminencia de las leyes respecto de los gobernantes. Al igual que en el caso de Montesquieu, se defiende el concepto de la división de poderes y que, sus diferentes partes

\footnotetext{
2 Maquiavelo, entiende a la "virtud" como la capacidad de prepararse y resistir la adversidad cuando cambia la fortuna. El autor explica que, ser virtuoso, no es actuar siempre bien, sino que es saber cuándo actuar bien y cuándo actuar mal. Agrega que, para sobreponerse, hay que dirigir las circunstancias con armas propias utilizando todo lo que se tenga a disposición (recurriendo a la ley o a la fuerza con inteligencia). (Maquiavelo, 2003: principalmente en capítulos XIII, XIV, XV, XVIII, XXIV y XXV).
} 
(la ejecutiva, la legislativa y la judicial), deben actuar a modo de controles, frenos y contrapesos mutuos.

Como se aprecia en esta breve reseña, a excepción de los casos de Platón y de Maquiavelo, el liderazgo aparece íntimamente relacionado con el cumplimiento de la ley.

3.5. Utilizando un enfoque distinto, Max Weber, agrega que el liderazgo debe ser entendido como una relación social en la que es central la aceptación del líder por parte de los seguidores. Por lo tanto, si las personas obedecen es porque se encuentran en una relación de dominación, donde éste último concepto es la probabilidad de encontrar obediencia a un mandato determinado. En consecuencia, no es lo mismo imponerse a alguien que recibir obediencia, ya que la obediencia se transforma en adhesión en virtud de la legitimidad, que hace que no sea necesario, excepto en casos muy particulares, el recurrir a la fuerza o a la amenaza. Incluso, la dominación puede ser legitimada a partir de diversas fuentes, lo que llevó a Weber a establecer sus tipos puros de dominación legítima: tradicional, carismática y legal. (Weber, 2009: 51)

Así, el poder político no es una capacidad personal sino una relación social. Por lo cual, mientras la autoridad esté legitimada por aquellos destinatarios de las normas al creer que las mismas provienen de principios de derecho tanto éticos como obligatorios, hasta el menos idóneo de los gobernantes puede ejercer el poder y recibir obediencia. Esto significa que la dominación y el liderazgo son siempre relacionales y no pueden operar exclusivamente de manera unilateral. De aquí proviene la idea de que son las características propias de la sociedad, junto con las relaciones de situación que ella genera, las que sirven para explicar todo comportamiento político.

Ahora bien, de acuerdo con Norberto Bobbio (en Raimundo, 2008: 1-2), es posible decir que existe una tensión en la figura del líder político ya que se enfrenta y se ubica ante la Ley al mismo tiempo. Por lo tanto, mientras que uno de los objetivos claves de la ley es el de equilibrar y proteger a los ciudadanos y sus intereses de las arbitrariedades del ejercicio personal del poder, los sujetos encargados de los destinos de los gobiernos pueden influir sobre la aplicación de las normas.

\section{II.2. El ámbito de lo político y el liderazgo}

Dentro de los cuatro marcos de referencia mencionados en el capítulo anterior, cambia la manera en la que los líderes utilizan el poder y la influencia. Estos dos términos resultan de difícil comprensión y pertenecen a las definiciones más sobresalientes en el estudio del liderazgo.

Sostiene Julien Freund (Freund, 1968: 34-50) que en el ámbito de lo político se pueden encontrar constantes y realidades inmutables. Estas constantes se mantienen independientes de las variaciones históricas, de las contingencias del tiempo y del espacio. Por ejemplo, es posible decir 
que cualquier clase de política implica el hecho de mandar y de obedecer; y ésta, es una constante que resultará necesario comprender. Sin embargo, las formas del ejercicio del poder varían según las épocas y la estructura característica de la unidad política

Es importante saber que lo político está en el corazón de lo social; es una esencia, un elemento constitutivo de la sociedad, que, como dominación del hombre por el hombre, permanece idéntico a través del tiempo. Es una esencia porque por una parte, es una de las categorías principales, constantes e inextirpables de la naturaleza humana en sociedad, en el sentido de que el hombre es ya un ser social por naturaleza, y por otra parte, una realidad que permanece idéntica a sí misma, sin importar las variaciones del poder y de los regímenes y de los cambios de fronteras en el planeta. Además, todas las esencias son originarias, ninguna se explica por otra, pero cada una puede comprenderse por sí misma. Lo que quiere decir que el hombre naturalmente es un ser político. Esto es así, si entendemos por "esencia" los presupuestos propios y el fin específico de una actividad.

La política, en cambio, es la fuerza ordenadora; introduce el orden y la justicia, la igualdad y la jerarquía. Es una actividad normativa, circunstancial, casual y variable en sus formas y en su orientación, al servicio de la organización práctica y de la cohesión de la sociedad. Es ella la que da a la sociedad sus estructuras, sus formas; es ella la que crea las convenciones, las instituciones, las leyes y los reglamentos; la que modifica las situaciones y permite al hombre adaptarse a las condiciones variables según el espacio y el tiempo. Lo político, por el contrario, no obedece a los deseos y a las fantasías del hombre, que no puede impedir ser lo que es. Entonces, se puede definir a la política como la actividad social que intenta asegurar por la fuerza, normalmente basada en el derecho, la seguridad exterior y la concordia interior de una unidad política, asegurando el orden en medio de luchas que nacen de la diversidad de las opiniones y los intereses.

Ahora bien, el orden implica obligaciones, prohibiciones, coerción, debido a que el hombre no puede hacer todo lo que quiere ni todo lo que le gusta: está sometido a la sujeción de la política. Porque mientras el hombre siga siendo un ser político siempre habrá dos grupos antagónicos.

La encargada de tener como objeto el análisis de la esencia de lo político es la filosofía política. Ella explica los presupuestos, distinguidos de la condición empírica que varía con el espacio y el tiempo, que son la condición propia y universal de una esencia; aunque es conveniente aclarar que el hecho de que un presupuesto sea propio de una esencia no significa que le pertenezca exclusivamente. Es decir, designa las constantes que permiten entender lo real. Pero también son lo real mismo.

La noción de liderazgo, que es el fenómeno a estudiar, se aborda también de manera de procurar captar y describir la realidad; apoyándose entonces sobre lo que enseña la experiencia y la 
historia humana. Por ello, es que se tratará de analizar lo más correctamente posible las realidades y los datos originarios de esta actividad. En verdad, no existe un problema independiente de los hombres que lo viven, o exterior a la conciencia que lo considera como problema. Las dificultades que van unidas a una situación son la consecuencia de las contradicciones de la actividad humana. Entonces, como nada prohíbe hacer intervenir consideraciones psicológicas o éticas en el análisis concreto de un tipo de mando, serán utilizadas también pero teniendo presente que tienen un valor circunstancial. Lo que significa que las continuas transformaciones de las situaciones son una adaptación de la esencia a las circunstancias concretas y a las urgencias.

Es importante observar que desde un punto de vista, cualquier actividad humana divide, al mundo humano en dos categorías de relaciones contrarias. Así, la moral divide las acciones en buenas y malas; la estética divide las obras en bellas y feas, etcétera. Cada una de estas divisiones es específica, no se corresponden, en el sentido de que algo verdadero podría ser idéntico al bien y a lo bello, o inversamente. La relación mando y obediencia es dialéctica, por lo que puede hacerse un análisis de esta forma, lo que además significa que las relaciones entre las nociones pueden ser de colaboración o discordia dependiendo de la circunstancia. Dicha relación, divide de manera específica y absoluta, desde el punto de vista conceptual, el universo humano en dos categorías de hombres: por un lado los que obedecen y por otro los que mandan. El presupuesto del mando y la obediencia no designa de antemano quién debe mandar y quién debe obedecer. No afirma que haya hombres que nazcan para mandar y otros para obedecer. Es éste un condicionamiento empírico que depende de los hombres y las situaciones. Luego, es fundamental conocer que si bien puede existir el fenómeno del mando sin política, no puede haber política sin mando. Es decir que si un presupuesto es propio de una esencia no significa que le pertenezca exclusivamente.

Lo que se trata de hacer no es exaltar o denigrar las virtudes del mando y la obediencia, sino considerar las cosas tal como son. Porque a pesar de que la política sea sólo un sector del conjunto social, involucra a toda la humanidad, ya que ninguna persona puede evadir al dominio político, sea obedeciendo, sea investido de mando. En definitiva, todo esto se vuelve muy necesario para poder comprender el liderazgo.

\section{II.2.1. Mando}

Según Freund (Freund, 1968: 128), se distinguen dos maneras de considerar el mando. La primera, que no es la elegida por el autor para explicar dicho concepto (aunque sí será vista más adelante) investiga al titular del mando, ofreciendo una teoría de las cualidades necesarias para ser jefe o mediante la enumeración de los consejos prácticos que conciernen la mejor forma de ejercer el mando. La segunda, que será estudiada a continuación, consiste en explicar la noción atendiendo a la importancia política. 
De acuerdo a este último punto de vista, el mando consiste "en la relación jerárquica que se establece en el seno de un grupo por la potencia que una voluntad particular ejerce sobre otras voluntades particulares, modelando asi la cohesión del grupo" (Freund, 1968: 129). Entonces, se llama jefe al que posee el privilegio del mando, y autoridad (que se explicará con más detalle a lo largo del actual capítulo) a la idoneidad para estar a la altura de las tareas de la función que se realiza. Sin embargo, el mando político generalmente no se ejerce directamente sobre los miembros de una sociedad, sino mediante el aparato administrativo y burocrático o a través de la fuerza de los partidarios que se unen a la finalidad del mando, o también se apoya en una o más clases sociales. Este conjunto social forma el poder.

Por consiguiente, como ninguna masa se organiza sola se requiere la intervención de una voluntad superior, porque una voluntad colectiva es como mucho un deseo de cohesión que sólo las voluntades individuales realizan. Esto es tan así que, sea cual sea el nivel en el que se considere el mando (grupo en vías de formación, organización ya establecida, Estado) parece que la individualización es uno de sus rasgos permanentes y que el mando nunca es anónimo. En definitiva, el mando es una voluntad individual al servicio de una colectividad. Sin embargo, es cierto que sólo existe mando efectivo cuando lo reconocen los demás, sin que importen demasiado las causas de este reconocimiento: el carisma, el homenaje, el respeto a la autoridad, la tradición, la legalidad o el miedo a la violencia; la capacidad de mandar es independiente de estos motivos, porque al jefe lo empuja el instinto de dominación, la voluntad de potencia. Ocupar una posición de mando es voluntad particular, es haberlo querido y buscado, de otro modo es sólo un objeto de molestia. Y, si bien no existe ningún método para la selección y formación de jefes, éstos se revelan por sí mismos. No obstante, existe algo cierto y es que el instinto de las personas se inclina hacia los hombres en el que, según el lenguaje de Maquiavelo, se unen virtú y fortuna.

Maquiavelo (Maquiavelo, 2003: 220 y 221) da por cierto que la fortuna puede regir la mitad de las acciones, y hace una comparación con un río antiguo que cuando se pone difícil inunda las llanuras y derriba lo que está alrededor llevando la tierra de un sitio al otro. No obstante, los hombres en el tiempo en que esto no sucede, pueden tomar precauciones, por ejemplo, construyendo diques de forma tal que si el río crece nuevamente lo haga de una forma menos perjudicial. Continúa diciendo el autor que lo mismo sucede con la fortuna que "se manifiesta con todo su poder alli donde no hay virtud preparada para resistirla y dirige sus ímpetus alli donde sabe que no se han hecho diques ni reparos para contenerla". Maquiavelo piensa que quien confía ciegamente en la fortuna perece ni bien ella cambia, por lo que observa que obtiene mejores resultados quien concilia la forma de obrar con las circunstancias, ya que es sabido que dos hombres pueden llegar al mismo fin que se proponen utilizando caminos distintos, como así 
también de dos hombres que utilizan los mismos medios uno alcanza el resultado y el otro no. Esto se debe también a la índole de las circunstancias que armoniza o no con el comportamiento elegido. Así, el éxito depende de adecuar el proceder a todos los cambios de las circunstancias al mismo tiempo. Aunque, para lograrlo, se requiere una ductilidad que en el hombre no existe; por ejemplo, el hombre cauto fracasa cada vez que hay que ser impetuoso.

Retomando, es necesario destacar que el mando también es poder. Es dominación y, sea de la clase que sea, en todos los casos el ejercicio del mando va acompañado por la represión. No existe mando que esté exento de ella o que deje de emplearla, al menos, como una amenaza. El mando para cumplir con su propósito precisa su poder ya que cualquier disminución de poder deriva en una disminución de la autoridad lo que deja paso a los abusos, la desunión y al desorden. Esto no impide que el mando trate de regular las relaciones internas de los individuos, sea actuando sobre su vida emocional para obtener su aprobación, o con pedagogía para mejorarlas. La función del mando es política y consiste en mantener el orden y la cohesión de la colectividad por los medios ofensivos o defensivos adecuados. No es el mando quien tiene que decir cuál es la verdad o cuál es el bien, porque este trabajo le pertenece a otras esencias, a la ciencia y a la ética. Las virtudes de sinceridad, austeridad o caridad simplemente no son atributos específicos del hombre político. Por ejemplo, para una colectividad, la prosperidad económica o financiera puede importar más que la honestidad de un hombre. Tanto es así que el gobierno más apto políticamente, no es por obligación el mejor moralmente, pero si es el que está capacitado para responder, en lo inmediato y en el tiempo, a los imperativos.

Es importante ver que el poder es la característica de mando, por lo que resulta que es distinto mando de guía. El guía conduce donde las personas han elegido ir; confían en él porque conoce el camino. El mando, al contrario, con su propia intuición busca el camino de igual manera que los miembros, pero a él es a quién le corresponde elegir.

Se observa entonces que el mando tiene una paradoja: el mando es decisión, es decir, es voluntad arbitraria y discrecional, y precisamente por ello, es que da seguridad contra la fortuna y el desorden.

\section{II.2.2. Obediencia}

El punto de partida para cualquier análisis del concepto de obediencia, de acuerdo al pensamiento de Freund consiste en tener presente que cualquier forma de mando pone en juicio el fenómeno de la obediencia.

De este modo, se entiende por obediencia al "acto que consiste en someterse, en interés de una actividad común determinada, a la voluntad de otros para ejecutar sus órdenes o bien para conformar la conducta con sus reglamentos" (Freund, 1968: 187). Esta definición general se aplica a 
cualquiera de las formas de obediencia, ya sea política o no política. Se puede afirmar que todos los individuos obedecen en algún lugar. Por ejemplo, alojarse durante las vacaciones en un hotel, significa cumplir reglamentos explícitamente notificados o tácitamente aceptados. Así, es que en la mayoría de los casos, la obediencia consiste en comportarse de acuerdo a ciertas normas generales sin las cuales ninguna coexistencia es posible. En este sentido, se puede considerar a la obediencia como resignación o como una sufrida disciplina. Otro ejemplo es el de un maestro que exige en su clase la obediencia de sus alumnos y, al mismo tiempo obedece a sus superiores, ya sea porque es funcionario de una administración, o porque cumple sus deberes de ciudadano (paga sus impuestos, etc.). Pero el principal punto es que el maestro exige la obediencia, no porque la disciplina de obedecer constituyera el fin, sino para obtener los medios de cumplir con su trabajo. Entonces, gracias a la obediencia y al orden que resulta, el alumno aprende y así se cumple la verdadera finalidad de la reunión del maestro y sus discípulos. Como es sabido, éstos aprovechan todas las oportunidades para tratar de perturbar la clase, sin embargo sólo despreciarán al maestro que se deje dominar, que les haga perder el tiempo que ellos ocupan a su gusto. Se ve rápidamente que la obediencia no es la pasividad o resignación, sino la participación y la colaboración en una obra común.

La finalidad de la obediencia es recibir, ejecutar y cumplir la obra proyectada, es acto, en oposición con el mando que es dar una orden con respecto a algo, que pertenece a la esfera de lo posible y de la virtualidad. Por ello la obediencia es un elemento regulador de la vida social.

Se obedecen las leyes y las órdenes del mando porque éste se impone como autoridad y se le acepta como tal. Las personas obedecen por distintos motivos, algunos sólo por prudencia, otros por abnegación que la pueden llevar hasta el heró́smo incluso arriesgando su vida, otros se someten a la fuerza y ven en la obediencia la humillación. Por lo cual, depende de cada individuo decir hasta dónde puede y debe llegar, no hay límite general sino tan sólo un límite particular y frecuentemente circunstancial. Entonces, se puede decir que la obediencia y el mando, son un fenómeno de voluntad.

No hay que perder de vista tampoco algunos aspectos fundamentales: sumado a que un mando seguro inspira confianza, es bueno conocer que si los líderes saben seguir, son ejemplo para otros. Es por tal razón que la prueba de la obediencia puede ser considerada como una escuela de mando, por ejemplo, en el marco de la administración civil o militar. Por otra parte, la obediencia, llegado el caso, se puede transformar en rebeldía, insurrección o resistencia.

\section{II.2.2.1. Resistencia}

Como se explicó, la relación de mando y obediencia tiene como base una relación de voluntades. A lo arbitrario del mando, el seguidor puede oponer lo arbitrario de su rechazo. Ya que 
por imperioso que sea el dominio del poder, puede suceder que choque contra otras voluntades tan decididas como la del que da la orden. Por consiguiente, tampoco el mando es totalmente absoluto, siempre es susceptible de ser juzgado y siempre corre el riesgo de levantar contra sí otras voluntades. Además, si quien resiste no teme a la muerte, se podría preguntar qué puede hacer la fuerza en ese caso. El choque de voluntades que resulta de la desobediencia puede generar desagradables situaciones al mando y por eso justifica la observación sobre el miedo recíproco que sufren los jefes y sus subordinados y que obliga al poder a provocar el miedo como consecuencia de su propio miedo.

Nunca hubo ni habrá un poder que esté completamente seguro de ser siempre obedecido; todos los poderes saben que la rebelión está latente y que pude estallar de un día a otro bajo el efecto de circunstancias imprevistas, por lo que bajo circunstancias precarias se ven obligados a emplear la fuerza para imponerse. Solamente, existe una única autoridad que no siente temor alguno, esta es la que nace del amor.

Este análisis enseña simplemente que ni siquiera la fuerza es capaz de suprimir en su totalidad las posibilidades de desobedecer. Justamente la responsabilidad personal que el individuo asume al desobedecer, es lo que constituye el testimonio de su independencia, es una manifestación de autonomía personal. Es únicamente el individuo quien toma la decisión de someterse a las órdenes por razones que juzga útiles, o bien de rechazar doblegarse a las órdenes del poder, aceptando las consecuencias del acto.

Así, al fijar sus límites, la obediencia fija también los del mando, es decir que se condicionan recíprocamente y que el uno tiene sentido gracias a la otra. Inclusive se entiende esta cuestión como una lucha entre dos arbitrarios que desempata la fuerza. Pero el hecho es que cualquier mando encuentra una oposición y que, según las circunstancias, la oposición se puede convertir en desobediencia. Podría decirse también que los abusos del mando y de la desobediencia son del mismo tipo, debido a que ni el poder ni la libertad nunca saben detenerse.

Entonces, desde que los hombres estudian el poder para entenderlo en su esencia, llegan siempre a la misma conclusión: el poder no cambia en su naturaleza durante el curso de la historia, es independiente de la doctrina utilizada. Cualquier nuevo poder vuelve a caer en las viejas costumbres y se hace conservador una vez que haya pasado la conquista.

\section{II.3. El poder en el ámbito de la política}

Es necesario decir que prácticamente no existe ninguna relación social en la cual no esté presente la influencia de un individuo o de un grupo sobre el comportamiento de otro individuo o 
grupo. Sin embargo, el ámbito en el cual el poder adquiere mayor protagonismo es claramente en el de la política.

Según el análisis ya clásico que del poder hizo Max Weber (Weber, 2009: 51), donde se pregunta entre otras cuestiones el por qué de la obediencia de los hombres, las relaciones de "mando y obediencia" que en mayor o menor medida permanecen continuas en el tiempo y que se hallan típicamente en la relación política, tienden a basarse no solamente en fundamentos materiales o en la costumbre de obedecer que tienen los sujetos que soportan el poder sino también en un específico fundamento de legitimidad del dominio. De este poder legítimo, que es generalmente denominado con la palabra autoridad, Weber individualizó tres tipos "puros": el poder legal, el poder tradicional y el poder carismático. El poder legal, que es principalmente característico de la sociedad moderna, se funda en la creencia en el cumplimiento de obligaciones estatuidas que definen el papel del detentador de poder. La fuente del poder es la ley (creada racionalmente), a la cual obedecen tanto los que prestan obediencia como los que mandan. El brazo administrativo del poder es el de la burocracia, con su estructura jerárquica vertical, en el cual las órdenes son dadas por funcionarios dotados de competencias específicas. El poder tradicional se basa en la creencia del carácter santificado del poder del "pasado" que existe "desde siempre". La fuente de poder es la "tradición" ejercido por los mandatos que el señor imparte a los súbditos. En el modelo más puro el aparato administrativo es de tipo patriarcal y está formado por servidores vinculados personalmente al señor. El poder carismático, que es sobre todo el que más interesa a esta tesis, se basa en la devoción de los seguidores a la persona y a las cualidades del jefe: al carácter sacro, la fuerza heroica, el valor ejemplar o la potencia del espíritu y del discurso que lo distinguen. Los hombres no le obedecen ni se someten afectivamente en virtud de la tradición o de lo estatuido, sino porque creen en él. Lo que significa también que se reconoce al líder como conductor de hombres a causa de un "llamado" interior. El que manda es típicamente el guía (por ejemplo, el profeta, el héroe guerrero, el gran demagogo) y aquellos que le prestan obediencia son los discípulos, seguidores y partidarios.

En verdad los tipos puros no se ajustan exactamente a un tipo real, aunque todos los reales pueden guardar semejanzas con ellos. Sin embargo, tomando los ejemplos dados por Christian Bay (Bay, 1961: 329-330) parece que la autoridad del gobierno democrático es la que más se aproxima al tipo de autoridad legal; la autoridad del Papa es la más parecida al tipo tradicional y las de Lenin y Hitler las más cercanas al tipo carismático.

Después de Weber, el interés de los estudiosos por el concepto de poder se ha incrementado notablemente. Una de las principales corrientes que ha dado vida a la ciencia política y que se hará mención ha tenido su mayor representante en Harold Lasswell. Ésta corriente, se 
contrapuso a las teorías jurídicas y filosóficas anteriores que centraban las investigaciones en el concepto de estado, y concentró el análisis de la política en el estudio del poder como fenómeno empíricamente observable. Lasswell, comprendió, por un lado, que el poder es el elemento principal del aspecto político de la sociedad y, por el otro, examinó utilizando conceptos psicoanalíticos de origen freudiano las relaciones que existen entre poder y personalidad (ver capítulo III), separando incluso a la personalidad política en aquella que está orientada hacia la búsqueda del poder. Los estudios lasswellianos fueron además el inicio de las posteriores investigaciones sobre la personalidad autoritaria.

En la actualidad, el poder es considerado como una de las variables fundamentales en todos los sectores de estudio de la política.

\section{II.4. Definiciones del poder}

Para dar inicio al análisis de esta compleja noción, se tomarán las palabras de Bobbio (Bobbio, 2008: 1190 y 1191), quién explica que el poder estudiado en un sentido específicamente social, es decir en relación con la vida del hombre en sociedad, es la capacidad del hombre para determinar la conducta del hombre (poder del hombre sobre el hombre). El hombre es el sujeto pero también el objeto del poder social. De donde, el poder social es, por ejemplo, la capacidad de un padre de dar órdenes a sus hijos, o el ejercicio de los contrapoderes.

Es preciso observar que no existe poder si no existe, por un lado, un individuo (o grupo) que lo ejerce, y por el otro, un individuo (o grupo) que se comporte de la forma deseada por el primero. Obviamente, el poder puede ser ejercido utilizando instrumentos o cosas. Tomando el caso del dinero, se puede decir que a cambio del mismo, es posible inducir a una persona a tener una determinada conducta. Pero si alguien se encuentra solo o si el otro no acepta comportarse como se le pide por ninguna cantidad de dinero el poder desaparece. Esto demuestra claramente que el poder no reside en ningún objeto, sino en el hecho de que haya una persona y que ésta sea inducida por otra a comportarse de una manera dada. Por lo tanto, el poder social no es una cosa o su posesión, sino que es una relación entre hombres.

Debe agregarse que el poder social es una relación triádica. Para definir al poder, no alcanza con nombrar a la persona o al grupo que lo ejerce y a la persona o al grupo que lo sufre, hace falta determinar también la esfera de actividades a la cual el poder se refiere, esto es la esfera del poder. Una persona o un mismo grupo pueden estar sometidos a distintas clases de poder vinculados con diversos campos; al poder del médico que se refiere a la salud; al del maestro que se refiere al aprendizaje; al del empresario que se refiere al trabajo (especialmente en la esfera económica y en la actividad profesional); al de un superior militar que imparte órdenes que pueden 
comportar el uso de la violencia. Además, la esfera del poder puede ser más o menos amplia y puede variar en la claridad de su delimitación. El poder basado en una competencia específica se limita al área de la competencia, mientras que el poder político o el del padre sobre su hijo se puede ejercer en una esfera muy amplia; y la esfera de poder de quien ocupa un puesto en el ámbito de una organización formal se define de un modo en general preciso y taxativo, mientras que la esfera del poder de un líder carismático no está claramente precisada.

\section{II.4.1. El poder actual}

Bobbio (Bobbio, 2008: 1192-1194) afirma que en el momento en el que la capacidad de determinar la conducta de otras personas se concreta, el poder de ser una posibilidad se transforma en acción, en ejercicio del poder. Por lo tanto, se hace posible efectuar la diferencia entre el poder como posibilidad o poder potencial, y el poder efectivamente ejercido o poder actual. El poder actual es una relación entre comportamientos. Se trata del comportamiento de A (que puede ser un individuo o un grupo) que intenta modificar la conducta de B (individuo o grupo), y se trata del comportamiento de B el cual modifica la conducta por deseos de A.

Hay que señalar que el comportamiento que adopta B al sufrir el poder de A posee al menos algo de voluntariedad; sin embargo no es posible asegurar que B es consciente de actuar de la forma querida por A. Primero hay que decir que consiste en un compromiso voluntario, lo que no significa que la conducta sea "libre". Por ejemplo, si existe poder coercitivo, B se comporta como desea A por la simple razón de que quiere evitar un mal conocido, entonces el comportamiento no es libre, pero como lo cumple, se entiende que está compuesto de un mínimo de voluntariedad. Esta breve explicación permite ahora hacer notar la distinción entre el ejercicio del poder coercitivo y el uso directo de la fuerza o violencia (frecuentemente empleado en las relaciones sociales y políticas). En este último caso A no modifica la conducta de B sino que actúa sobre su estado físico (lo mata, lo hiere, lo inmoviliza, lo recluye dentro de cierto espacio, etc.). Por otra parte, A puede generar un comportamiento deseado en B sin pedirlo explícitamente y ocultando también a B que él quiere tal comportamiento, e incluso, sin que B se entere de tener una conducta querida por A. Este tipo de relación, verificada por ejemplo en ciertos casos de propaganda disfrazada, es conocida como manipulación y es parte del concepto del poder.

\section{II.4.2. El poder potencial}

El poder potencial es la capacidad de fijar los comportamientos de otras personas. Entonces, por un lado, A tiene la capacidad de tener un comportamiento que provoque una modificación en la conducta de B; por otro lado, si esta capacidad es utilizada es probable que B se comporte como es deseado por A. Por ejemplo, un jefe militar ejerce poder sobre sus subordinados cuando da una orden y sus subordinados la obedecen; y tiene poder sobre ellos cuando es probable 
que sus subordinados cumplan la orden si el jefe lo ordenase. Entonces, como ejercer poder incluye tener la posibilidad de ejercerlo, en un sentido general el poder social es la capacidad de modificar intencional o interesadamente los comportamientos ajenos. (Bobbio, 2008: 1194-1195).

Para que exista una capacidad como la descripta primero es preciso disponer de los recursos que pueden llegar a ser utilizados para ejercer poder. Entre dichos recursos se destacan la riqueza, la fuerza, la información y el conocimiento, el prestigio, la legitimidad, la popularidad, tener relaciones con personas que poseen poder, etcétera. Pero los recursos por sí sólo no alcanzan. La capacidad mencionada depende también de la habilidad con la cual se convierten en poder los recursos que tienen los hombres a su disposición. No todas las personas tienen la misma virtud al momento de emplear los recursos para ejercer poder; por ejemplo, una favorita puede ser más hábil que otras figuras femeninas, que han gozado de posición análoga, para usar con fines de poder su relación íntima con un hombre muy poderoso. Obviamente esta habilidad se refiere tanto a la utilización de un solo recurso como a la combinación del uso de varios de ellos.

No obstante, poseer recursos y habilidades aun en un grado superior no es suficiente para hacer que A tenga poder sobre B. Es posible que A tenga mucho dinero y sin embargo puede carecer de poder sobre el pobre B respecto a determinados comportamientos si el segundo no quiere tener tales comportamientos por ningún precio. De forma análoga, una persona que dispone de poderosos medios de violencia no tiene poder sobre un hombre que prefiera la muerte antes que tener un comportamiento dado.

Ahora bien, como consecuencia del análisis realizado sobre el poder potencial es posible detectar las relaciones de poder estabilizado, que son muy importantes en la vida social y política. El poder está estabilizado cuando "a una alta probabilidad de que B cumpla con continuidad los comportamientos deseados por A corresponde una alta probabilidad de que A cumpla con continuidad acciones dirigidas a ejercer poder sobre B" (Bobbio, 2008: 1195). El poder estabilizado se observa normalmente en una relación de mando y obediencia, que puede ser asistido por un aparato administrativo que haga cumplir lo requerido por el poder (como en el caso del poder de gobierno), o puede no ser asistido (como en el caso poder del padre sobre el hijo).

El poder estabilizado también puede ser edificado sobre las características personales del detentador del poder (por ejemplo el carisma) o puede construirse en base al papel del detentador del poder. Cuando además, la relación de poder estabilizado se amalgama con una variedad de papeles bien establecidos y coordinados, se dice que se trata de poder institucionalizado. Un gobierno, un partido político o las fuerzas armadas entre otros, se desempeñan en la sociedad con una institucionalización del poder. 


\section{II.5. El rol de las percepciones sociales y de las expectativas}

Bobbio (Bobbio, 2008: 1195) agrega que el poder no resulta solamente de la posesión de ciertos recursos sino que también deriva de determinadas actitudes de las personas envueltas en la relación. Entre estas actitudes aparecen las percepciones (o imágenes sociales del poder) y las expectativas que se refieren e influyen sobre los fenómenos del poder real. La imagen que un individuo o un grupo se forma de la distribución del poder, contribuye a modificar la conducta con relación al poder. El individuo A puede hacer uso de un poder que sobrepasa los recursos efectivos que tiene a disposición (y su voluntad y habilidad de transformarlas en poder) si quienes soportan su poder creen que A tiene más poder de lo que justifican sus recursos.

Con respecto de las expectativas, resulta evidente que en un ámbito de poder dado, el comportamiento de cada actor es determinado también por lo que el actor prevea sobre las acciones futuras de los otros actores y sobre la evolución de la situación. El caso más evidente es el de las relaciones de poder que trabajan por intermedio del mecanismo de las reacciones previstas. El poder funciona de esta forma cuando B modifica su conducta, como desea A y sin una intervención directa de A, porque B prevé que A tomará reacciones desagradables para él si no cambiase su conducta.

\section{II.6. Formas en la que el poder es ejercido}

Existen muchas formas en que los recursos pueden ser usados para ejercer poder; pueden ir desde la persuasión hasta la manipulación, desde la amenaza de un castigo hasta la promesa de una recompensa. Hay definiciones que sostienen que el poder aparece solamente cuando la modificación de los comportamientos ajenos es basada en la coerción $\mathbf{n}^{\mathbf{3}}$ : que es posible definirla como un elevado grado de constricción (o amenaza de privaciones). Cuando esto sucede es posible efectuar la diferencia entre poder e influencia (éste último término se explicará luego con más detalle). Sin embargo, son muchos los ejemplos en los que se emplea el concepto poder para indicar relaciones no coercitivas: en algunos casos se puede hablar de un poder basado en la persuasión.

Por lo tanto, es importante analizar aquí el problema de la conflictividad del poder que se vincula con los modos específicos a través de los cuales se establece la conducta ajena. Se puede decir que existe un conflicto entre la voluntad de A y la de B en dos momentos determinados: en el que A quiere ejercer poder sobre B (momento inicial del ejercicio del poder) o en el que B tiene el comportamiento deseado por A (momento final del ejercicio del poder). El hecho de que haya un conflicto inicial entre la voluntad de A y la de B está dentro de la definición del poder, porque es

\footnotetext{
${ }^{3}$ Poulantzas, Nicos (1985): Poder politico y clases sociales en el estado capitalista, México: Siglo XXI Editores.
} 
notorio que B habría actuado de distinta manera a la que lo obliga a seguir A. El problema a resolver es el de establecer si hay siempre un conflicto entre la voluntad de A y la de B también en el momento final. La respuesta es negativa, ya que la conflictividad depende del modo del ejercicio del poder. Por ejemplo, se observa que en un ejercicio de poder basado en la persuasión no hay conflicto de voluntad, y en un ejercicio de poder basado en la amenaza de castigo si hay un conflicto de voluntad.

Sin embargo, se puede decir que el carácter antagónico de las relaciones de poder puede derivar además de los conflictos de voluntad, de otros aspectos del poder. En el caso de la manipulación no aparece en principio un conflicto; pero lo que si hay es un conflicto potencial, que aparece cuando B se da cuenta de que su conducta fue manipulada por A. Por lo tanto cuando B se da cuenta de la operación manipulatoria que sufrió, siente un resentimiento y se forma un juicio negativo de la acción de A, lo que lleva al conflicto. Llevando este caso al grado extremo de instigación, la conflictividad de la relación puede nacer porque B se siente herido y aumenta el resentimiento por la notable desigualdad entre sus propios recursos y los de A, como así también porque A saca ventaja de esta situación de desigualdad. El resentimiento como consecuencia de la desigualdad de recursos y el antagonismo de voluntades forman la segunda y la primera matriz de la conflictividad del poder. Puede encontrarse también en general en todas las relaciones de poder puesto que toda forma de poder es normalmente la expresión de una desigualdad de recursos. Y en cuanto ésta es más sentida por la persona como una carga o como un ultraje, la relación de poder tiende en mayor medida a crear un antagonismo de voluntades y a preparar un conflicto abierto.

La segunda matriz de conflictividad del poder, que consiste en la desigualdad de recursos y en el posterior resentimiento social, es solamente un motivo potencial de conflicto. Esto se debe por un lado a que la desigualdad de recursos, que es el fundamento de una relación de poder continuado y asimétrico, puede no ser observada por los sujetos sometidos al poder. Por otro lado, existe la posibilidad de que logren ver la desigualdad de recursos, pero que la acepten como justa y legítima apoyándose principalmente en una doctrina política o social específica. En tercer lugar, aunque la desigualdad de recursos se perciba y se considere injusta, puede suceder que sea atribuida a otras personas o grupos de los que realmente tienen el poder. Por último, es posible que el sentimiento de injusticia o de resentimiento social sea dirigido contra quienes poseen el poder, pero que, sin embargo, resulte silenciado por los mismos oprimidos o no lleve a un conflicto abierto.

\section{II.7. Autoridad}


Para comprender mejor este capítulo hace falta explicar el concepto autoridad. Ésta noción constituye uno de los términos principales de la teoría política y se emplea en relación cercana con la noción de poder.

A modo de introducción se distinguirá sintéticamente los términos poder y autoridad en el marco de una organización. Así, Koontz y Weihrich (Koontz - Weihrich, 1998: 302) explican que el concepto de poder, que es más amplio que el de autoridad, es la "capacidad de individuos o grupos de inducir o influir en las opiniones o acciones de otras personas o grupos". La autoridad "es el derecho propio de un puesto (y por lo tanto de la persona que lo ocupa) a ejercer discrecionalidad en la toma de decisiones que afectan a otras personas".

\section{II.7.1. La autoridad como poder estabilizado}

La palabra autoridad ha sido utilizada con significados diversos, sin embargo como se dijo, el uso más común se ve al diferenciar el poder de la autoridad, considerando a esta última como una especie del género "poder" o también, en menor medida, como una simple fuente del poder.

Según Bobbio (Bobbio, 2008: 118) la primer forma de entender la autoridad como una especie de poder es la de definirla como una relación de poder establecido e institucionalizado en que los subordinados obedecen incondicionalmente. Entonces, una persona tiene autoridad cuando el sujeto pasivo de la relación de poder adopta como propio el mandato o la orientación del sujeto activo sin analizar el contenido. A esta actitud le puede corresponder también la actitud del jefe de no explicar las directivas y de esperar que sea cumplida incondicionalmente.

Por lo tanto, lo importante para identificar la autoridad, es observar el hecho de que las órdenes se obedezcan de modo incondicional sin tener interés el fundamento por el cual se adoptan incondicionalmente. Este fundamento puede consistir en la legitimidad del poder o en un condicionamiento basado en la violencia.

En definitiva, la autoridad es aquí entendida como poder estable, que continúa en el tiempo, al que los subordinados dan, dentro de algunos límites, una obediencia incondicional. Usualmente, todas las relaciones de poder más persistentes y más importantes son, en mayor o menor medida, relaciones de autoridad: el poder de los padres sobre los hijos en la familia; el del maestro sobre los alumnos en la escuela; el poder de un empresario sobre los trabajadores; el de un jefe militar sobre los soldados; el poder del gobierno sobre los ciudadanos del estado. (Bobbio, 2008: 119).

\section{II.7.2. La autoridad como poder legítimo}

La definición de autoridad como simple poder estabilizado les parece demasiado amplia a muchos politólogos y sociólogos. Por lo cual, la segunda y más común definición de autoridad, es la del tipo de poder estabilizado al que se llamará poder legítimo, según el cual no todo poder 
estabilizado es autoridad, sino sólo aquel poder estabilizado en el que la disposición a la obediencia incondicional se basa en la creencia en la legitimidad del poder. (Bobbio, 2008: 120).

La expresión "poder legítimo" se comprende como poder considerado legítimo por los individuos o grupos que forman parte de la misma relación de poder. En la esfera social a la que pertenece la autoridad se cree que la autoridad tiene el derecho de mandar (o de ejercer el poder) y que las personas sometidas tienen el deber de obedecerle. Este derecho y este deber pueden estar en mayor o menor medida formalizados, y pueden estar establecidos o en la obligatoriedad de la esfera ética, como en el caso de los tres tipos de legitimidad definidos por Max Weber, o en una mera conveniencia, como puede suceder en una autoridad fundada en una competencia particular.

Haciendo una combinación entre la primera y la segunda definición se puede concluir que, en la autoridad, lo que produce la actitud (estable a través del tiempo) de la obediencia incondicional a las órdenes, es la aceptación del poder como legítimo. Es evidente que esto último se cumple dentro de la esfera de la actividad a la que se refiere la autoridad. Hay que decir que la obediencia incondicional, aunque pueda ser durable, no es permanente. Por lo tanto, para que la relación de autoridad pueda perdurar, es preciso que en determinadas ocasiones se reafirme la cualidad de la fuente del poder que fundamenta la legitimidad. Por ejemplo, la legitimidad democrática necesita la renovación del procedimiento electoral.

\section{II.7.3. Eficacia y estabilidad de la autoridad como poder legítimo}

Como fue explicado, la definición de la autoridad como poder legítimo está compuesta en primer lugar de la aceptación obligatoria la obediencia incondicional y, en segundo lugar, de la pretensión a tal obligatoriedad, es decir, del derecho de que haya una obediencia incondicional. Por lo tanto, a partir de aquí, es posible construir un tipo "puro" de autoridad fundada exclusivamente en la legitimidad, que difícilmente pueda darse en la realidad, ya que frecuentemente la creencia en la legitimidad no es el único fundamento del poder sino sólo una de sus bases. El que ejerce el poder es obedecido no sólo a través de la legitimidad de su poder sino también llegado el momento basándose por ejemplo en su capacidad de obligar o castigar, de halagar o premiar. Además, la creencia en la legitimidad del poder como motivación de la persona que se adecúa a una orden, va acompañada normalmente de otras motivaciones, como la del temor a una amenaza o la de la persecución de su propio interés.

La relevancia de la creencia en la legitimidad, que modifica al poder en autoridad, tiende a darle al poder eficacia y estabilidad. Hay que destacar el efecto psicológico que la fe en la legitimidad del poder puede generar en quien lo ejerce. La fe tiende a darle al mandato ciertas características, como por ejemplo de convicción, de determinación, de energía, que favorecen la eficacia. En segundo lugar, la creencia en la legitimidad contribuye notablemente en la cohesión 
entre los individuos y grupos que detentan el poder. Dicha creencia limita los conflictos internos y proporciona normalmente el principio para su solución; de ahí es que se deriva la mayor cohesión y en consecuencia una mayor estabilidad y eficacia del poder.

Desde el lado de la obediencia, es importante comprender que a la creencia en la legitimidad le corresponde una actitud de obediencia a un deber, y tiende a generar una disposición a la obediencia incondicional. Entonces, si la obediencia se transforma en un deber, la relación de poder tiene mayor eficacia, ya que los mandatos son realizados a mayor velocidad, sin que quienes posean el poder necesiten recurrir, o lo hagan en menor medida, a otros métodos para ejercerlo, como son la coerción, la satisfacción de intereses de los seguidores o la persuasión. Por otra parte, al generarse la disposición a obedecer el poder se estabiliza, y esta estabilidad va volviéndose mucho más sólida cuanto más incondicional sea la disposición a obedecer, esto se cumple siempre dentro de la esfera de aceptación de la autoridad. Debe ser agregado que también existe una relación indirecta entre la creencia en la legitimidad del poder y la disposición a obedecer, porque en una esfera social determinada, en la que el poder es aceptado como legítimo, la persona que no lo reconoce puede estar sometido a presiones laterales (que provienen del resto de los individuos o grupos sujetos a ese poder) que tratan de instigarlo a obedecer para no ver alterada su propia vida.

\section{II.8. Autoritarismo}

Cuando se da el caso en el que finaliza la creencia en la legitimidad del poder por parte de las personas que reciben las órdenes, que puede producirse: a) porque los subordinados dejan de creer que la fuente del poder posea la cualidad que le atribuían antes, o b) porque los seguidores han dejado de lado el principio de legitimidad para tomar uno nuevo, se produce una situación muy conflictiva, debido a que tanto los superiores como los subordinados suelen pensar que han sido traicionados en sus expectativas y en sus valores. Entonces, la relación de autoridad desaparece inmediatamente y, sin embargo, lo que si continua es la pretensión de mandar por lo que aparece una situación de autoritarismo. De las diversas definiciones posibles, se elegirá el concepto de autoritarismo que designa una situación en la que las decisiones se toman desde arriba sin la participación o el consentimiento de los seguidores. Esto significa que una manifestación de autoritarismo es creer que se tiene derecho a mandar sin basarse en las creencias de los que sufren el poder, y es también una manifestación de autoritarismo procurar una obediencia incondicional cuando los seguidores quieren discutir el contenido de los mandatos. En definitiva, se puede establecer una situación de autoritarismo siempre que los que detenten el poder consideren legítimo mandar cuando el mando no es reconocido como legítimo por parte de los subordinados. Esta situación se agrava si el que ejerce el poder recurre a la fuerza o a otros instrumentos de poder 
para alcanzar la obediencia incondicional que no consigue a través de la creencia en la legitimidad. (Bobbio, 2008: 125).

\section{II.9. El poder en el ámbito de las organizaciones}

Desde la perspectiva de las organizaciones, el poder es una fuerza intangible que, aunque no se ve, su efecto se percibe. Así, en ocasiones el poder es definido como "la capacidad que puede tener una persona (o departamento) para influir en otras personas (o departamentos) con el fin de que cumplan sus órdenes o de que hagan algo que, de lo contrario, no habrían hecho"4. Otras definiciones posiblemente expresen que el poder es la capacidad de los que detentan el poder para lograr los resultados deseados.

Junto con Daft entiendo que la esencia de la definición es la consecución de los resultados deseados. Entonces se definirá al Poder como "la capacidad que tiene una persona o departamento de una organización para influir en otras personas para que produzcan los resultados deseados" (Daft, 2006: 489). Por lo tanto consiste en el potencial que tienen los sujetos que detentan el poder para influir en otros miembros de la organización con el objeto de que consigan los resultados que desean los primeros. Dicho potencial del poder es efectuado a través de los procesos de la política y de la influencia. Hay que señalar que, a veces, dependiendo del enfoque del autor, los términos poder e influencia son utilizados como sinónimos, no obstante existen diferencias entre los mismos. La "influencia es el efecto que los actos de una persona producen en las actitudes, los valores, las creencias o los actos de otros" (Daft, 2006: 489). Así, se puede decir que el poder es la capacidad para producir un cambio y la influencia es el grado real del cambio. Para que se comprenda mejor se darán los siguientes ejemplos: en la infancia una persona tal vez formó parte de un juego en el que no quería estar debido a que una persona del grupo influía para que se hiciera lo que ella deseaba. O posiblemente cambió de opinión respecto a la carrera que estudiaría por la influencia de alguien importante, o quizás adoptó otra mirada sobre un tema social debido a la influencia de un líder político. Es preciso aclarar que aunque sea común creer que el poder y la influencia pertenecen al líder, la realidad establece que son resultado de la interacción de los líderes y sus seguidores en situaciones específicas. Lo que significa que los seguidores también hubiesen podido influir en la conducta del líder.

\section{II.10. Los cinco tipos de poder del líder}

\footnotetext{
${ }^{4}$ Robert A. Dahl, The Concept of power, Behavioral Science 2, 1957 (citado por Daft, Richard (2006): La experiencia del liderazgo, México D.F.: International Thomson Editores, P.489).
} 
La mayoría de los estudios dedicados a este tema, como por ejemplo el de los autores Koontz y Weihrich (Koontz - Weihrich, 1998: 302), establecen diversos tipos de poder que pueden ser ejercidos por los líderes. De acuerdo con Daft (Daft, 2006: 489-491), se distinguen cinco tipos que suelen ser clasificados en dos grupos: poder por posición y poder personal.

Dentro del grupo denominado poder por posición se incluyen los tres primeros tipos de poder: poder legítimo, poder de recompensa y poder coercitivo. Estos tres tipos en general son definidos por las políticas y los procedimientos de la organización, por lo cual la posición que el líder ocupa en la organización indica la cantidad de poder que tiene, especialmente respecto a su capacidad para premiar o castigar con el fin de influir en la conducta de los subordinados. No obstante, debe ser aclarado que poder por posición y liderazgo no son sinónimos. Un sujeto que ocupa una posición de autoridad formal podría no ser un líder. Además, los líderes eficaces no dependen simplemente de la posición formal para influir en otros.

Finalmente, dentro del grupo denominado poder personal, se incluyen el poder experto y el poder referente, que están fundados en el conocimiento especial del líder o en sus características personales.

\section{II.10.1. Poder legítimo}

Es la autoridad que posee una persona debido a la posición formal que ocupa en una organización. Los subalternos entienden esta fuente de poder como algo legítimo y como consecuencia la respetan. A su vez, la persona que se desempeña en una posición formal de liderazgo goza de ciertos derechos, responsabilidades y prerrogativas. Los seguidores aceptan los derechos legítimos de los líderes formales para establecer metas, tomar decisiones y dirigir luego las actividades. En otras palabras, es el que surge de un puesto y "se deriva del sistema cultural de derechos, obligaciones y deberes" (Koontz - Weihrich, 1998: 302) en el que el puesto es aceptado como legítimo por las personas. En las empresas privadas, la autoridad de un puesto proviene del conjunto de derechos de la propiedad privada. En el gobierno, la autoridad proviene del gobierno representativo. La autoridad en una organización casi invariablemente se deriva del poder legítimo.

\section{II.10.2. Poder de recompensa}

Es el poder que se desprende de la autoridad del líder designado en la organización, quien controla los recursos y su repartición, para dar premios (como por ejemplo aumentos de sueldo o ascensos) y, de esta manera, utilizar los mismos para influir en el comportamiento de los subordinados. Los seguidores de los niveles inferiores dependen también de los líderes para recibir los recursos necesarios para realizar sus tareas. También puede ser aplicado por ejemplo a un profesor que puede conceder mayor o menor calificación al alumno. 


\section{II.10.3. Poder coercitivo}

Es la cara negativa del poder legítimo y del poder para premiar. Entonces, al ser lo contrario al poder para recompensar, el líder goza del poder coercitivo para sancionar o sugerir una sanción (por ejemplo al despedir a un subalterno, bajarle de categoría, criticarle o no autorizar aumentos de sueldo).

\section{II.10.4. Poder experto}

Es el poder que se deriva del conocimiento o de la habilidad especial de un líder respecto del trabajo que realizan los seguidores. Cuando el líder es un experto, sus recomendaciones son seguidas debido a que él es quien tiene los mayores conocimientos. Es más, los líderes pueden retener o divulgar información especializada de manera que permita lograr los resultados deseados. Sin embargo, puede suceder que los líderes que ocupan niveles de dirección, carezcan de poder experto porque los subalternos tienen mayor cantidad de conocimientos acerca de los detalles técnicos que ellos. Incluso, los subalternos que poseen más experiencia y conocimientos, pueden usar los mismos para influir en las decisiones que toman sus superiores. Un ejemplo sería el caso de un médico que puede ejercer notable influencia en los otros por sus conocimientos especializados.

\section{II.10.5. Poder referente}

Este tipo de poder se deriva de las características de la personalidad del líder y no de su título o de su posición formal, y se hace visible en el liderazgo carismático. Estos líderes despiertan la identificación, el respeto y la admiración de tal forma que los seguidores quieren emularlos. El poder referente no sólo es la influencia que pueden ejercer personas sino, también, grupos debido a que los demás creen en ellos. Ejemplos de este tipo pueden ser Martin Luther King, quién influyó en la conducta de muchas personas o simplemente una estrella de cine que podría poseer un poder de referencia considerable.

\section{II.11. Respuestas al uso del poder por posición y al uso del poder personal}

Cuando un líder utiliza los distintos tipos de poder para influir en otros con el propósito de modificar el comportamiento de los subordinados y así poder lograr las metas de la organización, se puede encontrar con tres posibles respuestas: el cumplimiento, la resistencia y el compromiso.

Cuando las personas ejercen correctamente el poder de su posición la consecuencia es el cumplimiento, lo que significa que los subordinados aceptan las órdenes de la persona que hace uso del poder, sin importar si están conformes o no con ellas; es decir que las obedecen a pesar de que no les gusten. Sin embargo, existe el riesgo de que en muchos casos, aparezcan inconvenientes debido a que los seguidores pueden trabajar lo mínimo necesario solamente para satisfacer al líder, 
por lo que posiblemente no den el máximo de su potencial. Además, si el ejercicio del poder por posición (particularmente la coacción) supera el nivel que los seguidores creen legítimo responderán con la resistencia. Éste término significa que los empleados tratarán de desobedecer las órdenes de manera intencional.

La respuesta que el poder personal genera frecuentemente en los subordinados es el compromiso. Aquí, las personas de los niveles inferiores voluntariamente aprueban y siguen la perspectiva del líder y cumplen sus instrucciones con entusiasmo. Una gran diferencia entre cumplimiento y compromiso radica en que el primero puede alcanzar para problemas de rutina, pero el segundo tiene gran importancia cuando el líder intenta cambiar las cosas. Entonces, como el cambio conlleva riesgo o incertidumbre, el compromiso colabora para superar el temor y la resistencia que se manifiestan con los esfuerzos para producir dicho cambio.

\section{II.12. La dependencia}

Se sabe por la experiencia propia que si una persona controla alguna cosa que otros quieren y necesitan, esa persona adquiere más poder.

Una de las características básicas del poder es que está en función de la dependencia. Por lo tanto, mientras la persona $\mathrm{B}$ dependa más del poder de la persona $\mathrm{A}$, tanto mayor será el poder que A tenga sobre B. Las personas tienen poder porque otras dependen de ellas, ya sea para obtener información, recursos, cooperación. Cuantas más personas dependan de alguien, en general, más poder tendrá esa persona.

La naturaleza de las relaciones de dependencia entre los líderes y los subalternos varía dependiendo por ejemplo de la dificultad de encontrar trabajo y de la tasa de desempleo. Cuando hay mucha oferta de buenos trabajos, las personas sienten que dependen en menor medida de sus jefes y que estos dependen más de los empleados porque son difíciles de reemplazar. Cuando es difícil encontrar trabajo y cuando hay mucho desempleo, los líderes, al ser beneficiados con la curva de oferta y demanda, tienen más poder sobre los empleados porque si estos pierden su empleo tal vez les resulte muy difícil encontrar otro para poder subsistir.

La dependencia en este sentido afecta en primer lugar al poder por posición, porque está fundado en la autoridad formal y en la capacidad para otorgar premios o imponer castigos. Cuando los líderes dependen de los empleados, como en la situación mencionada de un mercado de trabajo apretado, deben esforzarse para tener más poder personal, ya que las personas podrían preferir quedarse en un trabajo, aunque existan otras oportunidades, si admiran y respetan al líder. Cuando hay faltante de empleos, los líderes podrían recurrir más al poder por posición, pero de esta forma no obtendrán el compromiso de los empleados. 
La dependencia tiene una relación estrecha con el control de los recursos (empleos, premios, apoyo económico, experiencia, conocimiento, materiales, información y tiempo). Las personas son más dependientes de los que detentan el poder si los recursos están sujetos a tres características: su importancia, su escasez y su imposible sustitución. Los sujetos deben percibir que el recurso es importante, porque si nadie quiere lo que uno tiene, eso no producirá dependencia. La escasez resulta de la facilidad o dificultad de obtener los recursos. Un recurso difícil de conseguir vale más y crea mayor dependencia que uno de amplia disponibilidad. La tercera característica, que es la imposible sustitución, significa que quienes tienen el control de los recursos sin sustitutos viables tendrán más poder. Pertenecen a esta clase de recursos el conocimiento y la experiencia, así como el acceso a personas que tengan mucho poder.

\section{II.13. Incrementar el poder por intermedio de actividades políticas}

De acuerdo con Daft (Daft, 2006: 500 y 501), otro aspecto del poder es la conveniencia de hacer que las personas reconozcan que los esfuerzos hechos por el jefe son importantes; entonces, quienes quieran expandir su poder siempre tienen que asegurarse de que las tareas que realizan sean visibles y apreciadas por los demás. Este aspecto es parte de la adquisición, de la ampliación y del ejercicio del poder que a su vez son en gran parte un proceso político debido a que, la política, incluye actividades que son necesarias para adquirir, ampliar y ejercer el poder con el fin de obtener las metas deseadas. Por ejemplo, muchas organizaciones usan las actividades políticas para influir en las políticas públicas y así tratar de influir en decisiones que las beneficiarán.

Las personas y los diversos sectores de las organizaciones también poseen actividad política, ya que, la incertidumbre y el conflicto son algo natural y la política es el mecanismo para conseguir cosas que no pueden ser controladas exclusivamente a través de políticas formales o del poder por posición. El ejercicio adecuado de la política y el poder para conseguir lo deseado es un aspecto importante del liderazgo.

Por lo tanto, los líderes ejercen la política de distintas maneras con el objetivo de incrementar su poder personal. Una de ellas es adquirir más responsabilidades, por ejemplo, a través de trabajos que presenten gran dificultad. Esta clase de trabajos frecuentemente permiten conocer sujetos que tienen poder en la organización y crearse una buena reputación entre ellos. Además, cuando se percibe que los líderes de niveles más bajos tienen amistad con personas más poderosas, su poder personal aumenta.

Otro enfoque político está fundado en saber cómo manejar correctamente las impresiones, lo que significa que los líderes tratan de controlar la forma en que otros les perciben; luchan por dar la impresión de que tienen más poder. Para conseguirlo, existen entrenamientos que ayudan a 
desarrollar esta capacidad, por ejemplo se le enseña a las personas a mejorar la presencia, es decir, el efecto que se produce cuando el sujeto entra en una habitación, a través de una serie de pistas visuales sutiles que incluyen desde cómo le queda la ropa, hasta la forma de caminar. El manejo de las impresiones abarca una extensa variedad de tácticas. Nombrar a personas importantes en una situación, dando la sensación de que fue sin querer hacerlo, puede dar la impresión de que el líder tiene buena relación con personas de una posición alta. Del mismo modo, la adulación es un método para manejar las impresiones que es utilizada para que una persona parezca perceptiva y agradable. Estas tácticas políticas pueden ser muy útiles cuando hacen ver el valor que el líder tiene, sin embargo, pueden ser contraproducentes si las personas son percibidas como poco sinceras, falsas o arrogantes.

\section{II.14. Tácticas que mejoran la influencia del líder}

El presente parágrafo intenta estudiar las principales tácticas utilizadas por los líderes para ejercer con mayor eficacia el poder. Es decir, el cómo los líderes usan el poder para influir en otros, ya que ello requiere de habilidad y de voluntad. Para dar inicio, hay que decir que gran parte de la influencia es interpersonal y de uno a uno; una influencia social que involucra alianzas, premios e inspiración. Pero existe también una influencia muy interesante que consiste en cómo influir en toda la organización o en personas que no están dentro de ella. Obviamente, no todos los intentos por ejercer el poder obtienen una influencia real, debido a que algunos son rechazados por los seguidores, especialmente si los consideran impulsados por el egoísmo. Los líderes tienen que decidir cuál es la mejor forma para ejercer el poder; deben elegir el planteamiento que se estima que ofrece más probabilidades de influir, analizando las situaciones, las personas y los grupos involucrados. Generalmente los líderes adoptan una combinación de estrategias de influencia y, frecuentemente, los que son percibidos como individuos de notable poder e influencia son los que utilizan la mayor cantidad de tácticas.

Ahora bien, como existen incalculables tácticas de influencia para reafirmar la influencia del líder, serán clasificadas, como dice Daft (Daft, 2006: 503-506), en siete categorías básicas de acciones de influencia con el propósito de alcanzar una mejor comprensión. Queda aclarar que la mayoría de ellas usan el poder personal y no recurren exclusivamente al poder por posición ni a usar los premios y castigos.

1) La persuasión racional. Es probablemente la táctica de influencia utilizada con más frecuencia y consiste en usar hechos, datos y argumentos lógicos para persuadir a las personas de que la mejor manera de alcanzar una meta deseada es seguir lo que dice el líder. Esta táctica suele ser eficaz como consecuencia de que la mayoría de las personas confía en los hechos y los análisis. 
2) Tratar de caerle bien a la gente. Las personas prefieren decir "sí" a alguien que les agrada y responden más ante la amistad y la consideración. Si un líder muestra preocupación por los demás, demuestra confianza y respeto, y trata a todos de manera justa, es probable que las personas lo ayuden y hagan lo que se les pida. Además, la mayoría de los individuos estarán complacidos con un líder que los haga sentirse bien consigo mismos. Los líderes nunca deben menospreciar el elogio.

3) Recurrir a la regla de la reciprocidad. Es la explicación de la dependencia y de cómo los líderes adquieren poder si tienen alguna cosa que los otros quieren. La forma más importante de transformar este poder en influencia es compartir lo que se tiene (tiempo, recursos, servicios o apoyo emocional). Las personas sienten, casi universalmente, que unas deben pagar por lo que otras hacen. Esta ley tácita de reciprocidad quiere decir que quienes hacen un favor pueden esperar que otros también les hagan favores.

4) Conseguir aliados. La reciprocidad también es importante en la formación de redes de aliados que puedan colaborar con el líder para lograr las metas deseadas. Los líderes, por ejemplo, pueden influir en otros y hacerse de aliados si invierten tiempo en hablar con todas las personas fuera de los lugares formales para poder entender sus necesidades e inquietudes, así como para detallar sus propios problemas y explicar su perspectiva.

También es posible extender la red de aliados tratando de establecer contacto con más personas. Algunos líderes amplían sus redes por medio del proceso de contratación, transferencias y ascensos. El líder que identifica puestos clave y acomoda en ellos a personas que coinciden con sus proyectos dispondrá de ayuda para alcanzar las metas que quiere.

5) Pedir lo que se quiere. Si los líderes no piden, excepcionalmente recibirán. Por lo cual, para tener influencia, un camino posible es expresar con claridad lo que uno quiere y pedirlo directa y concretamente. La actividad política es eficaz, cuando el líder manifiesta explícitamente la visión, las metas y los cambios que desea. Una forma de persuadir es demostrando seguridad en sí mismo con valor, diciendo lo que se piensa. El comportamiento político eficaz precisa que el líder corra riesgos y tenga fuerza para tratar de llegar a los resultados deseados.

6) Principio de escasez. En general las personas quieren más cantidad de algo que no tienen; lo que significa que si la oferta es baja se vuelve más deseable. Los líderes pueden pedir y ofrecer destacando los beneficios únicos y la información exclusiva que están dando, para captar el interés de los seguidores. Una manera, es divulgar selectivamente la información que no está disponible a todos y así aumentar la probabilidad de que apoyen su posición.

7) Extender la autoridad formal con experiencia y credibilidad. Las autoridades legítimas están en posición de ejercer y reafirmar una influencia particular. La clave de la autoridad formal 
consiste en tener conocimiento y en ser creíble y confiable. Los líderes eficaces saben que la influencia depende fundamentalmente del poder personal y no del poder por posición, por lo cual, haciendo uso de los seis principios anteriores se puede conseguir ampliar el poder de la posición formal.

\section{Capítulo III. El individuo. Rasgos, valores y actitudes}

\section{III.1. Liderazgo y personalidad}

Es interesante revisar el pensamiento de Bobbio (Bobbio, 2008: 914 y 915) respecto del liderazgo, ya que según su mirada, no tiene mucho sentido insistir en tentativas de compilar alguna clase de lista de los atributos de personalidad y de habilidad intrínsecos a la figura del líder. Bobbio cree que estas tentativas han sido muy numerosas y que, sin embargo, las investigaciones realizadas en este tema se limitan a proporcionar resultados demasiado genéricos, o identifican cantidades de atributos personales del liderazgo, tan numerosos, como los tipos de grupos estudiados (y sus situaciones).

Entonces, como el liderazgo es una relación que existe entre personas que están inmersas en una situación social dada, los líderes en una situación no necesariamente pueden ser líderes en otras situaciones. Las virtudes en cuanto a la personalidad y habilidad del líder, como así también sus motivaciones, están insertos en el marco de los recursos que en un momento específico se utilizan para conseguir y conservar el liderazgo: dichos recursos pueden ser tan diversos como las razones por las que se establece una relación de influencia.

Esto no significa que la personalidad del líder no sea un factor importante. Simplemente lo que trata de decir es que los aspectos personales del líder no pueden generalizarse más allá de la banalidad si no es dentro de un marco preciso que todavía no se ha logrado. De esta forma, sólo se podrían convenir algunas cuestiones, como por ejemplo, al referirse a un líder político se puede decir que el rasgo característico de esta personalidad es la marcada demanda de algunos valores especialmente del poder y del respeto y, en menor medida, de la rectitud y del afecto.

Otro aspecto relevante es que, necesariamente, debe diferenciarse la personalidad del líder de la de su imagen: tanto en su forma de "autoimagen" que es la que el líder tiene de sí mismo o la que quiere acreditar, como en la forma de la imagen que los seguidores crean de su líder. Por ejemplo, la grandeza se manifiesta más probablemente como un atributo de la imagen que la del hombre al que se refiere.

Por su parte, Richard Daft, le otorga mayor importancia al tema y comienza el desarrollo de su análisis expresando que todas las personas son distintas en muchos sentidos, y que todas estas diferencias afectan la interacción entre el líder y el seguidor. Las diferencias de personalidad, de 
actitudes y de valores, modifican la manera en que las personas interpretan una tarea, en que reciban con agrado o no cuando les dicen lo que deben hacer, en cómo reaccionan ante los retos y en cómo se relacionan con otros. Las personalidades, las actitudes de los líderes, y su capacidad para comprender las diferencias que existen entre los seguidores, influyen en la eficacia del liderazgo.

Entonces, el enfoque de este autor en el presente capítulo, presta atención al individuo analizando algunas de las diferencias que existen entre los mismos. Se parte del estudio de la personalidad y algunas dimensiones de ésta que están vinculadas con el líder. A continuación, se habla sobre cómo los valores afectan el liderazgo y de cómo las actitudes del líder influyen en el comportamiento. Por último, se explora el liderazgo carismático y el transformacional, dos estilos de liderazgo fundamentados en las características personales del líder.

\section{III.2. Énfasis sobre la personalidad}

Es sabido que en diversas situaciones algunas personas se comportan siempre de manera agradable, mientras otras se comportan siempre de forma temperamental o agresiva. Cuando esta clase de conductas son explicadas, existe la tendencia a argumentar que ese individuo tiene una personalidad agradable o que tiene una personalidad agresiva. Ésta es la utilización del concepto de personalidad más frecuente, y va dirigido tanto a los patrones de conducta del sujeto, como a la forma en que los otros lo miran. No obstante, el término citado también tiene otro significado, por lo que se puede definir a la personalidad como "el conjunto de características y procesos imperceptibles que fundamentan un patrón de conducta relativamente estable cuando responde a ideas objetos y personas dentro del entorno" (Daft, 2006: 126). Así, quienes logran comprender que las personalidades son distintas, están en condiciones de tomar ese conocimiento y usarlo para mejorar la eficacia de su liderazgo.

\section{III.2.1. Ejemplo de un modelo de personalidad}

Como la mayoría de los individuos conciben la personalidad en términos de rasgos, se hace necesario explicar el significado que tiene esta noción; por ello, se entenderá por rasgos a las características personales que distinguen a una persona, como la inteligencia, la honradez, la confianza en sí mismo y la presencia física. Sin embargo, en términos generales, los estudiosos encontraron que solamente existía un vínculo muy frágil entre los rasgos personales y el éxito del líder. Más aún, se encontró que los líderes eficaces poseen una variedad de rasgos tan distintos, lo que denota que la capacidad para el liderazgo no es un legado genético. 
Muchos autores continúan pensando que existen algunos rasgos que son esenciales para el liderazgo eficaz, y que tienen validez en cualquier clase de organización y de situación, pero sólo si están combinados con otros factores. Algunos de los mencionados rasgos son:

- Confianza en uno mismo. Significa tener seguridad en los juicios, la toma de decisiones, las ideas y las capacidades propias. Un líder que manifiesta seguridad en su propia capacidad, enfrenta los retos, genera la confianza de sus seguidores y obtiene su respeto y admiración. La confianza que demuestra también motiva a los seguidores y gana su compromiso para lograr las metas propuestas.

Los líderes suelen iniciar cambios y, pueden llegar a tener que tomar decisiones sin contar con la información adecuada, por lo cual sino confían en sí mismos para avanzar y convencerse de que cumplirán las metas, o si les sucede que toman una decisión errónea, podrían paralizarse y en consecuencia podrían no actuar. Entre las funciones de los líderes se encuentran además superar los contratiempos, correr riesgos, manejar puntos de vista encontrados y tomar decisiones que no satisfacen a todos. Por lo tanto, la confianza en sí mismo es el único rasgo que permite enfrentar todos estos retos.

- Honradez/Integridad. Se entiende por honradez el decir la verdad y no mentir. Significa desempeñarse con sinceridad, característica muy apreciada por los individuos. Se entiende por integridad el carácter íntegro, de una sola pieza, que posee un líder, que está construido sobre principios morales fuertes en base a los cuales actúa. Por ello, si los líderes reflejan sus convicciones a través de sus acciones, despiertan admiración, respeto y lealtad. Se descubrió que los líderes exitosos actúan exactamente igual a lo que dicen que harán cuando dicen que harán eso. Estas virtudes son entonces fundamentales para ganarse la confianza de los seguidores.

Dinamismo. Se entiende como una gran motivación que lleva al líder a efectuar un enorme esfuerzo. Las personas que poseen el dinamismo intentan alcanzar el éxito, disponen de mucha energía, fuerza y tenacidad y, generalmente, muestran ambición e iniciativa para cumplir las metas desafiantes que se han propuesto. Con frecuencia, los líderes ocupan una posición alta porque persiguen sus metas muy activamente y trabajan muchas horas al día durante muchos años, lo que les permite mantener el ritmo y afrontar las exigencias y los retos.

\section{III.3. Valores y actitudes}

Además de la existencia de distintas personalidades, los individuos poseen otras características llamadas valores y actitudes que varían de una a otra persona y que modifican el comportamiento de los líderes y de los seguidores.

\section{III.3.1. Valores instrumentales y definitivos}


Para el fin de este trabajo, alcanza con definir a los valores como las "creencias fundamentales que un individuo considera importantes, que son relativamente estables con el paso del tiempo y que tienen efecto en sus actitudes y comportamiento" (Daft, 2006: 134). Los valores son las creencias que conducen a una persona, en ciertos terrenos, a que prefiera hacer las cosas de una manera determinada influyendo en su comportamiento diario. Los individuos siempre califican a los otros, a las cosas o a las ideas de buenas o malas, agradables o desagradables, éticas o poco éticas, etcétera.

Una forma de comprender a los valores es pensarlos y clasificarlos como coadyuvantes o definitivos. Los primeros, a veces también llamados valores contundentes, son creencias referidas a las metas valoradas por las cuales vale la pena luchar; por ejemplo, algunas personas creen que hay que pelear en la vida por la seguridad, por una vida cómoda o por tener una buena salud por encima de todo. Otras posiblemente concedan mayor valor al reconocimiento social, al placer o a una vida de emociones. Los segundos, también llamados valores instrumentales, son creencias referidas a los comportamientos que son considerados correctos para conseguir los resultados; entre estos valores se destacan la honradez, el valor o la responsabilidad.

No redunda aclarar que todas las personas poseen valores coadyuvantes y definitivos, las cuales otorgan a estos últimos diversos órdenes de prioridad, lo que explica el por qué existen grandes diferencias entre unos y otros. Parte de la diferencia en los valores depende, por ejemplo, de las distintas culturas o del origen familiar. Los valores, que son aprendidos, frecuentemente están sólidamente establecidos al llegar a la edad adulta, aunque los mismos también pueden cambiar a lo largo de la vida.

\section{III.3.2. Las actitudes}

Los valores colaboran también para determinar las actitudes que los líderes toman ante los seguidores, entendiendo por actitud a la evaluación (positiva o negativa) de las personas, los hechos o las cosas. Es posible decir que las actitudes están compuestas por tres elementos: el cognitivo (los pensamientos), el afectivo (los sentimientos) y el conductual. El elemento cognitivo corresponde a las ideas y a lo que el individuo conoce respecto al objeto de una actitud, por ejemplo, lo que un líder sabe y piensa sobre el desempeño y las capacidades de un subordinado. El elemento afectivo establece lo que un sujeto siente respecto al objeto de una actitud, por ejemplo, a un líder probablemente no le agrade tener que contestar generalmente las preguntas que le formulan o tener que ayudar a los empleados a realizar algunas tareas. El elemento conductual de una actitud predispone a actuar de una manera dada, por ejemplo, un líder podría evitar a un subordinado o no hacerlo participar en ciertas funciones del grupo. Como se ve, es menos difícil modificar actitudes que valores, sin embargo éstas suelen reflejar los valores principales, los 
antecedentes y las experiencias de un individuo en la vida. Un líder que valora más perdonar, sentir compasión y ayudar tendrá actitudes y comportamientos muy diferentes de los de otro que valora más la ambición personal y la capacidad.

\section{III.4. Liderazgo carismático y transformacional}

Si bien las características de los seguidores y de la situación desempeñan un papel muy importante, al momento de liderar es muy importante comprender el liderazgo carismático y el liderazgo transformacional ya que los dos son estilos basados ostensiblemente en las características personales de un líder y en su estilo cognoscitivo.

\section{III.4.1. El papel del carisma.}

El liderazgo carismático es, desde hace mucho tiempo, un tema de gran interés para quienes son los encargados de estudiar el liderazgo en la política, en los movimientos sociales y en las religiones. Pero actualmente, también es estudiado debido a la necesidad de conocer el efecto que el liderazgo carismático tiene en las organizaciones. El carisma no es fácil de definir, aunque algunos pueden describirlo como una llama que enciende la energía y el compromiso de los seguidores, generando resultados que sobresalen de las producciones obligadas. Los líderes carismáticos tienen la habilidad de inspirar y motivar a las personas para que hagan más de lo que harían comúnmente, no obstante los obstáculos y el sacrificio personal. Otros pueden describir al líder carismático como una persona capaz de convencer a los individuos de que hagan cosas que preferirían no hacer. La gente está dispuesta, incluso, a luchar hasta la muerte por él. El líder carismático no exige la atención, simplemente la capta.

Estos líderes consiguen generar un efecto en las emociones de las personas porque apelan al corazón de sus seguidores. Por ejemplo, tal vez expresen con emoción que quieren ubicarse en la posición más compleja con el propósito de cumplir con una misión, logrando así ser percibidos como individuos perseverantes a pesar de tener muchos obstáculos en su contra. Los líderes carismáticos suelen aparecer en épocas difíciles, en la sociedad o en las organizaciones, porque al tener una personalidad fuerte e inspiradora ayudan a disminuir el estrés y la ansiedad que sienten los seguidores.

El carisma, si es usado por el líder con sensatez y ética, aumenta el nivel de funcionamiento de la organización debido a que hace tomar conciencia a las personas respecto a nuevas y mejores posibilidades y las motiva para que dejen de lado los intereses personales para actuar priorizando los intereses colectivos de la organización. Es necesario entender que el carisma no se aprende, no obstante haya aspectos del liderazgo carismático que pueden ser utilizados por cualquier sujeto. En primer lugar, porque el carisma deriva de dedicarse a actividades que apasionan. Luego, los que 
tienen el don del carisma ganan la confianza de sus seguidores porque se muestran dispuestos a correr grandes riesgos personales. Entonces, al situarse en el frente y correr riesgos, reafirman su posición de defensores apasionados de la visión que persiguen y también incrementan el atractivo emocional.

Los líderes carismáticos ejercen aplicando sus emociones en la vida laboral diaria lo que los hace enérgicos, entusiastas y seductores. Además crean un ambiente de cambio y ofrecen una visión idealizada de un futuro que es notablemente superior que el presente. Tienen habilidad para comunicar las ideas y los fines complejos de un modo muy claro y atractivo, por lo cual cualquiera está en condiciones de poder comprenderlas e identificarse con su mensaje. Manejan la capacidad de inspirar una fe que subsiste en el tiempo, por lo que la fe misma es un premio para los seguidores. Los líderes carismáticos también actúan utilizando herramientas y medios poco convencionales para superar el status quo y generar el cambio.

La última característica que se citará es que su fuente de influencia proviene del poder personal, y no del poder del puesto. Ellos podrán estar en un puesto formal de autoridad, pero el liderazgo va más allá del poder que tienen, del título que ostentan y de la posición que ocupan en la empresa, ya que la influencia del líder está fundada en sus cualidades personales, en sus conocimientos o en su experiencia. A los seguidores les agradan esta clase de líderes, los respetan y los admiran, se identifican con él y desean ser como él.

\section{III.4.1.1. La parte negativa del carisma.}

Una característica que ha sido observada y resaltada, es que el carisma puede dar como resultado una bendición o una maldición. Líderes como Mahatma Ghandi y Adolf Hitler fueron líderes carismáticos, lo que quiere decir que el carisma no necesariamente es utilizado para el bien del grupo, de la empresa o de la sociedad, sino que también puede ser usado para fines egoístas y ello lleva al engaño, la manipulación y la explotación de otros. Por lo tanto, como la base del carisma es emocional, y no es lógica ni racional, existe un riesgo y podría llegar a ser muy peligroso.

Una explicación, que responde al por qué el carisma puede conducir tanto a resultados positivos como a resultados negativos, se refiere a la diferencia que hay entre los líderes que persiguen el provecho personal y los que persiguen el provecho social. Los que responden a los problemas de la organización en función de sus propias necesidades, y no de las necesidades del todo, pueden actuar de una manera tal que traiga consecuencias desdichadas para los demás; los que buscan su propio beneficio y no valoran a los otros, tienen la particularidad de intentar constantemente agrandar y mejorar la imagen que los seguidores tienen de él, ya que no son igualitarios ni tampoco solidarios. Generalmente, los líderes carismáticos negativos, causan un 
efecto perjudicial en el funcionamiento de la empresa en el largo plazo, lo que contrasta con los líderes que tienen un patrón de comportamiento orientado hacia el bien común, debido a que consiguen mejorar el desempeño de la organización.

\section{III.4.2. Introducción al liderazgo transformacional}

El liderazgo transformacional es una clase de liderazgo fundado en las cualidades personales, y su importancia radica en que tiene la capacidad de producir un efecto sustancial en los individuos, aunque también podría ser capaz de renovar a la totalidad del grupo. Según Daft (Daft, 2006: 156-158), uno de los modos de comprender el liderazgo transformacional es compararlo con el liderazgo transaccional.

\section{III.4.2.1. Liderazgo transaccional}

La esencia del liderazgo transaccional es la transacción o el proceso de intercambio entre los líderes y sus seguidores. El líder transaccional estudia y comprende las necesidades y los deseos de sus subordinados $\mathrm{y}$, en consecuencia, indica con absoluta claridad cómo podrán satisfacer dichas necesidades y deseos, a cambio de que cumplan con las tareas señaladas. Luego, los seguidores se benefician porque reciben premios por su desempeño laboral y el líder se beneficia porque ellos cumplen con las tareas. A ello se le suma, por un lado, que al tener la facilidad de explicar claramente lo que quieren de los seguidores, aumentan la confianza que éstos le tienen; y por otro lado, que al satisfacer las necesidades de los subalternos mejora no sólo la productividad sino también el estado de ánimo.

Los líderes transaccionales se concentran en el presente y logran que la organización funcione con eficiencia. Se destacan por su buen desempeño en las funciones tradicionales de la administración (como la planeación y la preparación de presupuestos), y suelen enfocarse en los aspectos impersonales durante la realización de los trabajos. Entonces, si bien es importante que todos los líderes cuenten con habilidades transaccionales, hay que comprender que como el liderazgo transaccional implica seguir las reglas, estos líderes intentan mantener siempre la estabilidad dentro de la organización en lugar de favorecer el cambio. Por lo tanto, en un mundo donde el éxito empresarial muchas veces depende de los cambios continuos, los líderes eficaces también están obligados a utilizar otro planteamiento.

\section{III.4.2.2. Liderazgo transformacional}

El liderazgo transformacional se caracteriza por la capacidad para producir cambios de gran importancia. Es capaz de iniciar los arduos cambios en la visión, la estrategia y la cultura de la organización y también de propiciar innovaciones en los productos y las tecnologías. En vez de pensar y controlar las transacciones con los seguidores utilizando reglas, instrucciones e incentivos, se concentra en cualidades intangibles, como la visión, los valores compartidos y las 
ideas, a fin de crear relaciones, de reforzar el significado de las tareas independientes y de ofrecer facilidades para enrolar personas en el proceso de cambio. El liderazgo transformacional está anclado a los valores, las creencias y las cualidades personales del líder y no a un simple proceso de intercambio entre los líderes y los subordinados. En resumen, el liderazgo transformacional se diferencia del liderazgo transaccional en cuatro áreas.

1) Lleva a los seguidores a convertirse en líderes. El liderazgo transformacional une a la gente alrededor de una misión y define el marco dentro del cual los seguidores pueden operar con un mayor grado de libertad para establecer su conducta con el propósito de alcanzar las metas de la organización. El líder transformacional despierta la conciencia de sus subordinados respecto de ciertos temas, y los ayuda a ver bajo distintas perspectivas para así poder alcanzar el cambio en la producción.

2) Hace que las preocupaciones de la gente ascienda del nivel más bajo de las necesidades, es decir las físicas (como seguridad y abrigo), al nivel más alto, es decir las necesidades psicológicas (como autoestima y autorrealización). Es fundamental satisfacer las necesidades de nivel bajo con salarios adecuados, con seguridad en las condiciones de trabajo, etcétera. Sin embargo, el líder transformacional también atiende a la necesidad de crecimiento personal. Lo que significa que asigna trabajos para satisfacer las necesidades inmediatas, pero también para elevar las necesidades y capacidades y para relacionarlas con la misión de la organización. Los líderes transformacionales cambian a los individuos para que éstos adquieran facultades y puedan colaborar a cambiar la organización.

3) Inspira a los subordinados a buscar el bien del grupo por sobre los intereses personales. Motiva a la persona para que haga más de lo que en un principio se esperaba de ella. Consigue que los subordinados tomen conciencia de las metas y de la necesidad del cambio que quieren crear y, simultáneamente, les enseña a ir más allá de sus intereses personales, e incluso a hacer sacrificios personales, para alcanzar el fin superior y lograr la misión de la organización. Los seguidores admiran a los líderes transformacionales, se identifican y confían en ellos.

4) Describe la visión de un futuro deseable y la comunica convenciendo de la importancia de hacer el esfuerzo aunque duela el cambio. Tal vez, la principal función del líder transformacional sea hallar una visión que resulte mejor que la anterior y enrolar a otros para que compartan el sueño. La visión es lo que pone en marcha a las personas y prepara el terreno para los demás aspectos del liderazgo transformacional que fueron expuestos. El cambio sólo se puede dar si las personas encuentran sentido y desean el fin que persigue la organización. Si no existe una visión, es imposible que haya transformación. 
En definitiva, la principal diferencia entre estos dos liderazgos, es que los líderes transaccionales buscan la estabilidad, y los transformacionales producen cambios importantes en los seguidores y también en las organizaciones. Los líderes eficaces aprenden a ser transformacionales y también transaccionales. Acentúan no sólo sus capacidades para crear una visión y aglutinar a las personas en torno a la misma, manifestando optimismo respecto al futuro, ayudando a sus seguidores a desarrollar su potencial, confiriéndoles facultades para que contribuyan a realizar el cambio e inyectándoles energía; sino también, utilizan las habilidades transaccionales necesarias para diseñar estructuras, sistemas de control y sistemas de premios que ayuden a los actores sociales a realizar la visión.

\section{Capítulo IV. La teoría del comportamiento y la teoría de la contingencia}

\section{IV.1. La teoría del comportamiento}

Como fue explicado, algunos de los rasgos y capacidades personales pueden distinguir a los líderes exitosos, sin embargo, los rasgos por sí solos aunque puedan aumentar la probabilidad de éxito no alcanzan para garantizar un liderazgo eficaz. Debido a ello, a los investigadores no les fue posible definir un liderazgo eficaz establecido solamente en los rasgos personales, razón por la cual el interés de los mismos se desplazó al estudio de la conducta y a la manera en que ésta colabora con el éxito del líder. La importancia otorgada a la teoría del comportamiento radica en la afirmación de que una persona cualquiera que observe la conducta adecuada puede desarrollarse como un buen líder, por lo que la pretensión se resume en descubrir cuáles son los comportamientos que observan los líderes para permitir que el liderazgo esté al alcance de todos.

Así, es posible decir que el camino que marcaron las investigaciones sobre los comportamientos del líder y también sobre los rasgos, es uno de los fundamentos en los estudios del liderazgo y continúa teniendo un enorme dinamismo para explicar el éxito o el fracaso de un líder.

\section{IV.1.1. La rejilla del liderazgo de Blake y Mouton}

De todas las teorías del comportamiento, tal vez la más conocida, es la que ofrecieron Blake y Mouton (Koontz - Weihrich, 1998: 540). Estos investigadores propusieron, fundándose en estudios precursores, una teoría bidimensional del liderazgo a la que se le dio el nombre de rejilla del liderazgo (Daft, 2006: 60-64). Los autores calificaron a los líderes en una escala del 1 al 9 bajo dos criterios: el interés por las personas y el interés por la producción. Colocaron las calificaciones obtenidas de estos criterios en la grilla en la cual cada eje representa a uno de los intereses mencionados. 
Figura de la rejilla del liderazgo 5

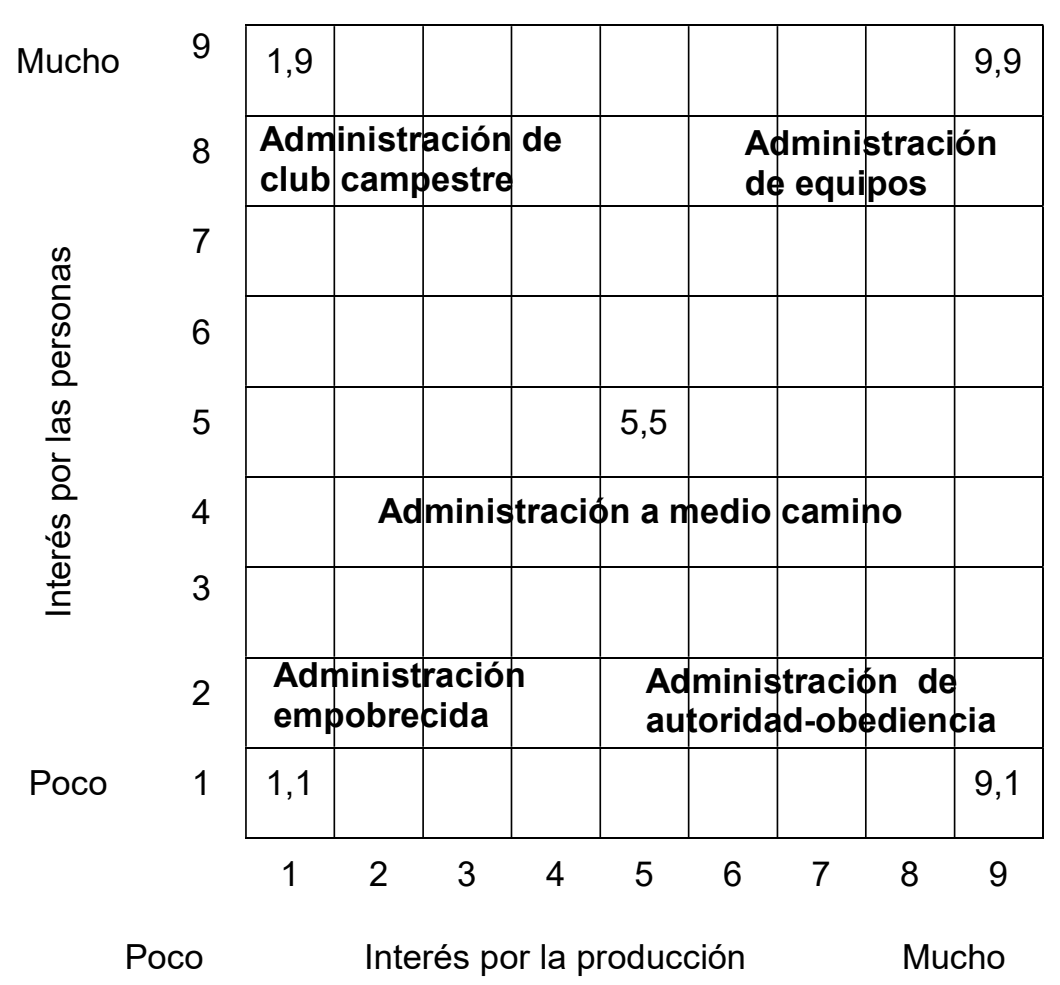

Con frecuencia se observa que:

- La administración de equipos $(9,9)$ es el estilo más eficaz y recomendable porque las personas que pertenecen a la organización trabajan mancomunadamente en el desempeño de las tareas. El trabajo es realizado por personas comprometidas. La interdependencia, construida sobre el interés común de la meta de la organización, conduce a vínculos confiables y de mucho respeto.

- La administración de club campestre $(1,9)$ aparece cuando se le priorizan las personas por sobre los resultados del trabajo. La atención centrada en atender las necesidades que tienen las personas de satisfacer las relaciones personales conduce a un lugar de trabajo cómodo y amigable en la empresa.

- La administración de la autoridad-obediencia $(9,1)$ es el estilo que se establece cuando la orientación dominante es hacia la eficiencia de las operaciones. Dicha eficiencia es la consecuencia de que las condiciones del trabajo han sido ordenadas de forma tal que a los elementos humanos se les otorga una prioridad mínima.

- La administración a medio camino $(5,5)$ posee un grado moderado de interés por las personas y también por la producción. El desempeño correcto de la empresa se logra a través de un

\footnotetext{
${ }^{5}$ Figura basada en la de Blake, Robert y McCanse, Anne (1991), Leadership Dilemma-Grid Solutions, Houston: Gulf publishing company -antes era la rejilla administrativa de Blake, Robert y Mouton, Jane- (Citado por Daft, Richard (2006): La experiencia del liderazgo, México D.F.: International Thomson Editores, P.61).
} 
equilibrio entre la necesidad de finalizar el trabajo y la necesidad de mantener el estado de ánimo de las personas en un grado adecuado y satisfactorio.

- La administración empobrecida $(1,1)$ es la ausencia total de un buen liderazgo, lo que significa que los líderes no se esfuerzan para que existan relaciones interpersonales y tampoco para que se realice el trabajo. Se trata de efectuar el menor esfuerzo posible para poder seguir perteneciendo a la organización.

En general, los estilos de liderazgo descriptos por los diversos estudios realizados, entre los que se incluyen el de Blake y Mouton, referidos a las teorías del comportamiento culminaron con dos clases predominantes de comportamiento que captan aspectos fundamentales de la conducta humana: el orientado a las personas y el orientado a las tareas. El tema de las personas comparado con el de las tareas está presente en gran parte de las investigaciones, lo que sugiere que hay comportamientos básicos que permiten a los líderes satisfacer las necesidades de los subordinados. Por ello, el enorme peso del estudio de estas dos dimensiones se debe a que los resultados están basados en investigaciones empíricas. En ellas se observa que aunque estos comportamientos no son los únicos importantes, requieren atención porque existe la idea de que los mejores líderes tienen un grado muy alto de los dos comportamientos.

Las investigaciones arrojaron que en el estilo de liderazgo que tiene un grado "alto-alto", es decir, en el caso de los comportamientos orientados tanto a las personas como a las tareas, existe cierto grado de universalidad, entendiendo por universal el comportamiento que normalmente será eficaz en todas las situaciones, a diferencia de situacional que significa que el comportamiento sólo tiene éxito en algunos contextos. Se entendió también que el comportamiento del líder con interés por las personas frecuentemente estaba relacionado con mayor satisfacción de los empleados y con menos problemas de personal en toda una variedad de situaciones. Mientras que el comportamiento orientado a las tareas estaba relacionado a una mayor productividad en gran cantidad de situaciones.

Se puede agregar que el liderazgo que tiene este tipo de grado no es el único estilo eficaz aunque se considera que este tipo de líder es candidato para triunfar en una amplia variedad de situaciones. Los estudios subsiguientes, sin embargo, afinaron el conocimiento de las situaciones con el objeto de precisar cuáles eran los casos en los que cada tipo de comportamiento resultaba más eficaz.

\section{IV.1.2. Liderazgo individualizado}

La teoría de los rasgos y la del comportamiento creen que un líder adopta un estilo de liderazgo y lo ejerce con todas las personas que pertenecen al grupo. Sin embargo, el liderazgo 
individualizado, estudia la relación específica entre el líder y cada uno de los miembros del grupo. Este liderazgo determina que un líder desarrolla una relación única con cada subordinado y que de dicha relación depende el comportamiento que el líder tiene con ese miembro, como así también, la conducta con la que el miembro responde al líder.

El liderazgo individualizado, intenta comprender por qué los líderes influyen más en unos subordinados que en otros. El enfoque se basa en la noción de intercambio: lo que una parte da y recibe de la otra. Por ejemplo, los líderes pueden satisfacer las necesidades emocionales de sus seguidores y expresarles que son un apoyo para elevar su autoestima, mientras que los seguidores ofrecen mayor compromiso y se esfuerzan con el trabajo.

La teoría del liderazgo puede ser desarrollada en cuatro etapas (Daft, 2006: 64-70).

Primera etapa: Se observó que existía una relación entre el líder y cada individuo y no entre el líder y un grupo de subordinados. Los primeros estudios indicaron que los subordinados describían de forma muy diferentes al mismo líder por lo que se descubrió que el líder tenía subordinados favoritos o distantes de él en un grupo. Así, se comprendió que los comportamientos y los rasgos de los líderes causan diversos efectos en los seguidores, creando con ello las dos categorías señaladas.

Todas las personas, en mayor o en menor medida, han integrado distintos tipos de grupos (escolares, deportivos o de trabajo), y saben que algunos líderes dedican mucho más tiempo a ciertos individuos "consentidos" a los que con frecuencia depositan confianza o incluso les brindan privilegios especiales. Entonces, a raíz de lo expuesto, se encontró que había grandes variaciones entre el estilo del líder y sus repercusiones dentro de un grupo de subordinados.

Segunda etapa: Se analizó que generalmente los líderes tienden a establecer relaciones de intercambio de mejor calidad con las personas que tienen características similares a las suyas, como serían antecedentes, intereses y valores similares, y con las que exhiben un grado elevado de competencia y de interés por el trabajo, por lo que se vuelven favoritas del grupo. La teoría propone entonces que la calidad de la relación de intercambio determina si el miembro es favorito o alejado del grupo y que, los favoritos, son quienes tienen un mejor desempeño y una mayor satisfacción.

Tercera etapa: Se investigó si era posible que los líderes adquieran alianzas deliberadas con individuos específicos del grupo ya que esto podría conducir a que se establezca una gran diferencia entre los favoritos y los alejados del grupo. Esta diferencia, podría dar lugar a ciertos peligros que irían desde los resentimientos hasta la hostilidad de los alejados, debido a que si los seguidores perciben que los líderes otorgan marcados beneficios y ventajas a los favoritos, podrían rebelarse y traer perjuicios a toda la organización. 
Por este motivo, se intentó averiguar si los líderes eran capaces de desarrollar relaciones positivas con todos sus subordinados y no sólo con algunos. El interés principal radicaba en cómo se podría relacionar con cada subordinado individualmente para establecer una alianza. La idea era que si los líderes lograban desarrollar una relación única y buena con cada persona podrían proporcionar a todos los actores sociales acceso a intercambios de gran calidad, generando así un entorno más equitativo y beneficios para los líderes, los seguidores y la organización.

El enfoque plantea entonces que el líder se esfuerce para poder desarrollar una relación diferente pero positiva con cada persona por separado. De esta manera, cuando consiga ofrecer a todos una relación de gran calidad, los seguidores responderán a la oferta mejorando su desempeño, ya que los líderes satisfacen las necesidades de cada uno.

Cuarta etapa: Posteriormente, esta idea se expandió e insinuó que las relaciones se pueden ampliar a efectos de incluir redes y sistemas más extensos. Por lo tanto, la teoría sugiere que los líderes deben construir redes de relaciones de uno a uno y utilizar sus rasgos y comportamientos selectivamente a fin de establecer relaciones positivas con la mayor cantidad posible de colaboradores. De esta manera, el líder podrá influir en una gran cantidad de personas y estos grupos de interés ayudarán a tener éxito en las tareas.

El desarrollo de la teoría del liderazgo a los largo de los años presenta algunas ideas de relevancia sobre el liderazgo. Se observa que si bien ciertos rasgos y capacidades personales incrementan la probabilidad de tener éxito en el rol de líder, por si solos no alcanzan para asegurar un liderazgo eficaz. Por consiguiente, los comportamientos también son muy importantes; es decir que el estilo de liderazgo que exhiba una persona determina en gran medida el resultado del liderazgo (siempre teniendo presente que normalmente lo más eficaz puede ser una combinación de estilos). Sin embargo, para comprender los efectos que el liderazgo tiene en los resultados, también es importante considerar el comportamiento del líder en su relación con cada individuo por separado.

\section{IV.2. La teoría de la contingencia}

Como los investigadores no consiguieron hallar una serie de rasgos o comportamientos universales de los líderes que pudieran determinar siempre un liderazgo eficaz, optaron seguir otro camino. Sin dejar de lado el comportamiento de los líderes, se dirigió el enfoque hacia la situación en la cual ocurría el liderazgo. Así, esta sección estudia el vínculo que existe entre la eficiencia del liderazgo y la situación en la que se desarrollan las actividades. (Daft, 2006: 82-85). 
Los líderes frecuentemente modifican su comportamiento adecuándolo a la situación; lo que significa que adaptan su estilo de liderazgo a la serie de factores que descubren en el entorno que afrontan. El planeamiento más eficaz para el liderazgo depende de muchos elementos, entre los que se destacan el líder, el seguidor y la situación, así como el efecto que cada uno de ellos produce en los otros. Es por ello, que la comprensión de los enfoques de contingencia, ayudan a adaptar el enfoque, aunque es importante indicar que los líderes también desarrollan su capacidad de adaptación como consecuencia de la práctica y de la experiencia.

El postulado básico de este planteamiento era entonces que un comportamiento que resultaba eficaz en algunas circunstancias podría no ser eficaz si variaban las condiciones. Por lo tanto, la eficacia del comportamiento del líder es contingente, ya que depende de las distintas situaciones de la organización.

Para entender estas teorías es necesario entender el término contingencia. Esta palabra quiere decir que una cosa depende de otras, es decir que para que un líder sea eficaz, su comportamiento y estilo deben adecuarse a las características de la situación. Un estilo de liderazgo que funciona en una situación determinada podría no funcionar en otra, por lo cual no existe un estilo óptimo de liderazgo. Las contingencias más importantes para el liderazgo son la situación y los seguidores. Las variables más sobresalientes de la situación son las actividades, la estructura, el contexto y el entorno. Por su parte, la naturaleza de los seguidores como las necesidades, la madurez y la cohesión de los seguidores hacen una diferencia significativa para poder saber cuál es el estilo óptimo de liderazgo.

Esto significa que los enfoques de contingencia intentan determinar las particularidades de las situaciones y de los seguidores y estudian cuáles estilos de liderazgo pueden lograr la mayor eficacia. Si se piensa que una persona es capaz de dar un diagnóstico correcto de una situación y de tener una flexibilidad tal como para adecuar a ella su estilo de comportamiento, entonces existen altas probabilidades de que obtenga muy buenos resultados. Por ejemplo, dos comportamientos fundamentales que los líderes pueden adecuar para enfrentar las diversas contingencias son el dirigido a las tareas y el dirigido a las relaciones. Así se puede adecuar el estilo, de modo que el comportamiento incluya un grado alto o bajo de orientación hacia estas dos dimensiones.

En definitiva, si los líderes disciernen las características de las tareas, los seguidores y las organizaciones, podrán encontrar el estilo que aumenta la posibilidad de conseguir resultados exitosos. Por lo tanto, el liderazgo eficaz precisa desarrollar habilidades de diagnóstico y de tener un comportamiento flexible. 


\section{Capítulo V. La importancia de las cuestiones humanas}

Toda profesión que se enfrenta constantemente con el peligro requiere un fuerte sentido de solidaridad para funcionar con eficacia, de manera tal de lograr en la mayor medida posible la cohesión del grupo. Por ello los líderes que se desempeñan en situaciones que incluyen riesgo, como en el caso de los líderes militares, pueden ser tomados como objeto de estudio para muchos autores. Es interesante observar que, actualmente, en las escuelas militares de muchos países, como por ejemplo la de Argentina o la de Estados Unidos donde se entrena a los futuros líderes de las Fuerzas Armadas, se enseña a los cadetes que los buenos líderes son los que se preocupan por sus soldados y los que nunca piden a otros que hagan algo que ellos mismos no estarían dispuestos a hacer. Con estas palabras se quiere decir que cada vez son más los autores que subrayan la importancia que tienen las personas y en consecuencia las relaciones. En tiempos de incertidumbre es común ver como los líderes recurren a las relaciones personales como un buen camino para unir a la gente.

En este sentido, al otorgarle la prioridad a las relaciones, en lugar de las reglas, presenta ciertas dificultades a los líderes tradicionales acostumbrados a pensar que los subordinados no tienen que actuar de acuerdo a sus emociones. En cambio, los líderes inteligentes comprenden que las emociones humanas son fundamentales y que, el respeto y el reconocimiento a los seguidores, mejora el funcionamiento del entramado social. La persona y sus emociones van unidas y, gracias a las emociones, los seguidores se comprometen con la visión y la misión compartidas, con los valores y la cultura que comparten en esa estructura social.

Por lo tanto, los líderes al preocuparse de las cuestiones humanas, especialmente en tiempos de incertidumbre y de cambios, podrán colaborar con los subordinados a explorar todo su potencial y así hacer que aporten lo mejor de sí mismos en su accionar. Algunos aspectos principales de dichas cuestiones son el poder transmitir a los empleados la idea de que sus actos tienen un propósito, el hacerlos sentir que son valorados y respetados y conducirlos adecuadamente para mantener un buen estado de ánimo y una gran motivación. Ahora bien, para comprender el tema planteado, resulta necesario analizar básicamente el significado de los modelos mentales y de la empatía que comienzan a ser explicados a continuación.

\section{V.1. Modelos mentales}

Un modelo mental es una perspectiva personal que establece cómo actúa y cómo elige una persona relacionarse con los otros. Estos modelos son simplemente teorías que las personas adoptan sobre los comportamientos que creen adecuados y sobre los sistemas específicos del mundo. Es preciso aclarar que se entiende por sistema al conjunto de elementos que forman un 
todo y se relacionan dando un resultado particular. Un ejemplo de un sistema es el caso de una organización.

Las personas poseen gran cantidad de modelos mentales que suelen dirigir la forma de interpretar las experiencias y de actuar ante los otros y las situaciones. Es por ello que el hecho de no reconocer tanto el modelo mental propio, como los modelos mentales ajenos influye en la manera de razonar, pudiendo desembocar en una carencia para comprender determinadas zonas que pueden permanecer ocultas. En apoyo a este concepto, es oportuno señalar que teniendo presente los rápidos cambios que se producen en todo el mundo, un elemento sustancial de los líderes para llevar al éxito a las organizaciones, es la capacidad que desarrollan para ir cambiando y adaptando el modelo mental propio en función del contexto.

\section{V.1.1. Supuestos}

Los supuestos son muy importantes debido a que son parte del modelo mental. Para explicarlo a través de un ejemplo, es posible señalar que si una persona supone que no se puede confiar en la gente actuará de una manera muy diferente de aquella que supone que si se puede confiar en la gente. Los individuos no sólo tienen supuestos sobre las personas, sino también sobre los hechos, las situaciones y las circunstancias.

No hay que olvidar que los líderes tienen supuestos, y que estos últimos son ideas temporales y no verdades fijas. Cuanto mayor sea el conocimiento que un líder tiene de sus supuestos, mejor entenderá el modo en que los mismos direccionan su conducta. Además, estaría en condiciones de empezar a cuestionarse si los antiguos supuestos se condicen con la nueva realidad y entonces podría modificarlos y llegar así a otros métodos exitosos; porque de lo contrario, corren el riesgo de quedarse aprisionados en sus supuestos si simplemente siguen la corriente de la forma tradicional de hacer las cosas. Por tal motivo, muchos han aprendido a expandir su mentalidad cuestionando la forma correcta de hacer las cosas. Han aprendido a estimar y a respetar otros valores y métodos, pero también a buscar formas que les permitan ir más allá de los límites de los supuestos culturales y encontrar oportunidades para innovar.

\section{V.1.2. Percepción}

La percepción es el proceso utilizado por los individuos para seleccionar, organizar e interpretar la información; por lo tanto, debido a que existen muchas formas de efectuar dicho proceso la percepción varía en gran medida de un sujeto a otro. Éste concepto, como además forma parte del modelo mental de los sujetos, establece la forma en que el líder ve a las personas, las situaciones y los hechos.

La percepción ocurre tan naturalmente que excepcionalmente alguien piensa en ella; no obstante, podemos dividir el proceso que ocurre en tres pasos. En el primero, la persona recibe la 
información del entorno a través de los sentidos (datos sensoriales). En segundo lugar, la mente selecciona algunos datos para procesarlos con más detalle. En tercer lugar, los datos elegidos son organizados de acuerdo a patrones que tienen sentido e interpretados para posteriormente ser respondidos. La realidad indica que toda la gente es consciente del entorno, sin embargo, la percepción de cada sujeto no concede igual importancia a cada elemento. Algunos datos son tomados pero otros son ignorados, ya que una persona escoge dependiendo de diversos factores, entre los que se destacan las características del individuo y los estímulos. Los valores, las actitudes, la personalidad y las experiencias adquiridas afectan en los estímulos o datos sensoriales que elija. Además, las personas tienden a advertir que algo sobresale entre los estímulos que los rodean, es decir que suelen notar más algo que sobresale de lo usual, por lo que las características de los datos mismos también influyen en la elección.

De esta forma, quienes sean capaces de tomar conciencia de los diversos factores que influyen en la percepción y que, en consecuencia, actúan en el pensamiento, evitarán algunas distorsiones en la forma de percibir que podrían perjudicar el desempeño. Una de estas distorsiones es el resultado del acto de estereotipar, que significa la propensión a colocar a una persona en un grupo o en una categoría más amplios, y luego, atribuirles generalidades muy extendidas referidas al grupo o la categoría. Los estereotipos no permiten llegar a conocer a los individuos y normalmente impiden que los individuos puedan hacer la mayor cantidad de aportes posibles en la estructura.

\section{V.1.3. Lograr el desarrollo de la mente de un líder}

Para llegar a un liderazgo eficaz, los asuntos de la mente son muy importantes. El hecho de estar consciente tanto de los supuestos como de las percepciones, y de llegar a entender la influencia que ejercen en las emociones y en los actos, es el punto de partida para poder cambiar los modelos mentales anticuados e interactuar con el mundo de una manera diferente, porque aquello que funcionó antes tal vez ya no funcione hoy. En un entorno que no se detiene y que cambia continuamente, suscribirse a la idea de "hacer las cosas como siempre se han hecho" probablemente sea un camino que termine en el fracaso. Es conveniente aprender a no dejar de cuestionar las creencias, los supuestos y las percepciones a fin de poder ver las cosas de una forma distinta y poder enfrentar los retos del futuro.

\section{V.1.3.1. Tener una mentalidad abierta}

Una de las formas de adquirir un pensamiento independiente es esforzarse en romper los esquemas mentales, o sea destruir los patrones de pensamiento por categorías que estamos condicionados a aceptar como correctos. Pensamiento independiente quiere decir cuestionar los supuestos e interpretar los datos y los hechos de acuerdo a la propia mirada, y no en función de 
reglas preestablecidas o categorías definidas por otros. Las personas que piensan de modo independiente tienen opiniones e ideas propias, y están dispuestas a conducirse basándose en sus creencias personales y no en lo que piensa la gente. Pensar con independencia significa tener mente abierta y sentido crítico, que también ayuda para aceptar otros puntos de vista y tomar lo mejor de cada uno.

A continuación, para entender el concepto de la importancia de tener una mente abierta, se ilustrará la fuerza que tienen los condicionamientos que guían los pensamientos y comportamientos a través de un experimento realizado por investigadores al que eligieron llamar el "síndrome del lucio".

Síndrome del lucio: En un experimento, los investigadores metieron un pez lucio en uno de los lados de una gran pecera dividida por un vidrio y del otro lado metieron a varias carpas pequeñas. El hambriento lucio hizo numerosos intentos por engullir a los pececillos de agua dulce, pero sólo consiguió chocar contra el vidrio y, al final de cuenta, aprendió que era inútil tratar de llegar a las carpas. Después los investigadores retiraron la división de la pecera, pero el lucio ya no intentó atacar a los pececillos, porque le habian condicionado a creer que era imposible llegar hasta ellos. Cuando las personas suponen que tienen información completa de una situación gracias a sus experiencias pasadas, presentan el sindrome del lucio, o sea, una incapacidad adquirida que se deriva de una aceptación rígida de algo que funcionó en el pasado y una negativa a considerar otras alternativas y perspectivas. (Daft, 2006: 191).

Los líderes eficaces necesitan mantener su mente abierta, para lo cual se esmeran por conseguir despegarse de muchas de sus ideas condicionadas a fin de poder abrirse a nuevas perspectivas. Esta apertura, es decir, el dejar a un lado ideas preconcebidas, creencias y opiniones, es comparable con la mente de un principiante porque refleja la apertura y la inocencia de un niño que está empezando a conocer el mundo. Así, logran comprender las limitaciones de la experiencia pasada y tratan de encontrar otros puntos de vista.

\section{V.2. Inteligencia emocional}

Según el enfoque de Goleman (Goleman, 2000), la humanidad queda más evidenciada en los sentimientos, por lo que si se consideran verdaderamente las emociones se podrá conseguir enriquecer los modelos mentales. De esta manera, como todas las personas mezclan intelecto y agudeza emocional en diversas proporciones, puede suceder que una persona muy inteligente podría no tener tanto éxito como una persona menos inteligente intelectualmente, pero con mayor inteligencia emocional. Goleman sugiere que los sentimientos más profundos, las pasiones y anhelos son guías fundamentales, lo que significa que las emociones son impulsos y que cada una de ellas ofrece una disposición definida a actuar. Por ejemplo se observa que un amor poderoso podría llevar a una persona a efectuar un importante sacrificio personal (como el sacrificio de un 
padre por su hijo) que podría ser irracional desde el intelecto; sin embargo, desde el corazón es la única elección posible.

Se puede decir que la dicotomía emocional-racional se aproxima a la distinción entre el corazón y la cabeza. En cierto sentido, existen dos cerebros, dos mentes, dos clases diferentes de inteligencia. Estas dos mentes, la emocional y la racional, trabajan en armonía aunque en los momentos en que aparecen las pasiones la balanza se inclina, y es la mente emocional la que domina a la racional. El poder de las emociones se puede observar en los momentos de apasionamiento en los que luego, una vez llegada la calma, llega el arrepentimiento y no logra comprenderse por qué se tuvo un comportamiento tan irracional: algunas frases comunes que se escuchan son "me volví loco, perdí la cabeza" o "no puede pensar correctamente".

Así, la facultad emocional guía las decisiones y trabaja en colaboración con la mente racional permitiendo (o no) el pensamiento. De la misma manera, el cerebro pensante influye en las emociones, a excepción de los momentos citados en los que las emociones quedan fuera de control y el cerebro emocional pierde sus frenos. En definitiva, el desempeño en la vida está determinado por ambas mentes, y lo importante no es sólo el cociente intelectual sino también la inteligencia emocional. Por lo tanto, como el intelecto no puede operar óptimamente sin la inteligencia emocional, sólo se trata de encontrar el equilibrio, de armonizar cabeza y corazón; de utilizar la emoción de manera inteligente.

Entonces, la preocupación en esta parte del capítulo pasa por un conjunto clave de características de la inteligencia emocional como las habilidades para ser capaz de motivarse y persistir frente a las decepciones teniendo esperanza y optimismo; controlar el impulso, evitar que los trastornos disminuyan la capacidad para pensar, mostrar empatía y tener esperanza. Es fundamental no ser esclavo de la pasión, por lo cual se requiere de autodominio y ser capaz de aguantar las emociones a las que nos someten los golpes de la fortuna. El objetivo es el equilibrio, porque cuando las emociones están descontroladas y son persistentes, se vuelven patológicas como la depresión inmovilizante, la ansiedad abrumadora, la furia extrema, etcétera. Mantener el control es la clave del bienestar emocional, teniendo siempre presente el alto impacto que produce en el ámbito laboral.

Daft (Daft, 2006: 196), basándose en Goleman (entre otros), piensa que cada vez es más reconocida la importancia que tiene la inteligencia emocional, y entiende a ésta como la capacidad que un sujeto tiene para percibir, identificar, comprender y manejar adecuadamente las emociones. Si bien existen cientos de emociones y muchos matices, las principales podrían ser amor, tristeza, miedo, alegría, asombro, disgusto, vergüenza, ira; aunque la inteligencia emocional también incluye características como la conciencia de uno mismo, la capacidad para manejar las 
emociones propias, la capacidad para tener esperanzas y optimismo a pesar de los obstáculos, la capacidad para sentir empatía con otros y las sólidas habilidades para las relaciones sociales interpersonales.

Esto significa que la comprensión y las habilidades emocionales influyen en el éxito y la felicidad, ya sea en el trabajo como en la vida personal. Entonces, los líderes pueden aprovechar y dirigir la fuerza de las emociones para mejorar la satisfacción, el estado de ánimo y la motivación de sus seguidores, así como aumentar la eficacia general de la organización.

\section{V.2.1. La empatía}

La empatía representa una característica muy importante de la inteligencia emocional y, según Goleman (Goleman, 2000: 123), es la habilidad de saber lo que siente el otro, pero construyéndose sobre la conciencia de uno mismo. Esto significa que una persona al estar más abierto a las propias emociones, tendrá más habilidad para interpretar los sentimientos en su conjunto. La capacidad de ser empático sirve en distintas situaciones de la vida, desde las ventas hasta la paternidad, pasando por las actividades políticas.

Hay que comprender que las emociones de la gente generalmente no se expresan en palabras como lo hace la mente racional, sino que se manifiestan a través de otras señales. Por lo tanto, la clave para intuir los sentimientos de otro se encuentra en la habilidad para interpretar el lenguaje no verbal, como el tono de voz, los ademanes, la expresión facial, los silencios, el cambio de postura, etcétera. Una regla empírica referida a las comunicaciones establece que el $90 \%$ o más de un mensaje emocional se expresa a través del lenguaje no verbal.

Estas habilidades para interpretar las emociones contribuyen a la eficacia del trato con los demás y, si existen déficits, se llegará a la ineptitud en el mundo social. La ausencia de dichas capacidades puede hacer que las personas más inteligentes fracasen en las relaciones interpersonales, ya que podrían quedar como arrogantes, desagradables o insensibles. Las habilidades sociales posibilitan movilizar o inspirar a otros, prosperar en las relaciones íntimas, persuadir e influir, e incluso tranquilizar a los demás.

Un principio básico de la vida social señala que las emociones son contagiosas, como si los sentimientos fueran un virus social. Las personas envían señales emocionales continuamente, y esas señales influyen a las personas con quien se interactúa. Cuanto más hábil se es socialmente, mejor se controlan las señales que se emiten. Hay que tener presente que cuando dos personas interactúan, la dirección en que se transmite el estado de ánimo, va desde el más enérgico para transmitir sus emociones al que es más pasivo. Esto varía de acuerdo a la sensibilidad de la persona. Por ejemplo, el solo hecho de ver a un individuo que manifiesta una emoción puede provocar con mucha frecuencia el mismo estado de ánimo, tanto si uno se da cuenta o no de que 
esta imitando una expresión facial. La transmisión del estado de ánimo determina que alguien sienta si la interacción fue exitosa. El grado de compenetración emocional que las personas sienten en un momento se refleja en la exactitud con que se combinan los movimientos físicos durante el diálogo. Este es un indicador de cercanía del que generalmente no se tiene conciencia pero que sucede, tal es el caso del asentamiento que un sujeto hace con la cabeza mientras el otro habla, o cuando los dos se mueven en su silla al mismo tiempo. En síntesis, cuanto mayor sea la sintonización física en el encuentro más parecidos terminaran siendo los estados de ánimo. En general, un elevado nivel de sincronía en la interacción entre personas significa que quienes participan se caen bien.

Entonces, si un líder es poderoso será capaz de influir en el público (como un orador político), del mismo modo que si una persona no logra percibir o transmitir emociones será propensa a tener inconvenientes en las relaciones, debido a que los demás tienden a sentirse incómodos en su presencia. La habilidad para fijar la emoción en una interacción es, en cierto sentido, un indicador de dominio ya que está guiando el estado emocional de alguien.

\section{V.2.2. La inteligencia emocional aplicada. Manejarse con el corazón}

Goleman (Goleman, 2000: 179-180) explica que, inevitablemente, existe un costo en la tarea cuando el líder se desempeña con bajos niveles de inteligencia emocional. Algunos de los motivos son evidentes, sólo hace falta imaginar las consecuencias que genera la incapacidad de un líder para evitar un estallido de ira o la incapacidad para ser sensible a lo que sienten las personas que los rodean. Cuando una persona esta emocionalmente perturbada no puede recordar, atender, aprender ni tomar decisiones con claridad. Dice Goleman que es común escuchar que "el estrés hace que la gente se vuelva estúpida”. En el aspecto positivo se pueden imaginar los beneficios que tiene para la acción ser hábil en las competencias emocionales como ser capaces de resolver acuerdos para que no se agudicen. Desde este punto de vista, liderazgo no es dominación sino el arte de persuadir a las personas para que trabajen para alcanzar el objetivo común. Un ejemplo característico es el que sucede en el sector de la aviación, específicamente en la cabina del piloto. Ha sido estudiado por los expertos que en gran parte de los accidentes aéreos los pilotos cometen errores que podrían haberse evitado, sobre todo si la tripulación que lo acompaña hubiera trabajado en equipo y más armoniosamente. Este caso es considerado como un microcosmos de cualquier organización que suele ser trasladado a cualquier empresa, diferenciado simplemente por el hecho de que al faltarle a éstas la dramática realidad que tienen los accidentes de aviación, los efectos perjudiciales de una moral miserable, de trabajadores que sufren intimidación, de los jefes arrogantes, etcétera, generalmente pueden llegar a notarse menos por quienes están fuera del ambiente. 
Otros autores, explican que las capacidades y los conocimientos del líder sobre las emociones ocupan un lugar privilegiado, especialmente, respecto al comportamiento de los líderes carismáticos y de los líderes transformacionales. Los primeros suelen tener convicciones emocionales muy sólidas, motivo por el cual atraen a los seguidores en el sentido emocional. Los segundos ofrecen una visión de cambio que inspira y motiva a los seguidores para tratar de conseguirla, lo que requiere el uso de todos los elementos de la inteligencia emocional. Estos líderes generalmente poseen confianza en sí mismos, determinación y persistencia ante la adversidad.

La capacidad del líder para manejar las emociones, le permite efectuar un análisis sustantivo de las necesidades de los demás, poniéndolas incluso por encima de sus propios sentimientos. Por ejemplo quien se deja llevar por un fuerte sentimiento de ira o de depresión intensificaría un enfoque egoísta, enfocado en las necesidades propias, y reduciría la capacidad para comprender las necesidades ajenas o para ver las cosas desde otros puntos de vista. Además, el estado emocional de la persona que lidera repercute en el grupo, porque como se explicó, todos pueden contagiarse de las emociones de otros. Si alguien tiene buen humor y es entusiasta, sus emociones positivas generalmente se le pegarán al que esté al lado. Del mismo modo, si alguien está de malhumor puede generar depresión en el otro. Este contagio de emociones significa que los líderes que poseen la capacidad de conservar el equilibrio y de mantenerse motivados son modelos positivos de roles que ayudan a motivar y a inspirar a quienes los rodean.

Sin embargo, probablemente lo más importante sea que la inteligencia emocional permite a los líderes reconocer y respetar a los seguidores como seres humanos completos con sentimientos, opiniones e ideas propias. Estos líderes tratan a los demás como individuos que tienen sus propias necesidades, capacidades y sueños; colaboran con los seguidores para que crezcan y se desarrollen, para que mejoren la imagen que tienen de sí mismos y su autoestima, y para ayudarles a satisfacer sus necesidades y a alcanzar sus metas personales.

Estima Goleman, que es posible asegurar que en las organizaciones la inteligencia emocional tiene tres aplicaciones fundamentales: "ser capaz de ventilar las quejas como críticas útiles [como cuando una crítica ingeniosa se centra en lo que la persona ha hecho y puede hacer en lugar de expresarla como un ataque al carácter personal que sólo logra desmotivar y poner a quién lo recibe a la defensiva y en una actitud poco receptiva], crear una atmósfera donde la diversidad resulta valiosa en lugar de ser motivo de fricción y trabajar eficazmente en equipo" (Goleman, 2000: $181)$.

\section{V.2.3. Desarrollar la inteligencia emocional}

Es saludable recordar que todas las personas están en condiciones de aprender y desarrollar la inteligencia emocional. Por lo cual, para que lograr una mayor comprensión, Daft (Daft, 2006: 198 
y 199), establece que las competencias y las capacidades de la inteligencia emocional se agrupan en cuatro categorías fundamentales.

1) Conciencia del yo: se puede decir que ésta es la base de todas las demás competencias. Incluye la capacidad para reconocer y comprender las emociones propias y determinar cómo afectan en la vida, así como la capacidad para evaluar con precisión las fortalezas y las limitaciones propias. También abarca tener el sentido de confianza en uno mismo.

2) Manejo del yo: principalmente incluye la habilidad para controlar las emociones negativas o perjudiciales. Es necesario aprender a equilibrar las emociones para que la preocupación, la ansiedad, el miedo o la ira afecten lo menos posible, lo cual permitirá pensar con claridad y ser más eficaces. Manejar las emociones no quiere decir reprimirlas o negarlas, sino comprenderlas para enfrentar las situaciones en forma productiva. Existen otras características de esta categoría como la confiabilidad, la dedicación y la capacidad de adaptación. Los líderes hábiles para manejar el yo no pierden la esperanza ni el optimismo a pesar de los obstáculos o los fracasos rotundos.

3) Conciencia social: se refiere a la capacidad para comprender a los otros. Los líderes que tienen conciencia social aplican la empatía, son capaces de comprender puntos de vista divergentes e interactuar eficazmente con distintos tipos de personas y de emociones. La característica de la conciencia organizacional se refiere a la capacidad para desenvolverse correctamente en ella, para construir redes y para utilizar eficazmente los comportamientos políticos a fin de obtener resultados positivos. Este elemento también incluye una orientación al servicio, lo que significa la capacidad para reconocer y satisfacer las necesidades de los seguidores.

4) Manejo de relaciones: capacidad para vincularse con otros y construir relaciones positivas. Quienes tienen un elevado grado de inteligencia emocional tratan a los demás con comprensión, sensibilidad y amabilidad.

Los individuos considerados como buenos líderes usan todos los elementos para combinar o variar sus estilos, dependiendo de la situación o del problema en cuestión. Y debido a que son sensibles a sus emociones y a las de otros, también son capaces de reconocer el efecto que están teniendo en los otros y adecuar así su mirada para obtener un mejor resultado.

\section{V.3. La conveniencia de dirigir con amor en lugar de con miedo}

Este tema ha sido estudiado desde hace ya mucho tiempo por diversos autores. Uno de los grandes exponentes que lo ha trabajado fue Maquiavelo (Maquiavelo, 2003: 151-153) que en sus textos clásicos se preguntaba si es mejor ser amado que temido, o ser temido que amado. La respuesta que encuentra es que lo mejor es ser ambas cosas a la vez. Sin embargo, debido a que es muy 
difícil reunir ambas a la vez, cree que es preferible ser temido que amado. Y esta conclusión tiene su base en lo que piensa de la generalidad de los hombres, es decir, que son, entre otras cosas, ingratos, simuladores y ávidos de lucro. Piensa que mientras se les hace bien ofrecen todo lo que tienen porque saben que ninguna necesidad se tiene de lo que ofrecen, no obstante, cuando aparece la necesidad y se les pide lo que habían ofrecido, se rebelan. Sucede que quien se ha confiado en la palabra empeñada pierde debido a que las amistades que se consiguen con dinero no se disponen cuando son requeridas, por lo que cuando llegue el momento no se las podrá usar. Además, los hombres ofenden más a uno que se haga amar que a uno que se haga temer, porque el amor es una relación de agradecimiento que los hombres, al ser perversos por su propia naturaleza, quiebran cada vez que pueden llegar a recibir algún otro beneficio. Por el contrario, el temor es miedo a la sanción y no se la pierde en ningún momento. Sin embargo, si se toma la decisión de hacerse temer, se lo debe hacer de manera tal que evite el odio, porque es viable ser temido y no odiado; simplemente debe proceder cuando la situación lo justifica. En definitiva, Maquiavelo concluye que como amar depende de la voluntad de los hombres y temer de la voluntad del [líder], la persona prudente se apoyará en lo propio y no en lo ajeno, esforzándose siempre en evitar el odio.

En un análisis más moderno, Daft (Daft, 2006: 204-209), explica que un entorno que muestra interés y respeto por las personas es mucho más eficaz que uno en el cual la gente se siente temerosa. El amor a las funciones desempeñadas significa que realmente existe interés por otros y que se comparte con ellos el conocimiento y la comprensión para que crezcan. Es sabido por todos que, en muchas organizaciones, se aplica el liderazgo tradicional que está basado en el miedo debido a una idea extendida de que éste es sano y benéfico para la organización. De hecho, la realidad indica que el miedo es un potente motivador, ya que cuando el éxito de la organización depende principalmente de que las personas obedezcan órdenes sin pensarlo, liderar por miedo en muchas ocasiones satisface las necesidades de la estructura. Sin embargo, el éxito en la actualidad depende de la mente y del conocimiento, del compromiso y del entusiasmo de todos los seguidores.

Un gran problema que trae el liderazgo ejercido a través del miedo es que da lugar a un comportamiento evasivo, porque nadie quiere equivocarse, y ello inhibe el crecimiento y el cambio. Los líderes pueden lograr que la gente se comprometa en busca de un propósito compartido empleando características más positivas, como serían el interés y la comprensión, así como escuchando a otros y estableciendo con ellos una relación personal. La emoción que incita en mayor medida a correr riesgos, aprender, crecer y avanzar unidos a la organización proviene del amor y no del temor. 
El respeto y la confianza no sólo conducen a las personas hacia un desempeño mejor, sino que también les permite sentirse unidas emocionalmente a la sociedad civil que constituyen. Los líderes tranquilamente pueden recurrir a emociones negativas como el miedo para acometer un accionar, pero al hacerlo, podrían estar destruyendo paulatinamente el ánimo de las persona, lo que traerá indefectiblemente consecuencias negativas. El miedo y la desconfianza que han dejado las jerarquías tradicionales donde los líderes daban órdenes y los seguidores se desesperaban por cumplirlas bajo amenaza de un castigo, todavía influye en las organizaciones. Por lo tanto, los líderes son los verdaderos encargados de generar un ambiente que posibilite a las personas sentirse seguras de decir lo que piensan. Dar la oportunidad de que haya una saludable realimentación permite corregir errores.

El amor es entonces un buen motivador porque hace que la gente se sienta bien y decidida a participar. Si el líder puede lograr que los individuos hagan las cosas por gusto, sería algo muy bueno, ya que cuando alguien efectúa actividades que resultan agradables, inmediatamente pierde la noción del tiempo. Además, como todo el mundo se vuelve más carismático cuando se dedica a una actividad que verdaderamente le interesa, quienes aman lo que hacen consiguen contagiar su entusiasmo y pasión a otros. El amor lleva así a la acción, hace que la gente se comporte de una manera determinada, lo que puede traducirse por ejemplo en alguna clase de sacrificio o en una entrega hacia otros.

En definitiva, los líderes pueden optar por liderar con amor en lugar de hacerlo con miedo. Y si así lo hicieren, el amor les permitirá generar confianza, creatividad, entusiasmo y un rendimiento más eficaz en la organización.

\section{Capítulo VI. EI liderazgo moral y los seguidores}

\section{VI.1. El liderazgo moral}

Quien ejerce el liderazgo moral trata de servir a la sociedad antes que utilizarla. Lo que significa que resulta fundamental para el buen liderazgo colocar a los demás en un lugar superior al propio, siendo esto aplicable tanto en la política, la guerra, la educación, los servicios sociales o los negocios.

Como ya se vio en el capítulo anterior, la mente y el corazón son dos de los tres elementos que conforman el liderazgo exitoso. Sin embargo, para Daft (Daft, 2006: 222-230), existe un tercer elemento que es el espíritu o la capacidad para buscar en nuestro interior, para comprender la condición humana, para distinguir lo que está bien de lo que está mal, para ver lo que realmente es importante y para tener el valor necesario para defender lo valioso y lo correcto. De esta forma, los líderes tienen que preguntarse si pueden juntar la fuerza que necesitan para hacer lo correcto ante 
las grandes presiones externas actuando con base en principios morales universales. Sólo una persona de carácter firme sabe cuáles límites no se deben cruzar. Así, se puede decir que los líderes cuando promueven excesivamente su interés personal, cuando engañan y no cumplen con lo que ha sido acordado y cuando no tienen el valor para enfrentarse a las injusticias consiguen que la organización no funcione correctamente.

Los seguidores quieren tener líderes honrados y confiables. Es por ello que las principales actitudes de un líder moral son la humildad, el interés por el bien mayor, la honradez y la sinceridad, el cumplimiento de los compromisos, la lucha por la equidad, la asunción de la responsabilidad, el respeto hacia todas las personas, la motivación y la preocupación por el desarrollo de los otros, la vocación de servicio, la defensa valiente de lo correcto. Un líder que por ejemplo, para quedar bien calla ante una situación incorrecta, está apoyando ese tipo de conducta. Si un líder sabe que un colega está tratando injustamente a otro y no hace nada, está sentando un precedente para que otros también se comporten de manera injusta. Muchas veces es difícil defender lo correcto, pero es el camino principal para poder crear un entorno íntegro. Los líderes inmorales intentan siempre llevarse el mérito del éxito y culpan a otros cuando las cosas no salen bien. Piensan que las personas son un simple medio para lograr un fin y no se interesan por tratarlos como seres humanos ni por ayudarles a mejorar. Éstos líderes sólo piensan en sí mismos.

Por eso, es fundamental para la organización que a quienes les corresponda mandar se comprometan con la ética tanto en sus palabras como en los hechos. Los buenos líderes respaldan las elevadas normas morales y hacen lo correcto incluso cuando piensan que nadie los ve; ya que los que infringen reglas cuando piensan que nadie lo notará, tarde o temprano tendrán consecuencias negativas. Esto significa que el liderazgo no está disociado de lo correcto o lo incorrecto debido a que todas las prácticas se pueden utilizar para bien o para mal, por lo cual tienen una dimensión moral. Entonces, es posible dar la siguiente definición: el liderazgo moral es saber diferenciar entre el bien del mal y elegir hacer lo correcto (lo justo, lo honrado, lo bueno), pero también utilizando la conducta correcta al aplicarlo. Esta clase de liderazgo permite a las personas estar mejor de lo que estaban sin el líder.

En el nivel más extremo de desarrollo, los líderes morales son guiados por principios internos reconocidos universalmente como buenos o malos. Llegado el momento, las personas que se encuentran en este nivel pueden incluso desobedecer las reglas o las leyes que violan esos principios que defienden. Estos valores internos mantienen en equilibrio el interés personal y el interés por los otros y por el bien común. Sin embargo, para lograrlo se requiere tener ciertas características de la personalidad, como por ejemplo la fuerza del ego, la seguridad personal y el sentido de independencia que hacen que los líderes se comporten moralmente ante la oposición. 
No existe ninguna duda de que para hacer lo correcto se precisa tener coraje. Se necesita valor, que no significa la ausencia de duda o temor, sino la capacidad para avanzar a pesar de ellos. Los líderes morales superan los miedos para aceptar la responsabilidad, correr riesgos, hacer cambios, decir lo que piensan y luchar por lo que consideran justo. Algunas de las fuentes de valor son estar convencidos de un propósito superior, querer a otros (un padre que arriesga la vida por su hijo), haber fracasado (el dolor de aprender fortalece) y canalizar la ira (ésta emoción, en cantidades moderadas, es saludable porque produce mucha energía para avanzar. El desafío está en canalizarla y en aprovecharla debidamente).

\section{VI.2. Los seguidores}

No es posible concebir el liderazgo sin la existencia de seguidores. La realidad indica que todo el mundo en algún momento es seguidor, siendo más frecuente que los individuos sean seguidores que líderes.

Se observa que muchas de las cualidades que son deseables en el líder son las mismas que debe tener un seguidor eficaz, por ejemplo, demostrar iniciativa, compromiso con las metas comunes y valor; pero nunca éste último tiene que llegar al extremo de desafiar la autoridad y a los valores u objetivos de la organización. Algunas de las estrategias para que el seguidor sea considerado eficaz son convertirse en un recurso valioso para el líder, colaborar para que se desempeñe lo mejor posible, entablar una buena relación con él. Hay que señalar que los seguidores quieren ser liderados pero no controlados, es decir que, como fue explicado, el líder tiene que procurar crear un entorno que permita a las personas dar lo mejor de sí y ayudarlo a ser eficaz. Por estos motivos, se puede decir que existe una interdependencia dentro de la organización que hace que los actos de los seguidores influyan en quien lidera y viceversa. Así, la esencia de las relaciones entre ambos entraña reciprocidad, lo que significa que hay un intercambio recíproco de influencia.

En este sentido, Bobbio (Bobbio, 2008: 916 y 917) coincide con el análisis manifestando que, probablemente, lo más importante que hay que decir acerca del concepto de seguidores es que éstos también desempeñan papeles activos. En los estudios tradicionales, el liderazgo se consideraba como una relación unilateral: "uno, o guía o es guiado"; sin embargo, se advierte que todos los que guían son también guiados. Está claro entonces, que el líder y sus seguidores se encuentran dentro de una relación de influjo recíproco. Son dos realidades complementarias: tanto que los seguidores se pueden definir como colaboradores del liderazgo.

Desde el punto de vista relativo a las razones por las que se unen al líder, los seguidores pueden dividirse en dos tipos: "los fieles, que se comprometen por razones de carácter moral, y 
los mercenarios, que lo hacen por motivos de interés" (Bobbio, 2008: 916). Se trata de una distinción donde se señala que la relación entre líder y seguidores es de la misma naturaleza en ambos casos. Un líder no puede influir y dirigir los actos de sus subordinados sino es en la medida en que reparte recursos; y las relaciones morales son consideradas también como un recurso. Por otra parte, del mismo modo que los mercenarios desean un pago, los fieles imponen obligaciones a su líder, al menos la obligación de seguir sirviendo a la causa y de comportarse como el modelo de sus ideales. Por lo tanto, en los dos casos se realiza una relación de transacción.

En definitiva, se observa y se concluye que el problema de fondo es el de saber por qué el que es guiado sigue al que lo guía pero, en términos generales, éste es el mismo problema del poder y de su legitimación.

\section{Capítulo VII. La motivación}

Este capítulo estudiará cómo los líderes pueden sacar lo mejor de sus seguidores a través de la motivación, que es entendida como las fuerzas que trabajan dentro o fuera de un individuo y que despiertan su entusiasmo y perseverancia para lograr una meta determinada. Este concepto influye en la productividad, por lo que una de las funciones del líder es canalizar la motivación de los subordinados con el objeto de que alcancen la visión y las metas de la organización. En tal sentido, se verá que efectuar un análisis detallado ayudará a comprender qué es lo que conduce a las personas a emprender la acción y por qué perseveran en la acción a través del tiempo.

Ahora bien, para comenzar se ilustrará por medio de la siguiente figura (Daft, 2006: 301) un modelo muy simplificado de la motivación humana. Este modelo indica que las personas tienen necesidades básicas, como las referentes al alimento, al reconocimiento o a los beneficios económicos que se traducen en una motivación hacia conductas específicas que contribuyen a la satisfacción de dichas necesidades. Si el comportamiento lleva al éxito, su premio será la satisfacción de esa necesidad, aunque el premio también señala que el comportamiento fue el adecuado y que lo puede observar otra vez en el futuro. Es importante tener presente que los líderes, al hacer uso de la teoría de la motivación, pueden conocer como satisfacer las necesidades de los seguidores e incrementar su accionar. Por lo cual, cuando los seguidores no están motivados para alcanzar las metas de la organización, el responsable de la falla suele ser el líder.

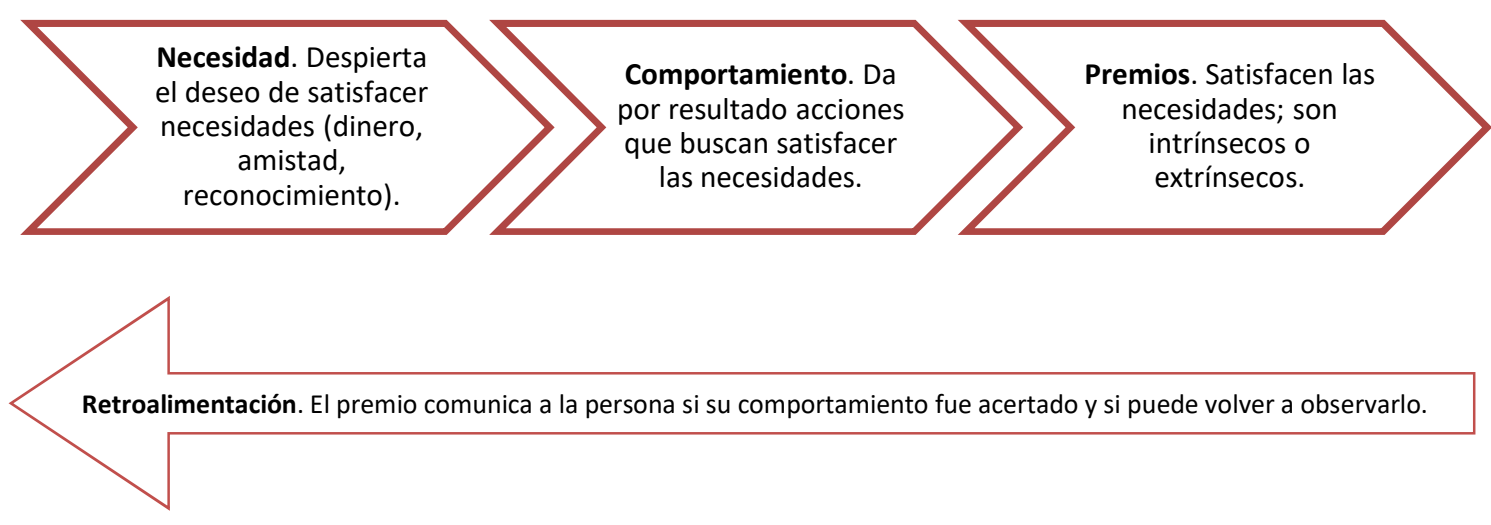




\section{VII.1. Premios intrínsecos y extrínsecos}

Los premios pueden ser intrínsecos o extrínsecos y pueden ser aplicados a todo el sistema o a los individuos. Los premios intrínsecos son las satisfacciones internas que siente un individuo mientras realiza una acción dada. Por ejemplo, solucionar un problema en beneficio de otros puede cumplir una misión personal, como así también terminar una tarea muy difícil puede dar como resultado un sentimiento de realización. En cambio, los premios extrínsecos tienen su origen en el exterior, son recompensas que una persona extiende a otra como resultado de haberla complacido: la gente observa un comportamiento dictado por una fuente externa que les proporciona a su vez lo que necesitan como serían los casos de ascensos o de dinero para poder sobrevivir.

Es sabido que los premios extrínsecos son importantes, no obstante, hay que esforzarse para lograr que las personas ganen premios intrínsecos, porque quienes reciben una satisfacción intrínseca de su accionar suelen hacer mayor esfuerzo. Todos han observado que las personas voluntariamente invierten tiempo y energía en las actividades que disfrutan (como serían por ejemplo los pasatiempos), por lo cual, es probable que en algún momento los sujetos deban realizar algunas actividades que no les agradan, los líderes tratan de asignar a cada persona puestos y tareas que les gusten. En este sentido es que los líderes crean un entorno que obtiene lo mejor de las personas, en el cual puedan sentir que son valoradas y que están contribuyendo a algo valioso, ayudando a los seguidores a obtener premios intrínsecos del sistema entero. Así, se conseguirá que la gente sienta orgullo de formar parte de la organización en la que se desempeña.

\section{VII.2. Necesidades de orden superior y de orden inferior}

Los premios intrínsecos pertenecen a las necesidades de "orden superior" de las personas, como los logros, la competencia y la realización. Los premios extrínsecos pertenecen a las necesidades de "orden inferior", como lo material, la estabilidad mínima y la seguridad. Hay que recordar, que la recompensa intrínseca se encuentra en el interior del empleado, por lo que una recompensa que es intrínseca para una persona podría no serlo para otra. Una de las maneras en que los subalternos pueden obtener premios intrínsecos es que el líder les ceda más control sobre su propio trabajo y les otorgue facultades para modificar los resultados dejándoles en libertad para determinar sus propias acciones.

\section{VII.3. Teoría de la motivación basada en las necesidades}

Las teorías basadas en las necesidades tienen un papel destacado debido a que hacen hincapié en lo que motiva a las personas. Las necesidades de los individuos son las cosas que estos 
desean y que están ocultas, por lo cual, es preciso trabajar para poder obtenerlas. Si los líderes logran descubrir las necesidades de los seguidores podrán diseñar un sistema de recompensas acorde, con el objeto de estimularlos para que dirijan su energía y sus prioridades hacia la consecución de las metas compartidas.

\section{VII.3.1. Teoría de la jerarquía de las necesidades}

Probablemente, la más famosa de las teorías basadas en las necesidades sea la desarrollada por Abraham Maslow. Esta teoría argumenta que los seres humanos están motivados por múltiples necesidades y que éstas se presentan en un orden jerárquico donde las necesidades de orden superior no pueden ser satisfechas mientras las necesidades de orden inferior no hayan sido cubiertas. Éste autor concluye diciendo que una vez que una serie de necesidades humanas hayan sido satisfechas, las mismas dejan de actuar como motivadoras (Koontz - Weihrich, 1998: 506-507). Estas necesidades se hallan relacionadas entre sí dispuestas en una jerarquía de prepotencia. Esto significa que:

El objetivo más prepotente monopolizará la conciencia y tenderá por sí mismo a organizar la selección de las diversas facultades del organismo. Las necesidades menos prepotentes son minimizadas, o incluso olvidadas o negadas. Pero cuando una necesidad está plenamente satisfecha, surge la siguiente en orden de prepotencia para dominar la vida consciente y para servir como centro de organización del comportamiento, puesto que las necesidades satisfechas no son motivadores activos ${ }^{6}$.

Maslow señaló cinco niveles generales de necesidades que nos motivan ${ }^{7}$.

\section{Jerarquía de las}

\section{necesidades}

\begin{tabular}{|c|}
\hline $\begin{array}{c}\text { Necesidad de } \\
\text { autorrealización }\end{array}$ \\
\hline Necesidad de estima \\
\hline Necesidad de pertenencia \\
\hline Necesidad de seguridad \\
\hline Necesidades fisiológicas \\
\hline
\end{tabular}

\footnotetext{
${ }^{6}$ Maslow, Abraham H.: A Theory of Human Motivation, en Ed. Harriman, Philip L. (1946): The Philosophical Library, Nueva York: Twentieth Century Psychology, P.46 (citado por Bay, Christian (1961): La estructura de la libertad, Madrid: Editorial Tecnos S.A., P. 394).

${ }^{7}$ Es necesario señalar que esta clase de teorías siempre continúan siendo sometidas a consolidación empírica o a prolongada discusión.
} 
- Fisiológicas. Entre las principales necesidades fisiológicas humanas se encuentran el alimento, el agua y el oxígeno; pero, en el marco de la organización, las necesidades se manifiestan en una temperatura adecuada, en un sueldo base que permita sobrevivir, etcétera.

- Seguridad. Este nivel presenta la necesidad de un entorno físico y emocional seguro y estable, sin amenazas. En una organización, las necesidades de seguridad están representadas por contar con prestaciones adecuadas.

- Pertenencia. La persona desea ser aceptada, amada, tener amistades y ser parte de un grupo. En la empresa, estas necesidades se traducen en el deseo de pertenecer a un equipo de trabajo y de tener buenas relaciones con los jefes y los compañeros.

- Estima. Es el deseo de tener una imagen propia positiva de uno mismo y de que otros brinden su atención, reconocimiento y aprecio. En las organizaciones se reflejan a través de una motivación por el reconocimiento, una mayor responsabilidad, un estatus elevado y el mérito por los aportes realizados.

- Autorrealización. Es la necesidad de una realización personal, es decir, desarrollar y mejorar todo el potencial que uno tiene. La organización puede satisfacer las necesidades de realización ofreciendo oportunidades para crecer, facultades y la posibilidad de ser creativos.

Según la teoría de Maslow, las necesidades fisiológicas, las de seguridad y las de pertenencia, llamadas de orden inferior son prioritarias; es decir, deben ser satisfechas antes de que entren en operación las necesidades de orden superior o de crecimiento. Así, las necesidades se satisfacen en secuencia: las necesidades fisiológicas se satisfacen antes que las de seguridad, éstas se satisfacen antes que las necesidades sociales, y así sucesivamente. Por ejemplo, una persona que quiera tener seguridad física intentará conseguir un entorno más seguro y no se preocupará por la estima o la autorrealización. Cuando una necesidad queda satisfecha, su importancia disminuye y entra en operación la siguiente necesidad superior.

En resumen, las personas motivadas actúan para satisfacer una secuencia de necesidades, debido a lo cual el enfoque del liderazgo, si bien intenta satisfacer todas las necesidades, suele centrarse en las de orden superior de los subordinados y en las necesidades del sistema. Por ello es que fue explicada la teoría de la jerarquía de necesidades de Maslow, a fin de entender lo que motiva el comportamiento de los individuos. Pero debe aclararse que existen muchas teorías de la motivación, como por ejemplo, las que se concentran en los premios extrínsecos y los castigos y que a veces son llamadas métodos de motivación de "la zanahoria y el palo". Es decir, las personas se desempeñan debidamente para recibir la zanahoria (por ejemplo el aumento de sueldo o un ascenso) o evitar el palo (por ejemplo un descenso de categoría o la negativa a aumentar el 
sueldo), porque no necesariamente obtienen una satisfacción intrínseca de su trabajo. Estos planteamientos observados normalmente en la administración convencional pueden ser eficaces y se basan en controlar el comportamiento de las personas mediante la manipulación de sus decisiones sobre cómo actuar; ello significa que establece la relación entre el comportamiento y sus consecuencias. De esta manera, las necesidades de orden superior tal vez no sean satisfechas porque prefieren utilizar su accionar a cambio de premios externos.

Por supuesto que existen alternativas para la motivación, como es el caso de la atribución de facultades (empowerment), donde proporcionar facultades se refiere a compartir el poder, a delegar funciones o autoridad a los subalternos de la organización, lo que les permite conocer la dirección de la organización y gozar de autonomía para actuar conforme consideren conveniente para seguir esa dirección. Los líderes que utilizan este enfoque otorgan a los seguidores los conocimientos necesarios para que puedan contribuir a la organización, las facultades para tomar decisiones trascendentales y los recursos para efectuar la tarea. Es fundamental indicar que la atribución de facultades frecuentemente satisface las necesidades de orden superior, y está vinculada a la tendencia hacia facilitar que los seguidores encuentren sentido en su acción, a crear un entorno que propicie el crecimiento y a lograr que las personas se comprometan con su trabajo para conseguir que la satisfacción, el desempeño y las utilidades crezcan.

Para autores como Koontz y Weihrich empowerment significa que "los empleados, administradores o equipos de todos los niveles de la organización tienen el poder para tomar decisiones sin tener que requerir la autorización de sus superiores" (Koontz - Weihrich, 1998: 303). La idea de éste concepto radica en el enriquecimiento de funciones y participación de los subordinados. Muchas razones, llevan a que los superiores decidan compartir la autoridad y el poder, entre ellas, la necesidad de responder rápidamente a las demandas o el hecho de tenerlos en cuenta (participar en las decisiones colabora a su vez para generar un sentido de pertenencia, realización y autoestima).

Ahora bien,

(...) para una administración eficaz se requiere de la sincera aceptación del empowerment, basada en la confianza mutua, sustentada en la transmisión a los empleados de la información pertinente para el desarrollo de sus tareas y que se otorgue a personas competentes. Además, los empleados merecen ser premiados por ejercer su autoridad de decisión. (Koontz - Weihrich, 1998: 304-305).

Hay que tener presente que la mayoría de los problemas del desempeño del actor social no son repentinos sino que se desarrollan lentamente con el tiempo. Si no se actúa un día estalla. Ésta resulta la peor manera de motivar a alguien. (Goleman, 2000: 184). 
Por supuesto, la delegación está muy relacionada con el empowerment (ambos términos implican que las personas acepten la responsabilidad de sus acciones y tareas). Entonces, se dirá que delegar, cuyo aspecto fundamental es la descentralización, es indispensable para la existencia de una organización, siendo que existe un número limitado de personas que los individuos pueden supervisar eficazmente; superado ese límite, la autoridad debe delegarse y conceder a un subordinado la discrecionalidad para la toma de decisiones. Es común apreciar que quienes insisten en verificar todo no se dan cuenta que al accionar de este modo restan tiempo y atención a decisiones mucho más importantes que benefician más a la organización. Claramente se observa que tener cuellos de botella en la toma de decisiones, excesiva transferencia de pequeños problemas a los superiores, la sobrecarga de detalles y el subdesarrollo del personal de niveles inferiores dan evidencia de que la negativa a delegar autoridad en un grado considerable es un error.

Hay que saber que al permitir que un subordinado tome la decisión, puede suceder que éste no resuelva la situación igual a como lo habría hecho el superior, sin embargo, es conveniente aceptar otras ideas, colaborar con quien recibe la capacidad de decidir e incluso elogiar la inventiva. La persistente supervisión para garantizar la ausencia de errores vuelve imposible la verdadera delegación. Además, dado que todas las personas comenten errores, se debe permitir a los subordinados que los cometan (siempre que el error no sea grande) y su costo debe considerarse una valiosa inversión en su desarrollo personal. La paciente asesoría y las preguntas orientadoras son métodos para una adecuada delegación que no representan desalentar a los subordinados con críticas intimidatorias o con el insistente señalamiento de sus deficiencias.

Por último se dirá que para el empowerment o facultamiento eficaz es preciso otorgar autoridad de decisión, siempre teniendo presente que, aunque "la responsabilidad no se delega", el líder debe hacer responsables a los subordinados del cumplimiento de las tareas encomendadas.

\section{Capítulo VIII. La comunicación}

Todos los estilos de liderazgo, especialmente el carismático y el transformador, dependen de tener una comunicación eficaz, debido a que resulta clave compartir la visión con los demás para inspirarles y motivarles a luchar por conseguirla y para construir los valores y la confianza que permiten las buenas relaciones con el propósito de producir el cambio hacia la consecución de las metas o al futuro deseable. Asimismo, la buena comunicación incluye enviar, recibir y retroalimentar. Acciones tan simples como escuchar debidamente a los demás permite beneficiarse de las opiniones de los subordinados, ya que es posible que estos piensen algo muy útil y, si se les propicia un espacio adecuado para que se expresen libremente, el líder podría recibir información 
importante. Además, cuando las personas creen que han sido escuchadas se sienten mejor. Como señala Koontz y Weihirich (Koontz - Weihrich, 1998: 601) "escuchar exige total atención y autodisciplina. Requiere asimismo que el que escucha evite la evaluación prematura de lo que dice la otra persona. Es común la tendencia a juzgar (...) en vez de hacer un esfuerzo por comprender el marco de referencia del hablante." Por lo tanto, establecer un clima de comunicación abierto es esencial para crear un lazo de confianza con las personas y unir a las mismas a fin de conseguir que se comprometan con una visión.

Un gran comunicador puede emplear muchos métodos de comunicación, por ejemplo, puede elegir canales que tengan mucho potencial, usar relatos y metáforas y recurrir a la comunicación informal. Los líderes también se pueden dedicar, visible y simbólicamente, a actividades basadas en la comunicación, debido a que los actos logran transmitir el compromiso con el mensaje. Esto significa que los líderes se comunican de forma activa todos los días por medio de palabras y actos. Así, la regularidad es esencial para entablar relaciones personales con los seguidores al ser funcional para el éxito de una visión, ya que ésta no se comprende ni es aceptada de la noche a la mañana, tiene que avanzar paso a paso. La comunicación debe ir siempre incluida en las interacciones diarias, de modo que los seguidores la puedan interiorizar con el tiempo. Es importante entonces hacer un buen uso de la comunicación verbal, la no verbal y la simbólica para reunir a las personas en torno a una visión común.

Es necesario agregar que la "desconfianza, la amenaza y el temor minan la comunicación." (Koontz - Weihrich, 1998: 602). En un lugar que estén presentes estos factores, todo mensaje será visto con recelo. Los orígenes de la desconfianza pueden ser conductas incongruentes del superior o experiencias previas donde el subordinado fue sancionado por comunicar honestamente información desfavorable al jefe. Es común observar que ante la presencia de amenazas (reales o imaginarias) las personas prefieran replegarse, ponerse a la defensiva y distorsionar la información. Esto indica que es necesario propiciar un ambiente de confianza para facilitar la comunicación abierta y honesta.

Por ello, en la actualidad la capacidad para convencer a otros tiene mucho más valor que antes. La mentalidad de mando y control de los líderes que ordenaban a los seguidores qué hacer y cómo hacerlo quedó en la antigüedad; ahora los actores sociales quieren saber qué deben hacer, pero también por qué deben hacerlo. Es en base a lo expuesto que surge la importancia de dominar el arte de la persuasión que los líderes pueden practicar y mejorar siguiendo los cuatro pasos dados a continuación:

1. Establecer la credibilidad. La credibilidad está basada en el conocimiento y la experiencia del líder, así como en sus relaciones con los demás. Quien es capaz de demostrar que tiene 
experiencia en la toma de buenas decisiones, se gana la confianza de los subordinados. Otra manera de conseguir credibilidad es generando buenas relaciones con los demás y demostrando que tiene presente los intereses de los otros.

2. Construir los objetivos sobre un área común. Para persuadir a otros es posible describir lo que se va a pedir como algo que beneficiará a las dos partes. Si las personas entienden que la propuesta les generará un beneficio personal, normalmente querrán hacerlo. Si los líderes no ofrecen ventajas comunes probablemente sea un buen indicador de que deben replantearse los planes.

3. Lograr darle un atractivo a la visión. Las voluntades pueden atraerse en el ámbito emocional usando símbolos, metáforas y relatos que reflejen sus mensajes en vez de recurrir solamente a hechos y cifras. Al acceder a la imaginación de los individuos, pueden inspirarlos para que alcancen grandes resultados.

4. Conectarse emocionalmente. Si se tiene la capacidad para descubrir las emociones de los demás, es posible cambiar el planteo del mensaje de tal forma que se ajuste a la necesidad del público al que va dirigido. Además, al estudiar cómo las personas ha interpretado y respondido en el pasado a hechos ocurridos en la estructura, los líderes comprenderán mejor cómo podrían reaccionar los seguidores a sus propuestas.

La persuasión se trata entonces de un valioso proceso de comunicación utilizado para dirigir a los individuos hacia una solución deseada. Para persuadir e influir eficazmente, los líderes eligen los canales de comunicación adecuados, emplean metáforas y elementos de la narrativa y hacen uso de técnicas de comunicación formales e informales.

Es clave pensar que cada canal de comunicación tiene ventajas y desventajas, y que cada uno de ellos puede ser un medio eficaz de comunicación según las circunstancias. Al igual que las características materiales de un caño limitan el tipo y la cantidad de líquido que puede fluir por él, las características materiales de un canal de comunicación limitan el tipo y la cantidad de información que puede ser transmitida. Algunos ejemplos de canales de información son: la discusión frente a frente, las conversaciones telefónicas, los mensajes electrónicos, las notas y las cartas. Por ellos se pueden transmitir distintas cantidades de información en un momento dado, lo que se llama riqueza de un canal, y donde tres características influyen en la mencionada riqueza: la capacidad para manejar muchas señales simultáneamente; la capacidad para facilitar una veloz retroalimentación; y la capacidad para determinar un enfoque personal para la comunicación.

En ese sentido, como afirman Berger y Luckmann (Berger y Luckmann, 1994), el mejor canal se da en la situación cara a cara como resultado de un intercambio continuo entre las 
expresividades de las dos personas. El individuo A observa al individuo B sonreír, luego B reacciona ante el ceño fruncido de A dejando de sonreír, después sonríe nuevamente cuando A sonríe, y así sucesivamente. De igual modo, esta continua reciprocidad de actos expresivos puede ser utilizada por ambos simultáneamente. Por cierto es que algunos de los síntomas pueden ser interpretados erróneamente, sin embargo, ninguna otra forma de relación puede reproducir la abundancia de síntomas. Seguramente A puede interpretar erróneamente los significados de B también en la situación cara a cara, ya que es posible que el otro oculte hipócritamente sus significados. Aun así, tanto la interpretación errónea como la hipocresía son mucho más difíciles de mantener en la interacción frente a frente que en las formas menos cercanas de las relaciones sociales. Por ello, y para manejar mejor los canales de comunicación y la interacción, el individuo debe salir a conocerlos así como debe aprender a conocer la naturaleza de las cosas.

\section{VIII.1. Relatos y metáforas}

La narración es un medio muy fuerte para transmitir un mensaje y así conseguir influir en las personas y persuadirlas. Por ello, los narradores pueden generar un efecto profundo y duradero usando un discurso lleno de metáforas y relatos, ya que permiten establecer vínculos con los demás en los ámbitos emocional e intelectual. Además, usar imágenes para transmitir mensajes favorece la comunicación al dar sentido a las situaciones para que todos los miembros las entiendan. No es necesario que los relatos sean largos y complejos ni que estén cuidadosamente estructurados; es más, un chiste, una analogía o una descripción breve de una experiencia del líder también es un relato.

Del mismo modo, utilizando la narración, el líder puede lograr despertar imágenes visuales, ayudando a los seguidores a conectarse con el mensaje y con los valores importantes. Los individuos normalmente pueden aplicar alguna parte del relato a su caso personal y que ésta los convenza de algo. Incluso, es más probable que recuerde el relato mucho mejor que una simple orden o un conjunto de datos y cifras. Otro aspecto a destacar es que los relatos del pasado tienen la particularidad de unir a las personas y crear un sentimiento de que existe un propósito y un sentido compartidos.

\section{VIII.2. Comunicación informal}

Los relatos no sólo se comunican con palabras, sino también se transmiten mediante los hechos y la forma de vivir la vida. Las personas siempre miran al líder y consideran que su aspecto personal, comportamiento, actos y actitudes lo simbolizan. Por ejemplo la elección de un canal de 
comunicación transmite un mensaje simbólico; y hasta las visitas personales de un líder son interpretadas como señal de cooperación e interés.

Dentro de la comunicación informal los símbolos son instrumentos de gran valor para comunicar lo importante. En muchas ocasiones, las personas no se percatan de que continuamente están comunicando sin decir una palabra a través de sus expresiones faciales, su lenguaje corporal y sus actos. La comunicación no verbal, es decir los mensajes transmitidos por medio de actos y comportamientos, constituyen gran parte de todo el mensaje que se emite en un encuentro cara a cara. En consecuencia, los individuos entienden que los actos simbolizan, de la misma manera que se adjudica significado a las palabras. Es en este punto donde los seguidores interpretan las señales no verbales de un líder y determinan si sus actos son congruentes o no con sus mensajes verbales. Algunos estudios sugieren que cuando la comunicación verbal de una persona discrepa de la no verbal, el intérprete otorga mayor peso a la comunicación no verbal.

\section{VIII.2.1. Comunicación en una crisis}

En tiempos de cambio o de crisis, la capacidad de un líder para comunicarse, resulta incluso más necesaria que en épocas de estabilidad. Por lo tanto, en presencia de una crisis, para mejorar la comunicación se puede trabajar sobre los siguientes aspectos:

1) Calmarse y escuchar con más atención. Ya se estudió que las emociones de un líder se contagian, razón por la cual, es conveniente que se tranquilice y no pierda el enfoque. La función más importante de un líder en una situación crítica, probablemente sea la de absorber los temores y la incertidumbre de sus subordinados; es decir, escuchar con atención es fundamental. Los líderes también preparan sus mensajes con el propósito de transmitir esperanza y optimismo, pero siempre sin dejar de reconocer la existencia del peligro y las dificultades, de este modo brindan consuelo, inspiración y esperanza.

2) Dejarse ver. Cuando la incertidumbre aparece, con cierta ambigüedad, los seguidores necesitan sentir que alguien tiene el control. Muchos líderes menosprecian la importancia que tiene su presencia en una crisis $\mathrm{y}$, en general, existe una tendencia por querer esconderse, reunir información, pensar bien la situación, manejar las emociones y formular una estrategia para solucionar el problema. Sin embargo, ser líder significa ponerse al frente rápidamente para llevar calma y dar respuesta a las inquietudes de los subordinados. En tiempos críticos, la comunicación frente a frente con los seguidores es lo principal; ellos necesitan saber que sus líderes se preocupan y que entienden por lo que están pasando.

3) Comunicarse con la verdad. Luego de reunir información de tantas fuentes como se pueda y de esforzarse para establecer los hechos, llega el momento de revelar la verdad tan pronto como sea posible. Controlar los rumores es fundamental. 
4) Manifestar una visión del futuro. Si bien la prioridad es enfrentar las necesidades físicas y emocionales de los miembros, es preciso pensar en el accionar lo más rápido que se pueda. El grupo, la organización o la comunidad tienen que continuar avanzando y muchas personas quieren ser parte de la reconstrucción, ya que ello les ofrece un motivo para luchar. Los momentos de crisis dan una buena oportunidad para comunicar una visión del futuro que llegue a las emociones.

\section{Capítulo IX. El equipo y la diversidad}

\section{IX.1. El equipo}

La mejor manera de hacer frente a los desafíos, de incrementar la calidad, de brindar un servicio más eficaz y de satisfacer al entramado social, es mediante el esfuerzo alineado, coordinado y dedicado de todos los miembros. No obstante, los equipos no son siempre lo más adecuado, ya que su utilización o no está ligada a la situación que se presenta. Depende en definitiva de la naturaleza de la función a realizar; podría ser que un solo individuo la desempeñe mejor, como sería el caso de las obras escritas. Pero en las tareas que sea conveniente tener un equipo eficaz, el rol del líder es crucial y consiste en construir la identidad del equipo, propiciar la participación activa de todos los miembros, actuar como entrenador y facilitador, e invertir tiempo y recursos para que el equipo crezca. Es conveniente agregar aquí que un rol está formado por la sumatoria de comportamientos que se esperan del individuo que ocupa un puesto dado. Por lo cual, para ser líderes eficientes de un equipo, las personas deben estar predispuestas a cambiar, a abandonar tanto su zona de comodidad como muchos de los supuestos que han guiado su comportamiento antes. Entonces, se puede decir que son tres los principios que sientan las bases para el liderazgo de equipo: reconocer la importancia del propósito y los valores compartidos, admitir los errores propios y apoyar y guiar a los miembros del equipo.

En la definición de Daft, un equipo es "una unidad de dos o más personas que interactúan y coordinan su trabajo con el propósito de alcanzar una meta o un objetivo compartidos" (Daft, 2006: 393). Un equipo es un grupo de personas, aunque equipo y grupo no son lo mismo. Por ejemplo, un profesor o un entrenador, podría reunir a un grupo de personas y, sin embargo, no formar un equipo. En la esfera de los deportes, es frecuente observar casos de equipos que ganaron campeonatos jugando contra un grupo de jugadores que eran mejores individualmente pero que no formaban un equipo mejor. Un verdadero equipo se crea cuando los individuos "subliman sus necesidades y deseos personales y sintetizan sus conocimientos, habilidades y esfuerzos para alcanzar una meta común" (Daft, 2006: 393). El concepto de equipo incluye también tener una 
responsabilidad colectiva. Es interesante ver la manera en la que se ilustra el espíritu de equipo en las denominadas lecciones de los gansos $^{8}$ ofrecidas a continuación.

\section{IX.1.1. Lecciones de los gansos}

Cuando los gansos realizan un desplazamiento, especialmente al recorrer grandes distancias, desarrollan un vuelo adoptando una formación en " $v$ ". Esto se debe a que cuando un ganso bate sus alas, crea un efecto aerodinámico que favorece la elevación de las aves que vienen por detrás, logrando de este modo que la bandada incremente un 71 por ciento la velocidad de su alcance comparada con la distancia de vuelo que conseguiría cada ave mediante un vuelo individual. Si un ganso se aparta de la formación, instantáneamente siente la resistencia de volar sólo, por lo cual, trata de regresar de inmediato a la posición previa para aprovechar la fuerza de elevación del ganso que vuela delante de él. Traducido a las personas, quienes siguen una dirección común y trabajan en equipo pueden llegar a su destino antes y con más facilidad porque se mueven con el impulso que se dan entre sí. Por ello es conveniente mantener la formación con aquellos que se dirigen hacia un mismo lugar aceptando y brindando ayuda a otros.

Cuando el ave líder de la formación se cansa, deja su lugar y ocupa la posición final de la misma, entonces, en forma rotativa, otro ganso vuela hacia delante para tomar la punta. Esto significa que es bueno compartir el liderazgo y turnarse para hacer las tareas difíciles.

Los gansos que van atrás de la formación graznan para animar a los que van al frente y para que éstos mantengan su velocidad. Es decir, el estímulo (ser fiel a los valores morales o centrales propios y estimular los valores morales o centrales de otros) en los grupos es muy importante, ya que no solo aumenta la creencia sino que también la hace más fuerte.

Por último, cuando un ave se enferma, es herida o derribada, dos gansos salen de la formación y lo siguen para ayudarlo y protegerlo. Se quedan junto a él hasta que muere o es capaz de volver a volar, momento en el cual, se incorporan a otra formación o alcanzan la que estaban. Es fundamental que los miembros se apoyen siempre, principalmente durante los tiempos más difíciles.

\section{IX.2. Cómo lideran las mujeres}

De acuerdo con Daft (Daft, 2006: 446-458) un aspecto que tiene un interés especial para las estructuras es la manera en la que el estilo de liderazgo de las mujeres difiere del de los hombres. Por ejemplo, en Estados Unidos, las características del liderazgo vinculadas tradicionalmente a los hombres blancos nacidos en el país están compuestas por la agresividad o la seguridad en sí

\footnotetext{
${ }^{8}$ Autor original desconocido. También en Daft op. cit., P.394.
} 
mismos, el análisis racional y una actitud de "yo" mando. Estos líderes tienen tendencia a ser competitivos, individualistas y prefieren las jerarquías verticales. Así, suelen apoyarse en la autoridad formal y en el puesto cuando tratan con los subordinados.

Las mujeres también pueden demostrar estas características, sin embargo, suelen estar más inclinadas hacia la creación de relaciones, la inclusión, la participación y la protección de los demás. Las líderes generalmente pueden estar más predispuestas a compartir el poder y la información, a estimular el desarrollo de los seguidores y a reforzar el sentimiento de valor personal de otros. Se observa que las mujeres tienden a tratar a las personas como les gusta que las traten.

Hay evidencia de que los hombres podrían sufrir una merma de su influencia en sus subordinados si los actores principales son las mujeres debido a que el enfoque de ellas se ajusta más a los requerimientos del entorno, fundamentalmente si es multicultural. Con respecto a la esfera académica, se ha notado una reversión de géneros y ahora ellas ocupan casi todos los roles del liderazgo, desde el jardín hasta la universidad. Además, las mujeres están consiguiendo más títulos de licenciatura y de maestría que los hombres. Esto puede ser explicado como consecuencia de que las mujeres, en general, son más capaces para cumplir con las necesidades de la sociedad actual que exige entre otras cuestiones prestar más atención, aceptar las reglas, hablar más adecuadamente y manejar las relaciones interpersonales.

Algunos autores sostienen que el enfoque de liderazgo femenino es un liderazgo interactivo. La líder normalmente se inclina por la colaboración y el consenso, y la influencia parte más de las relaciones, y no tanto del poder del puesto y la autoridad. Varios psicólogos sugieren que las mujeres pueden orientarse más hacia las relaciones que los hombres porque tienen diferentes necesidades psicológicas originadas de sus primeras experiencias. Estas diferencias han sido utilizadas en ocasiones para instalar que las mujeres no pueden liderar eficazmente porque no ejercen el poder. No obstante, de la misma forma que los hombres relacionan el liderazgo eficaz con un proceso verticalista de control y de mando, el liderazgo interactivo de las mujeres es el más adecuado en la diversidad y en las organizaciones que aprenden.

Un aspecto a destacar es que los valores vinculados al liderazgo interactivo como la inclusión, la creación de relaciones y el cuidado de los demás que frecuentemente son considerados femeninos, no son específicos de un género, y cada vez resultan más gravitantes tanto para las líderes como para los líderes. Todos pueden aprender a adquirir un estilo más incluyente si se interesa en el lenguaje no verbal y desarrolla habilidades como la de escuchar atentamente, la empatía, la cooperación y la colaboración. 
En este sentido, Koontz y Weihrich (Koontz - Weihrich, 1998: 539) describen la concepción del liderazgo de las mujeres como un medio para transformar el interés de los seguidores por ellos mismos en interés por la empresa utilizando sus habilidades para las relaciones interpersonales y de sus rasgos individuales para motivar a los subordinados. Este estilo "interactivo" incluye compartir el poder y la información, inducir de la participación y la valoración de cada persona.

Los resultados de una encuesta de liderazgo ${ }^{9}$ mostraron que las mujeres obtienen mayor calificación que los hombres en cuatro características que son dadas a continuación: 1) Influencia idealizada: los subordinados se identifican con la líder y desean emularla, confían en ella y la respetan, consideran que consiguen estabilizar normas elevadas y que tienen poder por sus dotes y no por el puesto que ocupan. 2) Motivación inspiradora: significa que las líderes aumentan el deseo de los seguidores, simbólica y emocionalmente, por efectuar un gran trabajo y por colaborar para lograr el propósito de la organización. 3) Consideración individual: ofrece un trato particular a cada seguidor, aunque todos reciben un trato equitativo; es decir, comprende las necesidades individuales y actúa en consecuencia. 4) Estimulación intelectual significa cuestionar los métodos tradicionales y desafiar a la gente a que razone y busque otra manera. Además, los subalternos piensan que las líderes son más eficaces, que es más grato trabajar con ellas y que son capaces de sacar lo mejor de cada persona.

\section{IX.2.1. Raíces de las diferencias emocionales entre hombres y mujeres}

Tomando como punto de partida el análisis efectuado por Goleman (Goleman, 2000: 160-164) y aplicado a la comprensión del liderazgo, se puede decir que las raíces de las diferencias emocionales pueden ser en parte biológicas y en parte pueden remontarse a la infancia y a los mundos emocionales separados en los que viven niños y niñas mientras crecen. Una propuesta surgida sobre investigaciones que estudiaron las diferencias en las emociones entre uno y otro sexo, explican que debido a que las niñas desarrollan la facilidad con respecto al lenguaje más rápidamente que los niños son más expertas en expresar sus sentimientos y más hábiles para usar las palabras que sustituyen reacciones emocionales tales como peleas físicas.

Según las investigaciones, a los trece años aparece una gran diferencia entre ambos sexos: las niñas se vuelven mejores que los niños en ingeniosas tácticas agresivas como el ostracismo, el chisme malévolo, y las venganzas indirectas. En contraste, los niños siguen siendo discutidores cuando están enojados, y pasan por alto estas estrategias más ocultas. Debe ser aclarado que esta es solamente una de las tantas maneras en que los niños (y luego los hombres) son menos expertos en la vida emocional.

\footnotetext{
${ }^{9}$ Basado en Bass, Bernard y Avolio, Bruce (1994): Shatter the glass ceiling: women may make better managers: Human resource management 33, Número 4,. PP. 549-560 (citado por Daft, op. cit., P.447).
} 
Es interesante observar que cuando las niñas juegan juntas lo hacen generalmente en grupos pequeños e íntimos, enfatizando en reducir lo más posible la hostilidad y maximizar la cooperación. En cambio, los juegos de niños se desarrollan en grupos mayores y enfatizan la competencia. Una notable distinción aparece cuando los juegos en grupo se interrumpen si alguien se lastima: si un niño se siente mal, se espera de él que salga y pare de llorar para que el juego siga. Si una niña se lastima el juego se interrumpe y todas tratan de ayudar a la que llora. Esta diferencia considerada clave representa que los niños se sienten orgullosos de su autonomía e independencia, mientras que las niñas se sienten parte de una red de relaciones. Así, los niños sienten una amenaza por algo que desafíe su independencia, pero las niñas sienten lo mismo si se genera una ruptura en las relaciones. Estos puntos de vista distintos significan que hombres y mujeres esperan algo distinto en una conversación, los primeros se conforman con hablar de “cosas", mientras que las segundas requieren una conexión emocional.

Los contrastes en el aprendizaje de las emociones benefician habilidades diferentes: las niñas se vuelven "expertas en interpretar las señales emocionales verbales y no verbales y en expresar y comunicar sus sentimientos", y los niños "en minimizar las emociones que tienen que ver con la vulnerabilidad, la culpabilidad, el temor y el daño" ${ }^{\prime 10}$. Prueba de estas posturas es que, por ejemplo, en promedio las mujeres son más empáticas, en principio por la capacidad de interpretar los sentimientos no expresados de un individuo en base de expresiones faciales, tonos de voz y otros indicios del lenguaje no verbal. De la misma manera, frecuentemente es más fácil interpretar los sentimientos mirando la cara de una mujer que la de un hombre ya desarrollado, porque a medida que transcurre la edad de la escuela primaria los varones se van poniendo menos expresivos. En definitiva, normalmente las mujeres expresan todas las emociones más intensa e inconsistentemente que los hombres, siendo posible concluir que las mujeres son más emocionales. Por supuesto lo expresado es una generalización, y no es real en todos los casos.

\section{IX.3. El entorno sociocultural}

Las culturas nacionales son intangibles, dominantes y difíciles de asir. Sin embargo, es imperioso para lograr una mejor comprensión del funcionamiento de un equipo, aprender sobre las culturas locales y lidiar con ellas de manera eficaz. Un planteamiento para interpretar las culturas consiste en analizar las diferencias que existen entre los sistemas de valores sociales.

\section{IX.3.1. Sistema de valores sociales}

\footnotetext{
${ }^{10}$ Brody, Leslie y Hall, Judith. Gender and emotion, en Lewis, Michael y Haviland, Jeannette eds. (1993), Handbook of emotions: Nueva York, Gilford Press, P.454 (citado por Goleman, Daniel (2000): La inteligencia emocional, Buenos Aires: Vergara, P.162).
} 
En el plano del análisis teórico que se intenta dar en este lugar, no es posible internarse en un estudio pormenorizado de las diferentes relaciones entre los distintos sistemas de valores. Aunque con todo, pueden hacerse algunas observaciones generales respecto a los mismos. Entonces, se puede comenzar hablando sobre la socialización donde, como expresan Berger y Luckmann, la animalidad del hombre se transforma, pero no queda abolida. Así, por ejemplo, el estómago del hombre sigue quejándose aun cuando éste prosigue su tarea de construir el mundo. Resulta posible por lo tanto hablar de una dialéctica entre la naturaleza y la sociedad. "Externamente consiste en una dialéctica entre el animal individual y el mundo social; internamente, es una dialéctica entre el substrato biológico del individuo y su identidad producida socialmente" (Berger y Luckmann, 1994: 224).

En el aspecto externo el organismo coloca límites a lo que resulta socialmente posible (por ejemplo que el hombre tenga hijos). Esto significa que los factores biológicos limitan las posibilidades sociales que se abren a todo individuo; pero el mundo social, que es pre-existente al individuo, al mismo tiempo impone limitaciones a lo que resulta biológicamente posible al organismo (por ejemplo, la limitación que establece la sociedad a las posibilidades biológicas del organismo lo constituye la longevidad, ya que la esperanza de vida varía con la ubicación social. La sociedad además puede mutilar y matar).

La sociedad también interviene en el funcionamiento del organismo, sobre todo con respecto a la sexualidad y a la nutrición. Ambas se canalizan en direcciones específicas, socialmente más que biológicamente, y esta canalización no sólo impone límites a esas actividades, sino que afecta directamente las funciones del organismo (por ejemplo puede establecer horarios para dichas actividades). Por ello, puede decirse que la realidad social determina no solo la actividad y la conciencia, sino también, el funcionamiento del organismo. La sociedad también establece la manera en que se usa el organismo en actividad; la expresividad, el porte y los gestos que se estructuran socialmente. En resumen, la dialéctica se manifiesta en la limitación mutua del organismo y la sociedad, es decir, que la cuestión es que la sociedad pone limitaciones al organismo, así como éste pone limitaciones a la sociedad.

En un ámbito más acotado, Daft explica que la mentalidad y los valores culturales influyen notablemente en las relaciones entre las personas y la organización y varían mucho de una cultura a otra, especialmente en temas como el individualismo en comparación con el colectivismo.

Autores como Bay (Bay, 1961) creen que el hombre no persigue la realización de su interés teniendo como única guía las posibilidades de sanción (recompensas y castigos); piensan que es un ser social que se vincula con los demás mediante la identificación y la internalización. Sin embargo, el hombre es también un individuo, y su conducta social tiene que ser estudiada en 
términos de sus funciones con respecto a la integración de su propia personalidad y con respecto a la integración del sistema social. El hombre solamente desempeñará su rol en el mantenimiento del sistema social si es capaz de mantener su propio equilibrio como organismo y como personalidad. La ciencia social ofrece entonces de modo incontestable que la naturaleza y los fines humanos están configurados por la biología del individuo y por los medios sociales y culturales, pasados y presentes.

Por lo tanto, debido a que la sociedad y la cultura están reflejadas e integradas en toda personalidad, las metas individuales están necesariamente condicionadas, pero no totalmente determinadas, por la estructura de los incentivos de la sociedad que constituyen su entorno. Una sociedad individualista puede incitar a los sujetos a buscar satisfacción en la persecución de fines privados, a la vez que una sociedad más colectivista puede condicionar a la mayoría a hacer propios los fines públicos en un grado superior. Así, Bay continúa diciendo:

En un sentido general, el egoísmo es necesario y deseable, en la medida en que la supervivencia física y el bienestar social de cada individuo normalmente ha de ser asunto suyo más continuamente que de nadie. No veo razón para deplorar este hecho. En un sentido estricto, el egoísmo parece innecesario e indeseable si se define como insensibilidad en relación con los intereses de los demás. El problema social implicado no es hacer más altruistas a las gentes, sino estimular un sentimiento de identificación con otros y un deseo perceptivo de evitar perjudicar innecesariamente a nuestros semejantes. Como se ve, se trata de un problema de organización social, de crianza de niños y de educación. Es, sobre todo, quizá un problema de creación de las condiciones óptimas para la seguridad individual básica. (Bay, 1961: 82 y 83).

Otra dimensión destacada por Daft, como ya fue vista, es la masculinidad y la feminidad, donde la primera refleja una preferencia por el logro, el heroísmo, la seguridad en sí mismo, la centralización del trabajo y el éxito material. La segunda, en cambio, refleja los valores de las relaciones, la cooperación, la toma de decisiones en grupo y la calidad de vida.

Evidentemente, las diferencias de valores sociales afectan el liderazgo, las relaciones de trabajo y el funcionamiento de la organización. Por ello se nombrarán algunas de las restantes e importantes características culturales como son la religión (que incluye los objetos sagrados, las actitudes filosóficas ante la vida, los tabúes y los rituales), las actitudes (respecto al tiempo, el espacio, la autoridad y el éxito. Por ejemplo, las personas que provienen de culturas urbanas suelen seguir horarios rígidos, mientras que las de culturas rurales se preocupan menos por los horarios), la organización social (cuyos elementos incluyen el parentesco y la familia, los sistemas de estatus y las oportunidades para una movilidad social) y la educación. En definitiva, es básico que quienes lideran reconozcan que la cultura afecta tanto la situación como el estilo de liderazgo.

\section{IX.4. Las diferencias}


Muchos miembros de minorías, son de la idea de que, independientemente de cuántos estudios tengan, cuántas horas trabajen, cómo se vistan, cuánto esfuerzo o entusiasmo inviertan, los demás nunca los considerarán de la misma manera que al resto.

El racismo y el sexismo en la sociedad muchas veces suelen ser expresados de modos muy sutiles a través de: la indiferencia que manifiesta un empleado por una tarea asignada; la poca urgencia por concluir una tarea importante; hacer caso omiso de los comentarios y las sugerencias planteadas; en algunos casos incluso combinados con la falta de respeto. Probablemente en la actualidad, el prejuicio pasivo tal vez sea un problema mayor que la franca discriminación.

Muchas mujeres y miembros de minorías también consideran que no son tratados con la misma justicia que sus compañeros del sexo masculino. Por ejemplo, en el caso de un jefe generalmente se ve como algo positivo que tenga familia; pero, en el caso de una mujer que quiere llegar a un puesto alto puede ser percibido como un obstáculo, debido a que implica que la dedicación de una mujer a sus hijos limita su dedicación a la compañía o a su capacidad para lidiar con las dificultades del liderazgo. Inclusive, las líderes frecuentemente renuncian al tiempo que tienen asignado para ellas, ya sea en amistades o para sus pasatiempos, porque siguen encargándose de cuidar a sus hijos y a su casa además de sus responsabilidades laborales. Otro ejemplo es que las mujeres y los miembros de minorías suelen ganar menos dinero que sus homólogos del sexo masculino.

Por tal motivo, para cambiar el status quo presente en las empresas, se necesita un liderazgo consciente y que tome la iniciativa de modo que las minorías tengan igualdad de oportunidades para alcanzar el éxito. Aunque para lograrlo, los líderes tienen que resolver una serie de barreras personales y organizacionales que les impiden llegar a un grado importante de concientización, aceptación y reconocimiento de la diversidad. Una barrera muy importante a superar es el estereotipo y el prejuicio. El prejuicio entendido como la tendencia a considerar que las personas que son distintas de lo estimado corriente, en términos de sexo, raza, antecedentes étnicos o capacidad física son deficientes. Un prejuicio es suponer, sin evidencia, que las minorías son inferiores, menos competentes para sus trabajos y menos acordes para desarrollarse como líderes. Indudablemente, los estereotipos siguen prevaleciendo en la sociedad.

En resumen, es posible decir que los líderes deben esforzarse mucho para unir a los seguidores en torno a un propósito común, al mismo tiempo que deben permitir que las diferencias individuales afloren. Sin un liderazgo fuerte, la creciente diversidad cultural puede conducir a un peor desempeño, sea en el lugar que sea, porque pueden formarse grupos que compitan mucho entre sí o incluso ser antagónicos. Así, el liderazgo se transforma en el elemento más importante para cambiar la cultura y valorar la diversidad. La meta final será entonces crear 
organizaciones que sean comunidades integradas, donde todos los individuos se sientan estimulados, respetados y comprometidos con propósitos y metas comunes.

\section{Capítulo X. Crear una visión y desarrollar la estrategia para conseguirla X.1. El liderazgo estratégico}

Una de las funciones sustanciales de un líder es la de proporcionar una visión convincente de un futuro mejor, que esté bien articulada y que sea correctamente comunicada, y desarrollar las estrategias adecuadas para alcanzarla, generando en la gente la motivación y la energía necesarias para acceder a dicho futuro. Los buenos líderes ven siempre hacia adelante, estableciendo un rumbo y haciendo que todos se muevan en la misma dirección. Por lo cual, es importante destacar la conveniencia de ejercer el denominado liderazgo estratégico, al que Daft define como la capacidad para anticipar y prever lo más posible el futuro, mantener la flexibilidad, pensar estratégicamente y trabajar con los demás a fin de iniciar cambios que se reflejarán en una ventaja competitiva para la sociedad toda y, en consecuencia, en un beneficio para cada individuo.

Las dificultades del entorno y la incertidumbre del futuro pueden ser agobiantes, por lo que algunos líderes sólo se concentran en las cuestiones de la organización interna y no en las actividades estratégicas. En general es más fácil luchar con las operaciones rutinarias debido a que les permiten tener resultados rápidos y sentir que tienen el control. Sin embargo, pensar en cómo satisfacer las necesidades futuras es fundamental; la globalización, la nueva tecnología, los cambios demográficos y de estilos de vida modifican como operan las compañías. El mundo cambia velozmente y los líderes tienen que determinar cómo adecuarán sus organizaciones en ese mundo.

Se puede decir que el liderazgo estratégico, ilustrado en la siguiente figura, tiene la función de establecer el vínculo entre el entorno exterior y las elecciones relativas a la visión, la misión, la estrategia y la aplicación de cada una de ellas. En la figura se observa que cada uno de los niveles de la jerarquía es el apoyo del nivel superior. "La visión refleja el entorno y opera acorde con la misión de la compañía, sus valores medulares, su propósito y su razón de ser". Luego, "la estrategia imprime el curso que se seguirá para traducir la visión a la acción y es la base para desarrollar mecanismos específicos que ayudarán a la organización a alcanzar sus metas. Las estrategias son intenciones, y la aplicación de éstas ocurre por medio de la arquitectura básica de la organización (estructura, incentivos) que permite que las cosas funcionen." (Daft, 2006: 524). En lo que sigue del capítulo, se analizarán cada una de las partes de este marco de referencia.

\section{Figura del liderazgo estratégico}


Visión

Misión

Estrategia

Arquitectura para la alineación y aplicación

\section{X.1.1. La visión}

La visión no es sólo un sueño, es un futuro ideal compartido, atractivo y creíble, que ayuda a la organización a lograr los cambios pero sabiendo que no son necesariamente fáciles de alcanzar. A veces, las visiones pueden ser breves, claras, inclusive pueden parecerse a un eslogan, por lo que resultan fáciles de comunicar y todos los miembros de la organización las pueden entender. Por ejemplo, uno de los más memorables eslóganes de la bebida Coca Cola: a) “Me gustaría comprarle al mundo una Coca Cola"11.

La visión puede ser representada como una estrella que sirve de guía y atrae a todos por un mismo camino hacia el ambicioso futuro. Está fundada en la realidad del presente, pero se refiere a un futuro sustancialmente diferente del status quo. Por supuesto, el encargado de conducir al grupo o a la organización por esta senda es el líder, quién tendrá como tarea la articulación de su visión optimista para el futuro a la realidad presente del sistema, de modo que inspire y desafíe a las personas a efectuar su mejor esfuerzo. Normalmente, las personas que tienen una imagen mental clara de su visión tienen más posibilidades de triunfar. No obstante, aunque la responsabilidad de ilustrar una imagen clara del futuro es de los líderes, no siempre le corresponde sólo a ellos. Para marcar una buena diferencia, la visión puede ser compartida y, con frecuencia, ser creada con la participación de otros. Por lo tanto, parte del trabajo de los líderes es ayudar a los demás a desarrollar su parte de la visión común para que se convierta en el hilo conductor que una a las personas, involucrándolas de forma personal y emocional con la organización. Entonces, con el propósito de desarrollar una visión compartida, los líderes expresan sus visiones personales con otros y les animan a manifestar sus sueños para el futuro. Esto requiere de apertura, de habilidades para escuchar y de valor para conectarse con otros en un plano emocional. La responsabilidad del líder es permanecer en contacto con las esperanzas y los sueños que mueven a los subordinados y

\footnotetext{
${ }^{11}$ En Página Web de Coca Cola Argentina: www.cocacoladeargentina.com.ar/historias/history-de-jingles-a-cancionespopulares-Coca-Cola-revoluciono-la-publicidad
} 
encontrar el terreno común que ligará sus sueños personales con la visión compartida de la organización.

De este modo, se observa que una visión eficaz opera en varios sentidos importantes: 1) establece una relación entre el presente y el futuro. Se dice que los buenos líderes poseen una "visión bifocal" porque por un lado atienden las necesidades y cumplen las obligaciones de hoy, y por otro intentan alcanzar los sueños de mañana. 2) Inyecta la energía y la motivación que necesitan los subordinados para dirigirse hacia el futuro a través de su mejor esfuerzo. Las personas desean sentir entusiasmo por su accionar, por lo que llegan a invertir voluntariamente su tiempo y su energía en causas en las que creen; por ejemplo en una campaña política, en alimentar a los hambrientos y desamparados o en distintas causas ambientales. En cambio, es común que estas mismas personas muchas veces dejen su entusiasmo y energía porque en su tarea no encuentran motivo alguno de inspiración. Los seguidores no estarán dispuestos a comprometerse emocionalmente sólo para aumentar la riqueza del líder, pero si lo estarán si la tarea vale la pena. 3) Otorga sentido y dignidad al trabajo de la gente. Incluso aquellos individuos que desempeñan tareas rutinarias se pueden enorgullecer si encuentran un propósito mayor en lo que hacen; tal es el caso de una empleada de limpieza que le entusiasma su trabajo en el hospital porque los líderes le ayudan a verlo como algo más que tan sólo limpiar los suelos. Ella se siente un miembro importante de un equipo que se dedica a ayudar a que los enfermos recuperen la salud, ya que sin una buena limpieza, el hospital no podría atender bien a sus pacientes. 4) Aclara y liga los valores y los ideales centrales de la organización y, con ello, establece una norma de excelencia e integridad para los empleados. Una buena visión saca lo mejor de las personas porque destaca valores importantes, toca su corazón y les permite formar parte de algo mayor que ellas.

\section{X.1.2. La misión}

La misión de una empresa no es lo mismo que su visión. La misión es el objeto central general de la organización y su razón de ser; define los principales valores de la compañía y sienta las bases para crear la visión. Entonces, mientras que la visión es un ambicioso deseo futuro que crece y cambia constantemente, la misión persiste a pesar de los distintos cambios del entorno, como puede ser el caso de la tecnología o de las condiciones económicas. La misión define por lo tanto el carácter duradero de la organización, es como el ADN espiritual que actúa como un pegamento que mantiene unida a la organización en tiempos de cambios y que guía las elecciones y las decisiones estratégicas para el futuro.

En general, es posible decir que la misión se compone de dos elementos básicos: los valores centrales y el objeto central. Por ello, muchas compañías exitosas tienen misiones que proclaman alguna clase de propósito noble. Por ejemplo, el de Motorola: "Moto existe para 
inventar, fabricar y ofrecer los mejores smartphones del mundo, mejorando la vida de miles de personas" $" 12$.

\section{X.1.3. Estrategias}

Las misiones y las visiones rectoras son muy importantes, sin embargo, para que tengan éxito, las organizaciones necesitan pensar en cómo llevar la visión, los valores y el objeto a la práctica a través de una estrategia. Entonces, a la estrategia, se la puede definir como el plan de acción que detalla la asignación de los recursos y otras actividades para interactuar con el entorno con el propósito de lograr las metas. El líder es el encargado de tomar las difíciles decisiones para formular e implementar estrategias específicas que conseguirán que la estructura se adapte a su entorno y avance hacia el futuro.

Es preciso comprender que, generalmente, las estrategias van cambiando con el tiempo para adaptarse a las nuevas condiciones del entorno. Por lo tanto, es común que los líderes para mejorar las posibilidades de éxito de las estrategias, las formulen concentrándose principalmente en dos puntos:1) La competencia central: es lo que una organización hace particularmente muy bien. Es decir, son las fortalezas singulares en torno a las cuales se construyen las estrategias. 2) La sinergia: es la interacción de los elementos de la estructura para producir un efecto conjunto mayor que la suma de las partes.

\section{X.1.4. Arquitectura para la alineación y aplicación.}

La implementación de la estrategia es la parte más importante y la más difícil de realizar porque requiere utilizar, y si es necesario adaptar, varios instrumentos o partes de la organización, además de determinadas técnicas, que sirven para direccionar los recursos al cumplimiento de las metas. Por ejemplo, la estrategia se puede implementar a través de elementos tales como el diseño de la estructura, los recursos económicos, las reglas, las políticas y los procedimientos. Esto representa la arquitectura básica de la organización. Además, la correcta implementación del plan estratégico requiere el apoyo de los subordinados, y los líderes son los encargados de generar un entorno que determina si las personas entienden y se comprometen con la dirección fijada. En resumen, la estrategia es la trascendente actividad de traducir la visión y la misión a la acción, siempre teniendo presente que al interactuar con el entorno cambia a lo largo del tiempo al igual que dicha visión, y es implementada mediante la arquitectura básica de la organización.

\section{Capítulo XI. La cultura empresarial}

\section{XI.1. Introducción a la cultura empresarial}

\footnotetext{
${ }^{12}$ En Página Web de Motorola Argentina: www.motorola.com.ar/institucional/sobre-nosotros
} 
De acuerdo con Schein (Schein, 1988: 20) se puede decir que entre las funciones más decisivas del liderazgo, bien pueden figurar la creación, la conducción e incluso hasta la destrucción de la cultura empresarial si fuera necesario. Por lo tanto, al examinar de cerca la cultura y el liderazgo, se observa que son dos caras de la misma moneda, que no pueden ser entendidas por separado. De hecho, existe la posibilidad de que la única función importante que tienen los líderes sea la creación y conducción de la cultura, y que el único talento de los mismos sea su habilidad para trabajar con la cultura. Entonces, si el concepto de liderazgo puede ser analizado como algo distinto de la dirección y de la administración, habrá que reconocer la importancia de dicha función de conducción de la cultura.

El concepto de la cultura empresarial esclarece la difícil tarea de entender y justificar buena parte de lo que se observa y se experimenta en la vida dentro de la empresa, ya que demasiadas cosas parecen burocráticas, políticas o simplemente irracionales. Permite comprender con más profundidad las variables culturales de las empresas no sólo para descifrar lo que pasa en ellas, sino para individualizar las cuestiones prioritarias para los líderes y el liderazgo.

Sin embargo, aunque efectuar un "análisis cultural” parezca lo más normal cuando se piensa en culturas étnicas o nacionales, no se ha atendido correctamente a la posibilidad de que grupos y empresas integrados en una sociedad desarrollen igualmente culturas que modifiquen en grado mayor a la forma en que sus miembros piensan, sienten y actúan. Investigar adecuadamente tales culturas empresariales es fundamental para entender bien por qué las empresas hacen lo que hacen o por qué los líderes tienen que hacer frente a ciertas dificultades. Así, el concepto de cultura empresarial es apropiado para lograr la comprensión de los hechos misteriosos y aparentemente irracionales que se dan en los sistemas humanos. Pero un concepto tal no puede ser de utilidad si se abusa de él o si se malinterpreta, por lo que el objetivo principal será detallar el significado de cultura empresarial, mostrar cómo puede ser usado mejor, y relacionarlo con el liderazgo.

A continuación, se dará una definición clara y práctica del concepto de la cultura empresarial.

\section{XI.2. Definición de cultura empresarial}

Por sí sola, la palabra cultura está dotada de muchos significados y connotaciones y, si además se le suma la combinación con el término "empresa", consigue generar una gran confusión semántica y conceptual. Por lo tanto, para aclarar la controversia, se dará una definición clara del sentido que la cultura empresarial tendrá en este lugar. 
El concepto cultura tendría que utilizarse solamente para el nivel más profundo de presunciones básicas y creencias que comparten los miembros de una empresa, las cuales trabajan inconscientemente y definen la visión que la empresa tiene de sí misma y de su entorno. "Estas presunciones y creencias son respuestas que ha aprendido el grupo ante sus problemas de subsistencia en su medio externo, y ante sus problemas de integración interna. Se dan por supuestas porque repetida y adecuadamente llegan a resolver estos problemas" (Schein, 1998: 24). Este nivel más profundo de presunciones es diferente de los "artefactos" y los "valores", ya que éstos últimos no son la esencia misma de la cultura sino manifestaciones de niveles superficiales de la cultura.

La cultura debería comprenderse como una propiedad de una unidad social independiente y definida. Lo que significa que siempre y cuando pueda demostrarse que un grupo determinado de individuos ha compartido una cantidad significativa de experiencias importantes durante la resolución de problemas externos e internos, es posible asumir que estas experiencias comunes, con el tiempo, han creado entre estas personas una visión compartida del mundo. Es condición necesaria haber atravesado un número suficiente de experiencias comunes para adquirir esta visión compartida y que la misma haya ejercido su influencia un tiempo suficiente para conseguir que sea dada por supuesta y desgajada de la conciencia. En tal sentido, la cultura es el resultado de lo aprendido de la experiencia grupal y, sólo localizable, donde exista un grupo definible y poseedor de una historia.

El hecho de que una empresa tenga o no una cultura propia, además de distintas subculturas, convierte al tema en una cuestión empírica que se resuelve a través de la localización de los grupos estables y de la determinación de sus experiencias compartidas, así como mediante la identificación de las experiencias compartidas de los miembros de toda la empresa. Puede descubrirse que hay varias culturas operando dentro de la unidad social mayor (que es llamada la cultura de la compañía), como es el caso de una cultura directiva, culturas de grupo basadas en la proximidad geográfica, etcétera.

La idea es estudiar unidades sociales que evolucionan dentro de una cultura mayor, lo que se logra a través de las teorías del aprendizaje y del desarrollo de un concepto dinámico de cultura empresarial. La cultura es aprendida, evoluciona con nuevas experiencias, y puede ser cambiada mediante un proceso de aprendizaje; por ello, quien quiera controlar o cambiar la cultura, debe interesarse en el aprendizaje de las complejas creencias y presunciones que sirven de fundamento al comportamiento social.

El término "cultura" se puede aplicar a unidades sociales de cualquier dimensión que hayan podido aprender y establecer una visión tanto propia como del entorno, es decir, a las que tienen 
sus propias presunciones básicas. En el primer nivel, están las civilizaciones y culturas pertenecientes a los mundos occidental u oriental; en el segundo nivel están los países de identidad étnica suficiente como para hablar por ejemplo de cultura argentina o de cultura uruguaya. Pero en el interior de un país existen además diversos grupos étnicos a los que se les atribuyen culturas distintas, perteneciendo estos al tercer nivel. El cuarto nivel es todavía más específico y consiste en el nivel de ocupación o profesión, ya que tales grupos pueden ser definidos como unidades estables con una historia compartida de experiencias que desarrollan su propia cultura. Por último, está el nivel de análisis que es objeto de los capítulos siguientes: el de las empresas. Dentro de las empresas existen subunidades que pueden ser reconocidas como grupos, los cuales pueden desarrollar culturas de grupo.

En definitiva, en cualquiera de estos niveles estructurales se llamará cultura a un modelo de presunciones básicas (inventadas, descubiertas o desarrolladas por un grupo particular al ir resolviendo problemas de adaptación externa e integración interna), que hayan ejercido la suficiente influencia como para ser aprendidas, consideradas válidas y luego enseñadas a los nuevos integrantes como la forma correcta de solucionar esos problemas. De esta forma, como consecuencia de que estas presunciones han funcionado repetidamente, están en condiciones de ser dadas por supuestas y desgajadas de la conciencia.

Como detalle, es importante mencionar que la definición no incluye modelos de conducta manifiesta, por lo que es posible que ésta esté siempre determinada tanto por la predisposición cultural (las presunciones, percepciones, pensamientos y sentimientos que son modelados) como por las contingencias que se derivan del medio externo (lo que complementaría lo explicado por Luckmann bajo el título de "sistemas de valores sociales" en el parágrafo IX.3.1.). Las regularidades de la conducta, podrían ser entonces tanto un reflejo del medio como de la cultura, y no deberían ser parte del fundamento para definir la cultura. Con otras palabras, se quiere decir que cuando se observan regularidades de conducta no se puede determinar si se está tratando o no con un artefacto cultural. Solamente cuando se hayan descubierto los estratos más profundos de lo que se está definiendo como cultura, se podrá establecer si es o no es un artefacto que refleja la cultura.

Por su parte, Daft coincide con Schein, y agrega que los líderes influyen en la cultura organizacional y configuran el entorno que establece el estado de ánimo y el desempeño de los subordinados logrando así que comulguen con la visión. Luego, define a la cultura empresarial como "el conjunto de valores, supuestos, formas de pensar y normas fundamentales que comparten los miembros de una organización y que enseñan a los miembros nuevos por ser lo correcto" (Daft, 2006: 571). Conviene aclarar que por "norma" se entienden los parámetros 
compartidos que determinan qué comportamientos son aceptables y deseables en un grupo. En su nivel esencial, la cultura está compuesta por supuestos compartidos sobre el modo de hacer las cosas en una organización; aunque, a medida que los empleados luchan con problemas (tanto internos como externos), desarrollan nuevos supuestos compartidos y normas de comportamiento y se los enseñan a los nuevos como la forma correcta de pensar, sentir y actuar ante los problemas.

\section{XI.3. Niveles de cultura}

La cultura consta de tres niveles, los cuales poseen distintos grados de evidencia. En el nivel superficial están los artefactos visibles, como por ejemplo la vestimenta, los patrones de comportamiento, los símbolos materiales, las ceremonias de la organización y la disposición de las oficinas; es decir, son todas las cosas que uno puede ver, oír y percibir al observar a los miembros de la organización. En el siguiente nivel de profundidad están las creencias y los valores expresados, que no son observables, pero que pueden ser distinguidos mediante la forma en que las personas justifican y explican lo que hacen. Las personas manejan de manera consciente estos valores. En el tercer nivel, algunos valores están tan profundamente arraigados que los miembros pueden no estar conscientes de ellos. Estos supuestos básicos son la esencia más profunda de la cultura y, en general, empiezan siendo valores expresados que con el transcurso del tiempo se arraigan más tan profundamente que no se abren para ser cambiados; esto significa que los miembros de una organización los dan por sentado y, en ocasiones, no están conscientes de los supuestos que gobiernan su comportamiento, su lenguaje, y sus patrones de interacción social. En la siguiente figura (Daft, 2006: 572) se observan los tres niveles representados a través de la imagen de un iceberg.

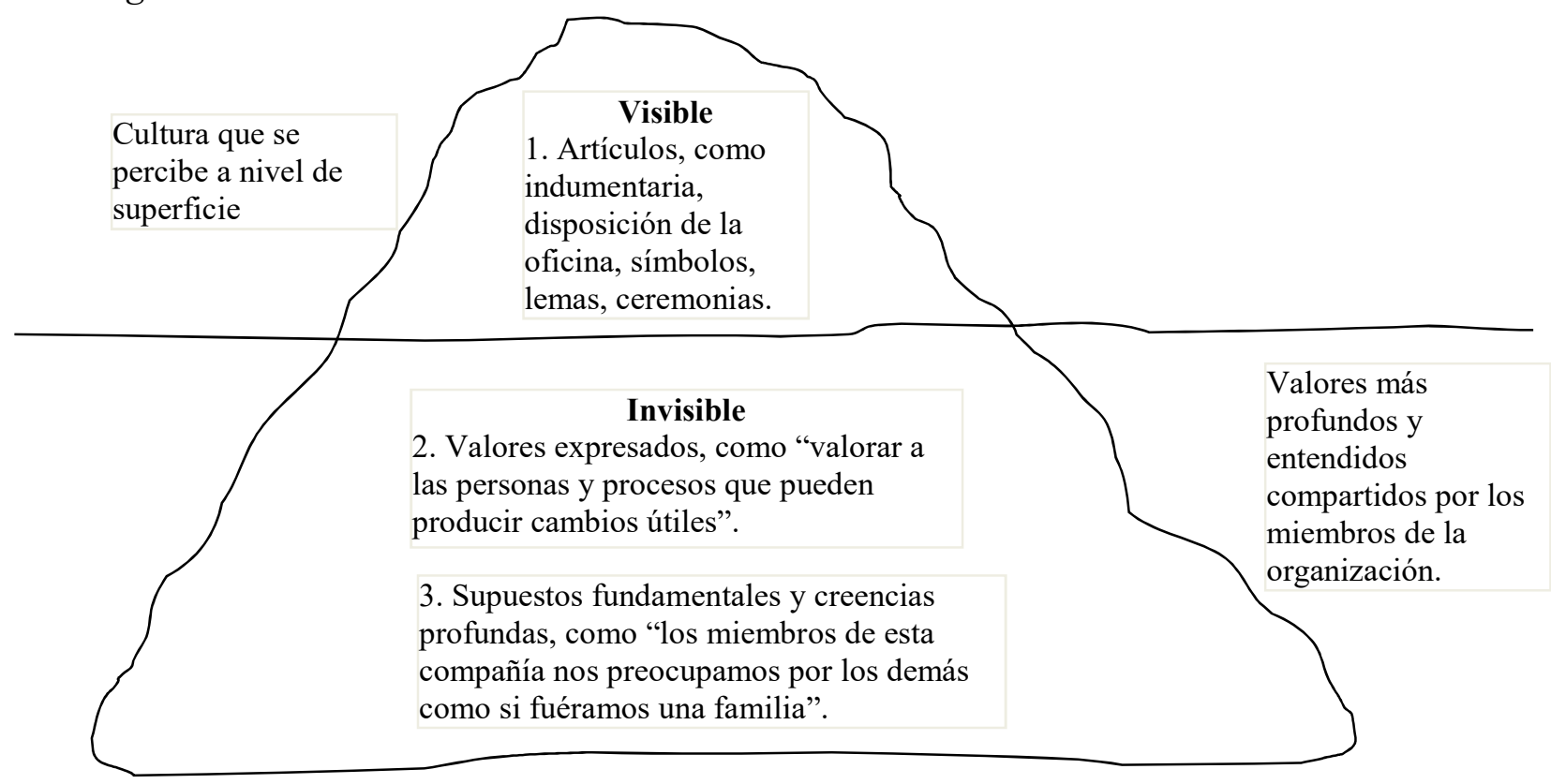


En la misma línea, Schein ofrece una distinción de los diversos "elementos" culturales que existen tratando a las presunciones básicas como la esencia, es decir, como lo que la cultura realmente es, y a los valores y conductas como manifestaciones derivadas de la esencia cultural. En este sentido dichos elementos son agrupados también en niveles de la cultura y descriptos a continuación a partir de la siguiente figura (Schein, 1998: 30).

\section{Nivel 1: Artefactos y creaciones}

- Tecnología.

- Arte.

- Esquemas de conductas visibles y audibles.

\section{Nivel 2: Valores}

- Confrontables en el entorno físico.

- Confrontables sólo por consenso social.

\section{Nivel 3: Presunciones básicas}

- Relación con el entorno.

- Naturaleza de la realidad, el tiempo y el espacio.

- Naturaleza del género humano.

- Naturaleza de la actividad humana.

- Naturaleza de las relaciones humanas.

\section{XI.3.1. Nivel 1: Artefactos y creaciones}

El nivel más visible de una cultura es el de sus producciones y creaciones que está determinado por su entorno físico y social. Aquí se destaca por ejemplo, el espacio físico, la tecnología disponible, el lenguaje escrito y hablado, las producciones artísticas y la conducta expresa de los miembros. Por supuesto, los integrantes de una cultura pueden no conocer sus productos por lo que no siempre es posible preguntarles sobre ellos, sin embargo lo que si siempre es posible es observarlos por uno mismo. Entonces, se sabe que cada aspecto de la vida de un grupo produce artefactos que son difíciles de entender, tanto en su significado, en su interrelación, como en los esquemas de fondo que puedan reflejar; no obstante, si una persona vive en el entorno cultural un tiempo suficiente, los significados se irán volviendo paulatinamente más claros, lo que permitiría deducir también que significados hay que atribuir a la conducta manifiesta.

Así, si se desea alcanzar este nivel de entendimiento, es necesario intentar el análisis de los valores centrales que se derivan de los principios que operan diariamente, y en base a los cuales los miembros de la cultura guían su conducta. 


\section{XI.3.2. Nivel 2: Valores}

El aprendizaje cultural refleja en última instancia los valores propios del individuo, es decir, su idea del "deber ser" a diferencia del "ser". Cuando un grupo se enfrenta a una nueva situación o problema, la primera solución propuesta tendrá la jerarquía de un valor solamente porque todavía no existe un principio aceptado para determinar lo que es real. Entonces, alguien en el grupo, probablemente el fundador, que tiene convicciones sobre la naturaleza de la realidad y sobre la forma de tratarla propondrá una solución en base a esas convicciones. La solución es propuesta como una creencia o principio basado en hechos, sin embargo, el grupo no puede sentir la misma convicción hasta que no sea admitida colectivamente como una solución válida al problema.

Si la solución avanza y el grupo reconoce su éxito, el valor pasa progresivamente por un proceso de transformación cognoscitiva hasta volverse creencia y finalmente presunción. En este punto, los miembros del grupo tenderán a olvidar que al principio no estaban convencidos y que por ello los valores eran objeto de discusión y confrontación. Cuando los valores son aceptados y se convierten en creencias y presunciones quedan desgajados de la conciencia, como las costumbres que terminan siendo inconscientes y automáticas.

Lógicamente, no todos los valores experimentan esta transformación principalmente porque la solución basada en un valor dado puede no dar resultado. Sólo los valores que consiguen una validez física o social, y que continúan siendo útiles para la solución de los problemas llegarán a convertirse en presunciones. Además, muchos valores continúan siendo conscientes y llegan a articularse explícitamente porque establecen la normativa o función moral que señala a los integrantes del grupo la forma de desempeñarse en situaciones clave. Los valores que se integran en la ideología o filosofía de una empresa, pueden servir como una guía que permita actuar ante la incertidumbre de eventos incontrolables o difíciles. Dichos valores predecirán parte de la conducta que puede observarse en el nivel de los artefactos; pero, si esos valores no están fundados en un previo aprendizaje cultural, es probable que sólo lleguen a ser vistos como lo que algunos autores han llamado "valores añadidos", los cuales consiguen predecir en gran medida lo que la gente va a decir en una situación dada, pero que pueden no coincidir con lo que realmente se hará en la situación en la que tales valores deberían ponerse en práctica. Así, la empresa puede decir que valora a las personas, pero sus antecedentes al respecto pueden contradecir lo que dicen.

En definitiva, se puede decir que para alcanzar el nivel profundo de comprensión de la cultura, para descifrar la estructura, para predecir acertadamente la conducta futura, tenemos que entender cabalmente la categoría de presunciones básicas.

\section{XI.3.3. Nivel 3: Presunciones subyacente básicas}


Cuando la solución a un problema sirve constantemente es aceptada como la forma correcta de hacer las cosas. Lo que al comienzo fue un supuesto sustentado simplemente por un presentimiento o un valor, llega a ser entendida como una realidad y se termina creyendo que la naturaleza actúa de esa manera.

Las presunciones básicas se convierten en algo tan aceptado, que no alcanzan a presentar grandes variaciones dentro de una unidad cultural. Esto significa que si una presunción básica se encuentra sólidamente arraigada en un grupo, sus integrantes considerarán inconcebible un comportamiento basado en alguna otra premisa. Por lo tanto, las presunciones básicas tienen la capacidad de orientar la conducta y enseñar la manera de percibir, pensar y sentir las cosas y, además, tienden a ser inconfrontables e indiscutibles.

Un aspecto importante de tales presunciones inconscientes es que pueden llegar a distorsionar los datos reales. Por ejemplo, si una persona presume sobre la experiencia pasada o sobre la educación, que otras personas se aprovecharán de él en cuanto se les presente la oportunidad, esperará que eso ocurra para interpretar posteriormente la conducta de otros de manera que coincida con lo que ha previsto. Entonces, si se da el caso en el que observa a un individuo en una actitud aparentemente ociosa ante su mesa, le parecerá que holgazanea en lugar de pensar que está ocupándose de un problema importante. En contrapartida, si presume que todas las personas están intensamente motivadas y son competentes, actuará de acuerdo con esta presunción.

\section{XI.4. La necesidad de comprender mejor la cultura}

Existen tres razones clave para Schein (Schein, 1988: 42) por las que el concepto de cultura empresarial debe ser comprendido mejor:

1. Debido a que las culturas empresariales son visibles y tangibles (la cultura es real ya sea que se estudie una sociedad, una empresa, un grupo dentro de una empresa, o simplemente una reunión).

2. Debido a que el desempeño individual y empresarial se comprenderá mejor si se considera la cultura de la empresa.

3. Debido a que el concepto de la cultura empresarial ha sido malinterpretado y confundido con otros conceptos, como por ejemplo con la filosofía, la ideología, el estilo.

A continuación se detallarán cada uno de estos tres puntos:

\section{XI.4.1. Visibilidad y tangibilidad de la cultura}

Los efectos de la cultura poseen principalmente cuatro rasgos: son profundos, están esquematizados, suponen una demanda de calidad e invitan a proyectar las presunciones individuales si los datos no son claros. 


\section{XI.4.1.1. Profundidad}

Cualquier persona que haya viajado, seguramente tuvo la oportunidad de ver que tan profundos pueden ser los efectos de las distintas culturas, ya que posiblemente se ha encontrado frente a un idioma nuevo, a costumbres raras, a paisajes desconocidos, a olores, a ruidos, etcétera. Lo más común en estos casos es que todos los sentidos y sentimientos sean absorbidos inmediatamente al tomar contacto con una nueva cultura, siendo necesario aclarar que con lo que realmente un individuo se topa es con los artefactos de la cultura, con sus manifestaciones visibles y tangibles, que son la causa de profundos impactos.

De esta manera, aunque con un efecto que suele ser menos intenso, es posible sentir lo mismo al ingresar a una empresa que posee una cultura distinta de la que provenimos. Por ejemplo, las personas en el rol de clientes frecuentemente notan las diferencias cuando comparan almacenes, Bancos, líneas aéreas o restaurantes como consecuencia de las diferencias entre los establecimientos en su aspecto y en la impresión que provocan, como así también en el trato diferente que dan los empleados de distintos almacenes o restaurantes.

\section{XI.4.1.2. Esquematización}

Los fenómenos relacionados con los artefactos se viven psicológicamente como algo más que el efecto que pueden causar los individuos; es decir, que existe una tendencia a decir de las empresas que son agradables o no, en lugar de atribuir estas cualidades simplemente a las personas. Por lo tanto, las diferencias se califican como fenómenos culturales ya que: 1) se nota que muchos de los miembros de la empresa aparentan actuar de la misma forma; 2) se nota que los demás entienden la conducta como la normal y esperada, y 3) la conducta se experimenta como algo intencionado y esquematizado y no como algo casual o inmotivado. Entonces, da la sensación de que lo que las personas hacen es porque hay una finalidad que aparentemente entienden los que viven la misma situación, si bien un tercero no alcanza a descifrarlo. Por ejemplo, en cualquier restaurante o Banco, la distribución física, el mobiliario, la pulcritud y porte de sus empleados, el ruido, sumado a muchas otras referencias suelen combinarse para crear la impresión de un esquema. Estas impresiones de esquematización se basan en expectativas derivadas de experiencias previas vividas en situaciones similares.

Tales esquemas son buscados principalmente porque encontrarse con algo inesperado genera ansiedad dado que no es posible prever y, en consecuencia, no permite estar preparados para afrontar lo que pueda venir después. De esta manera, si la conducta es ambigua, es posible atribuirle motivos y significados que tengan sentido para nosotros. "Los estudios sobre atribuciones han demostrado que cuando intentamos explicar la conducta de otro, tendemos a juzgarle como algo motivado y esquematizado, en vez de como algo determinado por las 
circunstancias o imprevisto" (Schein, 1998: 44). Por el contrario, cuando se trata de explicar la conducta propia, es posible darse cuenta de las circunstancias que modifican los esquemas de motivación básica, debido a lo cual se la considera más imprevista. Así, es probable que atribuir dichos motivos circunstanciales a los demás sea más difícil por la necesidad de tratar de predecir y controlar la conducta de otros, por lo que se recurre entonces a explicaciones más esquematizadas.

Esto significa que un individuo puede aceptar excepciones de esquemas previstos del propio comportamiento gracias a que conoce cuál es el esquema del que se está desviando, lo que hace de la excepción algo definible y tolerable. Cuando observa la conducta ajena sin poder descifrar su esquema, intenta, antes de considerar las excepciones circunstanciales que lo afectan, esforzarse en localizar el mismo. De ello se desprende que existe una tendencia a proyectar cualquier esquema que poseamos en la propia cultura como una hipótesis inicial para explicar lo que puede estar ocurriéndole a una persona proveniente de otra cultura.

\section{XI.4.1.3. Demanda de calidad}

Un individuo al enfrentarse a una situación cultural nueva tiene la necesidad de responder (haciendo lo correcto), encajar en la situación, superar la tensión que deriva de la incertidumbre, lograr la aceptación y contactos, etcétera. Es difícil conformarse con observar la situación y soportar las sensaciones de desarraigo y tensión que puede ser experimentada. Por el contrario, es preciso que descubra lo que se espera de él, lo que provoca una ansiedad que puede volverse cólera si percibe una presión determinada para adaptarse sin saber qué hacer para conseguirlo, o si percibe que la adaptación puede atentar contra el propio sentido de identidad. Si el individuo logra entender esto y tener éxito se sentirá optimista; si no lo consigue entender, sentirá cierta prevención y una leve sensación de peligro ya que la incomprensión puede ofender a otros.

\section{XI.4.1.4. Proyección}

En una situación cultural nueva suele atribuirse un sentido y un propósito a todos los aspectos de la escena, exagerando incluso el grado en que se reflejan las intenciones expresas de los demás actores. Por lo tanto, como esas proyecciones añadidas reflejan frecuentemente los propios prejuicios culturales antes que las intenciones de otros, habría que esforzarse por no otorgar un valor excesivo a los estímulos recibidos.

\section{XI.4.2. Efectos de los fenómenos culturales sobre la empresa y el individuo}

El estudio de las cuestiones culturales a nivel empresarial es esencial para lograr comprender lo que ocurre en las empresas y así encontrar la mejor manera de administrarlas y perfeccionarlas.

\section{XI.4.2.1. Efectos de la cultura sobre la estrategia}


Gran cantidad de compañías han descubierto que si bien podrían utilizar nuevas estrategias válidas desde el punto de vista financiero o productivo, no podrían implantarlas con éxito porque las presunciones, valores y métodos de trabajo que requieren para ello no son compatibles con las presunciones fundamentales de las empresas.

Estos asuntos se llaman entonces culturales porque las percepciones y los esquemas de conducta se formaron a partir de presunciones admitidas dadas por supuestas al derivarse de ellas el éxito inicial. Tales presunciones trabajan en un ámbito que supera al de los directivos, y están tan asumidas, que cualquier estrategia inspirada en presunciones de otro tipo probablemente se descarten de antemano.

Por lo cual, es frecuente examinar si alcanza con modificar la estructura de una empresa (que comprende esquemas de autoridad, reparto del trabajo, sistemas de control y circuitos de comunicación), o si realmente lo necesario es cambiar las actitudes y percepciones de la gente tanto como la estructura. Si se consideran estas cuestiones desde el punto de vista de la cultura empresarial, se observará que tanto la estructura como las actitudes son artefactos de la cultura; y, que si pretende transformar los artefactos sin confrontar las presunciones subyacentes no podrá obtenerse un cambio exitoso. La empresa simplemente retornará a sus antiguos métodos de trabajo.

\section{XI.4.2.2. Fracasos de fusión, adquisición y diversificación}

Cuando una empresa decide fusionarse con otra compañía o comprarla, lo normal es que se evalúe cuidadosamente, entre otras cuestiones, su capacidad financiera y su situación en el mercado. Pero extrañamente, sólo en contadas excepciones se revisan los aspectos que pueden ser considerados culturales (como la filosofía de la compañía o los orígenes tecnológicos), que podrían ser decisivos para conocer las presunciones básicas, y las ideas que tenga sobre su misión y futuro. Entonces, sí la cultura determina y limita la estrategia, en toda adquisición y fusión la disconformidad cultural representa un riesgo parecido al de una mala situación financiera o de producción. Por ejemplo, puede ocurrir un choque de presunciones sobre cómo debe ser ejercida la autoridad.

Problemas similares de cruce cultural suceden cuando las empresas se diversifican en nuevas áreas geográficas, cuando adquieren nuevas tecnologías, o cuando ingresan en nuevos mercados. En cada caso chocarán con subculturas regionales o profesionales, las cuales requieren de la adopción de conductas directivas diferentes para obtener los resultados deseados. Lo usual es que al principio el problema se entienda solamente como algo que consiste en la introducción de una nueva tecnología o producto en un terreno nuevo, no obstante el verdadero problema consiste en que la nueva tecnología o producto amenazan con modificar las presunciones culturales locales 
hasta un extremo desconocido, lo que da lugar al rechazo. También puede ocurrir que la diversificación como la fusión necesite el aprendizaje de una nueva cultura, lo que es incompatible con la cultura que tiene la compañía.

\section{XI.4.2.3. Fracasos en la adopción de nuevas tecnologías}

Insertar una nueva tecnología en un lugar, ya sea una profesión, empresa o sociedad, puede ser vista como un problema de cambio cultural. Las profesiones generalmente forman sus métodos, valores y su propia imagen alrededor de la tecnología que le es inherente. De forma análoga, una empresa que crece a través del dominio de una tecnología determinada, crea su propia imagen en torno a esa tecnología. Si la tecnología sufre una transformación sustancial, la empresa o profesión deberá aprender nuevos métodos y redefinirse a sí misma en base a premisas más esenciales y que impliquen las presunciones culturales de fondo. Sólo aquellas compañías que llegan a ser capaces de variar su criterio con relación a su negocio logran permanecer.

Los ejemplos más destacados son los relacionados con la automatización, los ordenadores, y la tecnología del procesamiento de datos. Con la introducción de los modernos sistemas de información y la automatización, en varios sectores fundamentales el subordinado sabe más que el jefe, y los grupos que antes carecían de poder pasan a desempeñar un papel determinante. Las personas que tienen el poder suelen prever estos cambios, y creen que la mejor manera de evitar la reducción de su poder, es la de oponerse por completo a la nueva tecnología. Además, incluso en el caso de que el razonamiento empresarial referido a la redistribución de poder fuera tan claro como para lograr que los empleados y directivos aceptaran el cambio, una segunda fuente de resistencia cultural está dada por la incertidumbre y ansiedad asociadas con la transición necesaria.

Para que la nueva tecnología triunfe, quienes la defiendan deben reconocer que la oposición que encuentra no es por la tecnología en sí, sino por las consecuencias de cambio cultural que se derivan de su introducción. Tomando el ejemplo de la tecnología del procesamiento de datos, se observa frecuentemente que la misma es introducida bajo el argumento de que la empresa ganará productividad, prestándose poca atención a las consecuencias en la distribución de poderes. Pero aun en el caso de que se tenga presente el tema relativo al poder, es común pasar por alto otro factor cultural, el hecho de que la nueva tecnología produce su propia cultura profesional. Así, con la nueva tecnología aparecen nuevas presunciones, valores y esquemas de conducta. La gente dedicada al procesamiento de datos desarrolla un vocabulario, normas, una visión de su importancia y una perspectiva "propia" sobre la forma en que la tecnología debe ser utilizada. Un interesante ejemplo es el que sucede en medicina, donde la inserción de tecnología para diagnosticar puede convertir a una generación de antiguos médicos en individuos obsoletos dentro de un campo básico de su trabajo. 


\section{XI.4.2.4. Conflictos intergrupales en la empresa}

Los grupos pueden formarse a causa de la cercanía física, de un destino compartido, de una profesión común, de una experiencia común de trabajo, de una raíz étnica similar o de una jerarquía parecida (como subordinados o líderes). Es básico comprender que desde que un grupo tiene un pasado, tiene una cultura. Entonces, si aparece alguna clase de conflicto entre los grupos no será fácil resolverlo, principalmente porque un grupo necesita mantener su identidad, resultando una de las mejores maneras de lograrlo comparar y contrastar el propio grupo con los demás. Esto significa que la comparación, la rivalidad y/o el conflicto intergrupales sirven para construir y mantener la cultura intergrupal. Esta formación de "subculturas" forma parte de una diferenciación entre los diversos componentes funcionales de una empresa y el desarrollo de una visión funcional establecida por cada componente.

Otro aspecto de la cultura que tiene que ser considerado es la ética, ya que si es posible reconocer la existencia de varias culturas en el marco de una empresa, se puede admitir en consecuencia la existencia de distintas bases para juzgar lo que es ético. Incluso en el caso de que una compañía posea una cultura empresarial fuerte e integrada, con principios claros, puede suceder que los mismos no sean aplicables a otras culturas. Por ejemplo, en algunas situaciones culturales, determinados regalos entre clientes y distribuidores o líderes se aceptan como un intercambio normal para la buena continuidad del negocio, pero en otras situaciones, tales obsequios son vistos sólo como sobornos.

\section{XI.4.2.5. Reuniones infructuosas y desavenencias en las relaciones personales}

Es preciso darse cuenta que, hasta los problemas diarios de la vida empresarial (como por ejemplo la reunión improductiva, la dificultad para lograr que un subordinado entienda la advertencia por bajo rendimiento, la dificultad para dar órdenes con la claridad adecuada para conseguir su correcta aplicación), pueden ser estudiados desde el punto de vista cultural. En otras palabras, en vez de juzgar los problemas de comunicación como consecuencia de la falta de claridad, la actitud defensiva o las diferencias de lenguajes, es posible decir que dichos problemas se derivan en muchas ocasiones de discordancias referidas a la forma de percibir y entender las cosas a causa de la pertenencia a distintas unidades culturales. Por consiguiente, la falta de entendimiento entre las personas debería ser siempre tratada al principio como un asunto cultural más que como un problema de personalidad.

La experiencia adquirida en reuniones y grupos enseña la velocidad con la que se puede formar la cultura. Se observa claramente que el grupo crea un lenguaje propio, interpreta los hechos en términos propios, y logra desarrollar presunciones sobre sí mismo y su entorno que influyen silenciosamente sobre las percepciones. Sin embargo, para la formación de determinadas 
culturas de grupo tiene que otorgarse un tiempo suficiente de manera que el mismo pueda ser efectivo; pero a la vez, también se sabe que en la medida en que el grupo produzca una cultura más dificultades tendrá para comunicarse con los otros grupos y más inflexible puede volverse en su funcionamiento.

\section{XI.4.2.6. Fracasos en la socialización}

Luckmann introduce al tema de la socialización expresando que no existe ninguna sociedad, dentro de las que se conocen, que no tenga cierta división del trabajo acompañada de cierta distribución social del conocimiento, por lo que, mientras así suceda, la socialización secundaria se convierte en una necesidad. Esto es así siempre que se entienda a la socialización secundaria como la internalización de submundos institucionales o basados sobre instituciones. De esta forma, en la socialización secundaria, suele aprehenderse el contexto institucional.

Haciendo uso de una definición muy restringida, es posible decir que la socialización secundaria es la "adquisición del conocimiento específico de "roles", estando éstos directa o indirectamente arraigados en la división del trabajo" (Berger y Luckmann, 1994: 175). La socialización secundaria requiere adquirir vocabularios específicos de roles dentro de un área institucional, por lo tanto el lenguaje específico de un rol es internalizado por el individuo debido a que involucra cierta identificación subjetiva. Los submundos internalizados en la socialización secundaria son frecuentemente realidades parciales que pueden contrastar con el mundo base adquirido en la socialización primaria (siendo conveniente destacar que esta última es la primera socialización por la que el individuo atraviesa en la niñez y, por medio de la cual, se convierte en miembro de la sociedad). Entonces, la socialización secundaria es también cualquier proceso posterior que induce al individuo ya socializado a nuevos lugares del mundo objetivo de su sociedad.

Es esencial comprender que los roles de la socialización secundaria comportan un alto grado de anonimato, vale decir, que se separan de las personas que los desempeñan. Por ejemplo, el mismo conocimiento que enseña un maestro de tantos puede enseñarlo otro; cualquier funcionario de su clase podría enseñar el mismo tipo de conocimiento. No obstante, los funcionarios individuales pueden diferenciarse subjetivamente de varias formas ya sea porque sean más o menos simpáticos, porque enseñen mejor o peor, etcétera. Además, el conocimiento internalizado en la socialización secundaria se descarta más fácilmente que el adquirido en la socialización primaria, debido a que se necesitan fuertes impactos biográficos para poder modificar la realidad masiva internalizada en la primera infancia, pero éstos pueden ser mucho menores para poder descartar las realidades internalizadas más tarde.

Ahora bien, en la socialización secundaria la internalización debe ser reforzada preferentemente por técnicas pedagógicas específicas para hacer que el individuo lo sienta como 
algo familiar. Estas maniobras son necesarias porque ya existe una realidad internalizada que permanece en el camino de nuevas internalizaciones. Incluso, el grado y el carácter de estas técnicas pedagógicas serán ajustados de acuerdo con las motivaciones que tenga el individuo para la adquisición del nuevo conocimiento. Cuanto más logren estas técnicas volver subjetivamente aceptable la continuidad entre los elementos originarios del conocimiento y los elementos nuevos, con más velocidad adquirirán el acento de realidad. Por ejemplo, una segunda lengua se aprende construyendo sobre la lengua materna. También, se puede observar que dentro de un mismo contexto institucional pueden existir diferencias de acuerdo con las tareas adjudicadas a las distintas categorías de los empleados. Así, en el ámbito militar, el grado de compromiso que logran los oficiales de carrera es muy distinto del requerido a los reclutas.

En el caso extremo de modificación de la realidad subjetiva, se requiere procesos de resocialización que se asemejan a la socialización primaria. Estos procesos deben desintegrar la anterior estructura por completo. Una situación en la que las transformaciones son drásticas, pero que se definen como temporarias por su corta duración, se da en el adiestramiento para una carrera militar. Aquí la diferencia con la resocialización total resulta fácil de advertir. Sin embargo, en este caso, ya se plantea la coherencia con la realidad e identidad previas (existencia del individuo como civil) mediante la suposición de que, en algún momento, se regresará a ella. En la resocialización el pasado se reinterpreta conforme con la realidad presente. En la socialización secundaria el presente se interpreta de modo que se halle en relación continua con el pasado, con una tendencia a minimizar las modificaciones que se hayan hecho realmente. Dicho de otra forma, "la base de realidad para la resocialización es el presente, en tanto que para la socialización secundaria es el pasado" (Berger y Luckmann, 1994: 204).

Ahora, con estas herramientas, es posible analizar adecuadamente el tema de la socialización en las organizaciones. Schein piensa que el proceso de aprendizaje cultural del recién llegado es muy complicado, motivo por el cual las empresas invierten mucho esfuerzo en la capacitación, adoctrinamiento y socialización de los individuos con los que cuenta, así como en otros mecanismos para procurar que la adaptación sea exitosa. Pero, si el proceso de socialización no se resuelve de la mejor manera o si el nuevo integrante no aprende la cultura del grupo que lo recibe, las consecuencias generalmente pueden ser graves. "En un extremo, si el nuevo empleado no aprende las presunciones fundamentales o centrales de la empresa, lo corriente es que se sienta segregado, incómodo, y también improductivo."(Schein, 1998: 57). Esos sentimientos pueden llevar a que empleados competentes dejen la organización. Del mismo modo, si el nuevo empleado aprende elementos de una subcultura opuestos a las presunciones fundamentales de la empresa en 
su conjunto, puede crear un sabotaje o la desaceleración del ritmo de trabajo en la empresa, y eventualmente el estancamiento, la revolución o la eliminación del disidente.

En el otro extremo, si el empleado tiene una socialización excesiva, lo que significa que consigue aprender todos los detalles de la cultura receptora, da como resultado un conformismo absoluto que lleva a la empresa a perder la capacidad innovadora o receptiva con las recientes demandas de su entorno. Así, la óptima socialización es el aprendizaje de solamente los elementos de la cultura que son esenciales para que la empresa sobreviva y continúe funcionando.

\section{XI.4.3. Análisis erróneos de la cultura}

Schein (Schein, 1988: 61) se da cuenta de que existe una gran probabilidad de que la cultura sea interpretada y analizada equivocadamente. Por tal motivo, distingue las formas principales en que se puede caer en una confusión.

En primer lugar indica que puede confundirse una parte de la cultura con el todo, lo que implica el peligro de que se atienda a algo trivial y se le otorgue excesiva importancia. En segundo lugar pueden llegar a confundirse los sintomas con las esencias, lo que significa que al observar una cultura dada, es fácil que se confundan las manifestaciones superficiales con las causas, esencias y esquemas subyacentes. Por ejemplo, el hecho de que el ambiente visible de una organización aparente ser informal y abierto, no implica que la cultura real sea informal y abierta. Es decir que cuando se comparan dos compañías, no se puede decir que la más formal y cerrada en apariencias maneja la información menos (o más) adecuadamente que la que parece más abierta e informal. Incluso, aunque los datos superficiales puedan ser muy precisos, hasta no profundizar no se sabrá si lo que se observa es solamente una manifestación superficial o una característica de la manera en que los individuos quieren ser percibidos, o si refleja esquemas más profundos del grupo.

Hay que ser precavidos y no suponer que la cultura se revela con facilidad; en parte porque rara vez se conoce con precisión lo que se busca, en parte porque los esquemas subyacentes pueden estar tan aceptados que probablemente resulten invisibles para los propios miembros del grupo. Las esencias culturales sólo pueden extraerse mediante un esfuerzo sostenido hasta lograr aclarar aquello que normalmente queda desgajado de la conciencia.

\section{XI.5. Fortaleza de la cultura}

Las culturas fuertes tienen la capacidad de poder unir a los individuos transformando a la organización en una comunidad y no solamente en un grupo de personas. Es por ello que Daft llega a definir a la fortaleza de la cultura como "la medida en que los empleados coinciden en cuanto a la importancia de los valores y las formas especificas de hacer las cosas. Si existe un 
consenso general, la cultura es fuerte y unida, y si no hay mucha coincidencia, la cultura es débil" (Daft, 2006: 574). No obstante, el efecto de una cultura fuerte no siempre produce resultados positivos, ya que en ocasiones puede fomentar valores equivocados y perjudicar tanto a la organización como a sus integrantes. Entonces, si bien es cierto que una cultura fuerte incrementa la cohesión de los empleados y su compromiso con los valores, las metas y las estrategias de la organización, también es cierto que algunas compañías suelen tener valores poco éticos o poco saludables para la propia organización. Por ejemplo, una cultura fuerte que no incentive la adaptación a su entorno puede ser más perjudicial que una cultura débil. Las culturas de las organizaciones que se adaptan difieren en los valores y comportamientos si se las compara con las culturas que no se adaptan. En las primeras, los líderes se preocupan mucho por los clientes, los empleados y los procesos que conducen al cambio útil. En cambio, en las otras, los líderes se preocupan por sí mismos y en sus proyectos personales, y esta clase de valores suelen desalentar el cambio.

La cultura de una organización no siempre coincide con las necesidades del entorno externo debido a que los valores y la manera de hacer las cosas pueden reflejar lo que alguna vez funcionó en el pasado. Los sistemas humanos (especialmente las normas y los valores de la cultura de la compañía) son lo que crea o disuelve una iniciativa hacia el cambio. Es por este motivo que las organizaciones pueden lograr ser más eficaces si su cultura se apega al entorno.

\section{XI.6. Cómo se configura la cultura}

Los líderes instituyen una perspectiva acerca de los valores convenientes que harán que las personas realicen la visión y las metas planteadas de la organización. Con frecuencia, la cultura organizacional refleja los valores que defiende su fundador o su líder máximo; sin embargo, los miembros también configuran e interpretan el carácter y la cultura organizacional y, distintas personas, pueden percibir a la organización de distintas maneras y relacionarse con ella de distintas formas.

Así, cuando una cultura saludable queda establecida, los líderes para mantener una cultura fuerte que permita una buena integración interna y una adaptación al exterior, tienen a disposición una serie de técnicas. Quienes detentan el poder pueden recurrir, como ya se adelantó en el capítulo VIII, a ritos y ceremonias, a relatos, a símbolos y a un lenguaje especializado para representar los valores culturales de la organización. Además, para fortalecer la cultura, también pueden hacer una selección cuidadosa de los individuos nuevos y optimizar la socialización; aunque probablemente, lo más importante sean los actos diarios a través de los cuales se envían señales de los valores culturales que quieren infundir en la organización. 


\section{XI.6.1. Ceremonias}

Una ceremonia es una actividad especial pensada que generalmente es orientada en beneficio de algunas personas. Los líderes planean ceremonias para ofrecer ejemplos dramatizados de lo que es deseable en la organización. Estos eventos refuerzan valores específicos y crean un vínculo entre los individuos porque les permiten formar parte y honrar a los miembros que simbolizan logros importantes. La ceremonia normalmente incluye la entrega de un premio.

\section{XI.6.2. Anécdotas}

Una anécdota es un caso que se fundamenta en sucesos reales que los subordinados comparten frecuentemente. Los líderes pueden relatar anécdotas a los nuevos con el objetivo de ilustrar los valores básicos de la organización o para reforzar los valores principales. Es posible, que en algunos casos los relatos no estén basados en acontecimientos verdaderos aunque si estén en consonancia con los valores y las creencias requeridas.

Los relatos constituyen un camino poderoso para establecer una conexión con otros en lo emocional, lo que contribuye a expresar valores culturales y a transmitirlos.

\section{XI.6.3. Símbolos}

Un símbolo es un objeto, un acto o un evento que tiene la función de comunicar valores culturales o un significado. En cierto sentido, las anécdotas y las ceremonias son símbolos, pero también lo son los objetos materiales que simbolizan valores concretos.

\section{XI.6.4. Lenguaje especializado}

El lenguaje configura los valores y las creencias de la organización; por lo que los líderes, en algunas ocasiones, utilizan lemas o refranes para expresar determinados valores esenciales que pretenden. Luego, las personas los aprenden y repiten con facilidad.

Los líderes también fortalecen los valores culturales con declaraciones públicas por escrito, como por ejemplo, mediante los enunciados de la misión u otros enunciados formales.

\section{XI.6.5. Selección y socialización}

La elección de las nuevas personas y su socialización colaboran para mantener los valores culturales. Cuando los individuos adecuados han sido seleccionados y contratados, lo que sigue a fin de crear una cultura fuerte y saludable es socializarlas para que entren en la cultura.

\section{XI.6.6. Actos diarios}

Las ceremonias, los relatos, los lemas y los símbolos son formas de comunicación que no sirven si los líderes no envían señales de los valores culturales más trascendentes a través de sus actos diarios. Los individuos aprenden lo que más valora la organización mirando las actitudes y los comportamientos que los primeros observan y premian, en cómo responden ante las crisis y en que el comportamiento se ajuste a los valores que predican. Por lo tanto, si bien los líderes saben 
que la cultura no es fácil de transformar, tratan de modificarla a través del gran impacto que generan sus actos y así lograr que se adapte al entorno y que se produzca una integración interna sin inconvenientes.

\section{XI.7. Qué son los valores de la organización}

Los valores de la organización son las creencias que perduran y que tienen importancia en la organización. Para determinar cuáles son los valores principales deben tomarse en cuenta el entorno externo, la visión y la estrategia de la estructura. Es por eso que la cultura puede variar bastante de una organización a otra, aunque las organizaciones de una misma industria poseen frecuentemente valores similares porque trabajan en entornos similares. De igual modo, los valores esenciales deben ser los que la organización requiere para ser eficaz, por ejemplo, se puede elegir entre los valores de cooperación o de competitividad. Sin embargo, de todos los valores que forman parte de la cultura, generalmente se considera que los éticos son los fundamentales.

No es sencillo definir la ética con precisión, y tampoco es el objetivo de este trabajo. Pero, en general y como referencia, se puede decir que la ética está compuesta por los principios y los valores morales que establecen la conducta de un individuo o de un grupo sobre lo que es correcto o incorrecto. Es decir que la ética fija normas que definen lo que está bien o mal tanto en una conducta como en la toma de decisiones. Incluso, gran cantidad de individuos son de la idea de que mientras no infrinjan la ley se están comportando de manera ética, pero desconocen que la ética con frecuencia va más allá de los aspectos legales. Como indica Daft:

(...) las leyes surgen a partir de un conjunto de reglas y reglamentos estatutarios que, por lo general, son aceptados por la sociedad y que adquieren carácter de obligatorios ante los tribunales. Las normas éticas se aplican, en su mayor parte, a comportamientos que no contempla la ley. Si bien las leyes actuales muchas veces reflejan un mínimo de normas morales, no todas las normas morales están instituidas por la ley. (Daft, 2006: 591).

Un ejemplo claro sería que la ley no obliga ni especifica el deber moral de una persona a ayudar a otra que se está ahogando.

Por lo tanto, cada empleado, y también cada organización, representan normas de comportamiento ético. De esta forma, los líderes pueden generar un clima que enfatice la importancia de que todos los subordinados se comporten éticamente.

\section{XI.8. Liderazgo basado en valores}

El liderazgo basado en valores es la principal vía para desarrollar y reforzar los valores éticos; lo que significa tratar de lograr una relación entre los líderes y los seguidores que se fundamente en los valores compartidos interiorizados que el líder defiende y a su vez pone en 
práctica. Como ya se explicó, los líderes influyen en los valores éticos a través del comportamiento personal y de los sistemas y las políticas de la organización.

\section{XI.8.1. Comprometerse con la ética personal}

Los subordinados aprenden los valores observando los comportamientos de sus jefes. Éstos últimos cuando actúan en base a los valores inspiran confianza y respeto, no sólo por apoyarse en los valores mencionados, sino también por demostrar coraje, determinación y sacrificio propio al defenderlos. Cuando los líderes están dispuestos a efectuar sacrificios personales por los valores que defienden, predisponen a los seguidores para hacer lo mismo.

Ahora bien, a fin de conseguir que las organizaciones sean éticas, debe haber un compromiso decidido con el comportamiento ético. Por esta razón, existen diferentes factores que apuntalan la posición ética personal del líder, ya que cada persona tiene un conjunto de creencias, valores, características de personalidad y rasgos de comportamiento personales, donde los antecedentes familiares y las creencias espirituales frecuentemente construyen los principios con los cuales se desempeñan. Además, ciertas características de la personalidad como el ego, la confianza en uno mismo y el sentido de independencia ayudan a los líderes a tomar decisiones éticas, especialmente cuando dichas decisiones no fuesen populares.

Los líderes influyen también en los valores éticos utilizando herramientas tales como los sistemas o las estructuras. Los sistemas formales son los códigos de ética que representan los enunciados formales de los valores éticos, comunican a los miembros lo que es la organización y establecen los valores y los comportamientos que se esperan; las estructuras representan las distintas posiciones o programas usados para motivar un comportamiento dado, tal es el caso de un comité de ética (que es un grupo de personas que tienen la función de controlar la ética de la organización y prestar resoluciones sobre asuntos éticos cuestionables) o de los programas de capacitación. En definitiva, las organizaciones sólo podrán ser éticas si sus líderes lo son.

\section{Capítulo XII. Lo trascendente de la cultura}

\section{XII.1. Las funciones de la cultura}

Cuando los individuos tienen éxito en sus emprendimientos, las ideas y los valores que los condujeron al éxito, se institucionalizan como un componente de la cultura organizacional. De esta manera, la cultura les da a los subordinados un sentido de identidad organizacional y también genera un compromiso con valores y formas concretas de hacer las cosas. Por lo tanto, se puede decir que la cultura cumple, entre otras, dos funciones principales en la organización: la integración interna y la adaptación al exterior. 
Schein (Schein, 1988: 64-66) coincide con Daft y establece que lo que la cultura hace es dar soluciones a los problemas básicos del grupo sobre 1) la supervivencia y adaptación al medio que lo rodea, y 2) la integración de sus procesos internos para afirmar su capacidad de supervivencia y adaptación. Explica también que para entender la dinámica de la cultura se necesita un modelo que exponga por qué aparecen las presunciones básicas y por qué permanecen. En ese sentido, piensa que una aproximación funcionalista del estudio de la cultura proporciona categorías acordes para el entendimiento de cómo funcionan los grupos y las empresas.

La cultura es un proceso dinámico $\mathrm{y}$, el proceso de formación cultural, es en similar al proceso de formación grupal ya que la misma esencia de la colectividad o la identidad de grupo (como los esquemas comunes de pensamiento, las creencias, los sentimientos y valores que resultan de las experiencias compartidas y el aprendizaje común) es lo que en última instancia se llama cultura de ese grupo. Si no existe un grupo no puede existir la cultura, y sin la existencia de un mínimo grado de cultura sólo se puede hablar de un aglomerado de individuos y no de un grupo. Por ello es que conviene considerar al crecimiento del grupo y a la formación de la cultura como dos caras de la misma moneda, siendo ambas el resultado de las acciones de los líderes.

Las cuestiones externas se relacionan con la definición que el líder y el grupo dan a su entorno y con la manera en que intentan sobrevivir en el mismo; las cuestiones internas tienen que ver con la definición del líder y del grupo sobre la manera de relacionarse entre los integrantes del grupo, para lograr sobrevivir en el entorno definido mediante el rendimiento efectivo y el bienestar interno. Además, aunque estas cuestiones son interdependientes, conviene indicar que a las cuestiones externas les corresponde la supervivencia en relación al entorno real, pero que en parte, está más allá del control del grupo. Estas realidades externas definen el objetivo principal o las funciones centrales del grupo que luego tiene que buscar la forma de cumplir su misión central y la de mantener su éxito frente al entorno cambiante. Pero para sobrevivir es necesaria la integración interna, que se ve favorecida por el éxito externo.

El sistema externo, que conviene aclarar que comprende el entorno físico, tecnológico y cultural, crea actividades e interacciones que a su vez crean sentimientos y normas. Una vez que dichos sentimientos y normas se han formado son vistos como el sistema interno que, recíprocamente, empezará a influir determinando las actividades e interacciones. En otras palabras, una vez que la cultura fue formada influirá sobre la manera de percibir y relacionarse con el entorno. Este entorno establece en un principio las posibilidades, opciones y obligaciones del grupo, forzando al mismo a especificar su objetivo y sus funciones principales. Por ello, determina en un principio la formación de la cultura, si bien, desde que está presente en la forma de 
presunciones compartidas, pasan a ser presunciones determinantes de lo que ha de ser percibido y definido como entorno.

\section{XII.2. Los problemas de adaptación externa}

La cultura establece la forma en la que la organización se relaciona con las personas del exterior y alcanza las metas. Los valores culturales adecuados permiten a la organización responder rápidamente a los requerimientos externos para alcanzar el éxito en su entorno. Por ejemplo, si el entorno requiere velocidad y flexibilidad, la cultura debe poseer valores que apoyen la capacidad de adaptación y la respuesta expedita a los cambios del entorno.

Schein (Schein, 1988: 66-67) desarrolla mejor la idea e indica que los problemas de adaptación externa determinan un ciclo o una guía que todo sistema debe utilizar frente a un entorno en permanente cambio. Por supuesto, aunque cada etapa del ciclo aparece en secuencia, es probable que cualquier empresa trabaje en la mayoría de ellas simultáneamente. A continuación se presentarán los elementos principales de ese ciclo para luego describirlos con mayor detalle:

1. Misión y estrategia: es la comprensión común de la misión central, la meta primordial y las funciones manifiestas.

2. Metas: es llegar a un consenso sobre las metas derivadas de la misión central.

3. Medios: se trata de alcanzar un consenso sobre los medios adecuados para cumplir las metas, por ejemplo la estructura de la organización, la división del trabajo, el sistema de recompensas, y el sistema de autoridad.

4. Medición: es lograr un consenso sobre los criterios para medir el desempeño del grupo en el cumplimiento de sus metas, por ejemplo a través de los sistemas de información y control.

5. Corrección: se trata de consensuar sobre las estrategias que conviene aplicar para corregir el rumbo con el propósito de alcanzar las metas.

\section{XII.2.1. Consenso en la misión central, en la meta primordial, y en las funciones tanto} manifiestas como latentes

Las organizaciones nuevas (o grupos nuevos) tienen que generar un concepto compartido sobre el problema de cómo sobrevivir del que normalmente se deriva su misión central o razón de ser. De forma tal que si no cumplen su misión central, que normalmente implica además el cómo sobrevivir en un entorno determinado, no lograrán subsistir.

Además de la misión central u objeto esencial, las organizaciones tienen funciones múltiples. Así, la primera de ellas puede ser definida como el objetivo más destacado en la jerarquía de prioridades. Estas prioridades pueden variar a medida que cambie el entorno interno 
y/o externo, pero lo que nunca cambiará la prioridad es el problema de supervivencia que pasa a ser un elemento cultural primordial.

\section{XII.2.2. Consenso en las metas derivadas de la misión central}

El consenso en la misión central no asegura la existencia de metas comunes en el grupo, ya que lo normal es que la misión sea comprendida pero que no sea articulada como corresponde. Para consensuar en las metas, es preciso que el grupo tenga un lenguaje común y presunciones compartidas sobre las operaciones básicas que permiten transitar desde algo tan abstracto o general como la misión, a metas tan concretas como por ejemplo el diseño, la fabricación o la venta de un producto o un servicio. Además, las metas pueden ser definidas en distintos niveles de abstracción y en distintos horizontes temporales, como en el caso de las metas planteadas para "la próxima semana".

Entonces, las metas no siempre son fáciles de alcanzar debido a que, por un lado, se necesita lograr un consenso en la forma de cómo resolver los temas y, por el otro, dichas soluciones deben funcionar repetidamente. Sólo de esta manera se podrá comenzar a pensar en las metas como elementos culturales potenciales en la organización.

\section{XII.2.3. Consenso en los medios}

El objetivo primordial no se cumplirá si no se consensua sobre los medios a emplear para alcanzar las metas. La forma de diseñar, elaborar o vender un producto tiene que ser acordada, como así también la forma en cómo será dividido el trabajo, los sistemas de control, de recompensas, etcétera. Por lo tanto, es durante el desarrollo de los medios donde el grupo define más claramente sus límites y las reglas a las que deben someterse sus miembros.

Las metas de la empresa, aunque están orientadas hacia el exterior, exigen una estructura interna del grupo que posibilite su realización. Por lo que la clase de estructura interna que se produzca, así como el modo en que se distribuyan los recursos y las tareas, reflejarán tanto las intenciones para con el exterior de los fundadores, como la dinámica interna de los miembros.

\section{XII.2.4. Consenso en los criterios para medir los resultados}

Debe haber también un consenso en la manera de juzgar el propio rendimiento para conocer qué clase de medidas correctoras hay que adoptar cuando las cosas no se desarrollen como se esperaba. Si los integrantes del grupo sostienen conceptos diferentes sobre la forma de evaluar los resultados, no podrán elaborar una acción correctora coordinada.

\section{XII.2.5. Consenso sobre las estrategias correctoras y de reforma}

Para la adaptación externa, se precisa en último lugar, llegar a un consenso sobre lo que hay que hacer cuando se necesita un cambio y sobre cómo conseguirlo. 
En este contexto es trascendental la reacción de la empresa ante las malas noticias, especialmente si atenta contra su supervivencia. Las empresas, al superar crisis de supervivencia, frecuentemente descubren cuáles son sus presunciones más profundas y sus valores. Esto significa que una parte importante de la cultura de la organización puede ser algo que está latente porque nadie puede saber de antemano cómo responderá ante una crisis, no obstante, el tipo de respuesta revelará ciertos elementos profundos de la cultura, en particular los que se relacionan con la integración interna. Por ejemplo, muchas organizaciones que están por entrar en quiebra descubren un elevado nivel de motivación y esfuerzo entre sus subordinados. Por el contrario, es común escuchar relatos referidos a los tiempos de guerra donde unidades militares que son alentadas para que ofrezcan una entrega total de los individuos, sólo dan como resultado que éstos pierdan las ganas de luchar, tanto es así que buscan excusas para escapar del combate y, más aún, hasta llegan a disparar por la espalda a sus propios oficiales. Además, en el caso de una organización de reciente creación, las crisis revelarán algunas de las presunciones del fundador que irán elaborando la cultura del grupo. Por ejemplo, en una organización que atravesaba por circunstancias económicas desfavorables, su fundador tomó la decisión de despedir a muchos de sus empleados. Por el contrario, en otra organización que atravesaba por una situación parecida, su fundador reaccionó poniendo a tiempo parcial a todos sus empleados y reduciendo sus sueldos, pero al mismo tiempo les aseguró que apreciaba a su gente y que deseaba retener a la mayor cantidad posible.

Las reacciones ante las crisis ofrecen entonces una gran oportunidad para observar la formación de una cultura, al mismo tiempo que revelan aspectos de las culturas ya constituidas. Desde esta perspectiva, este ámbito de adaptación empresarial es uno de los que más habrá que analizar, comprender y, en lo posible, gobernar.

\section{XII.3. Cuestiones de integración interna}

Significa integrar a los miembros del grupo de forma que sepan cómo vincularse entre sí. Debido a esto es que Daft señala que la cultura colabora con los individuos para que desarrollen una identidad colectiva y sepan cómo pueden trabajar juntos con eficacia. La cultura tiene la función de regir las relaciones y establece la manera en que las personas se comunican en la organización, el comportamiento que es correcto y la forma en que se consigna el poder y la posición. La cultura graba una serie de reglas tácitas en la mente del actor social que son básicas para determinar la conducta.

En la actualidad, las organizaciones tienden a esforzarse más en crear culturas fuertes que estimulen el trabajo en equipo, la colaboración y la confianza recíproca, ya que en un ambiente de 
confianza, existe mayor probabilidad de que las personas compartan las ideas y de que sean más creativas y generosas.

Ahora bien, Schein (Schein, 1988: 78-79) explica que crear un grupo supone simultáneamente 1) desarrollar las relaciones entre los individuos que hacen alguna tarea juntos; 2) la realización efectiva de lo que hagan. Y, si resultase imposible separar este proceso en términos temporales, hay que hacerlo en términos conceptuales. Entonces, lo que consigue la unidad de un grupo, es decir, la razón de ser o la "función de adaptación externa" en virtud del cual los grupos pueden realizar trabajos que los integrantes en forma individual no pueden lograr, es un aspecto diferente del "proceso" por el que se crea esa unidad.

Así, lo que se llama cultura del grupo, queda establecido por el proceso de adaptación externa y por el modo en que se forme y mantenga, lo que se denomina proceso de adaptación interna. Durante este proceso existen ciertas cuestiones internas que todo grupo debe superar para funcionar como un sistema social. Estas son:

1. Lenguaje común. Si los miembros no pueden entenderse, el grupo es por definición imposible.

2. Criterios para la inclusión y la exclusión. Una parte fundamental de la cultura es la del consenso sobre quiénes pertenecen y quienes quedan fuera del grupo, y los criterios que lo determinan.

3. Poder y jerarquía. Se refiere al orden jerárquico implantado en la organización, a los criterios y a las reglas que establecen cómo se obtiene, conserva y pierde el poder.

4. Intimidad, amistad y amor. Son las reglas sobre las relaciones entre iguales, las relaciones entre los sexos, y sobre cómo direccionar la confianza y la intimidad para conseguir las metas de la empresa.

5. Premios y castigos. Conocer cuáles son las conductas heroicas y pecaminosas; qué es lo que se recompensa otorgando posesiones, jerarquía, y poder; y qué es lo que se castiga con el cese de las recompensas y con la segregación.

6. Ideología y religión. Las organizaciones, al igual que las sociedades, enfrentan hechos inexplicables y misteriosos a los que hay que dar un sentido para que las personas puedan dar respuestas y evitar la ansiedad que supone afrontar lo inexplicable e incontrolable.

\section{XII.3.1. Formación de un lenguaje común}

Para que un grupo funcione los miembros tienen que tener un lenguaje común que les permita entender lo que sucede. Por ejemplo, los fundadores de grupos son quienes, por lo general, crean un sistema de categorías conceptuales para poder establecer ciertas abstracciones como 
cuando dicen "un buen producto" o "tan rápido como sea posible", de manera que todos estén de acuerdo en lo que se debe hacer, en lo que es importante, etcétera.

Un lenguaje y unas categorías conceptuales comunes son fundamentales para llegar a cualquier forma de consenso. No obstante, hay que señalar que los grupos desarrollan el lenguaje no sólo para llegar al consenso y sobrevivir, sino también como una forma de distinguirse y de lograr un sentido de identidad por medio de la jerga técnica que sólo pueden comprender las personas implicadas.

\section{XII.3.2. Criterios para la inclusión y la exclusión}

Es fundamental que exista en el grupo un consenso respecto de quién pertenece y quién no al nuevo grupo, así como sobre los criterios a través de los cuales se toman esas decisiones. Es importante señalar que los nuevos integrantes no podrán desarrollarse bien ni concentrarse en su tarea principal si sienten inseguridad sobre su integración, a la vez que el grupo no podrá adquirir una autodefinición si no posee una forma para determinar sus límites.

Al principio, los criterios para la inclusión tienden a ser fijados por el líder o el fundador; hasta que, a medida que el grupo aumenta su influencia, estos criterios son estudiados para alcanzar un consenso grupal. Un modo de encontrar "cuáles son las presunciones y los valores centrales del grupo, consiste en preguntar a los miembros ya integrados qué es lo que realmente pretenden de los nuevos miembros, y en examinar el historial profesional de aquéllos, al objetivo de averiguar qué es lo que cuenta para la inclusión del grupo.” (Schein, 1998: 83). Si no hay un consenso amplio sobre lo que debe pedirse a los nuevos integrantes, habrá que contemplar la posibilidad de que el grupo en su conjunto no tenga una cultura propia, o la posibilidad de que el mismo no sea más que un conglomerado de subculturas.

Por supuesto, el consenso descripto respecto del establecimiento de quienes están dentro y de quiénes están fuera de un grupo tiene consecuencias inmediatas como la aplicación de reglas discriminatorias. Los que logran pertenecer reciben beneficios especiales: son objeto de mayor confianza, obtienen mejores premios, y especialmente logran tener un sentido de identidad por su pertenencia a la empresa. Los que quedan fuera obtienen menos beneficios y además pierden identidad específica.

En definitiva, se puede decir que el consenso sobre los criterios para la integración es un medio válido para determinar si existe una unidad cultural en un grupo.

\section{XII.3.3. Criterios para delimitar la influencia, el poder y la jerarquía}

El problema crucial de la distribución del poder se debe a la naturaleza biológica propia del ser humano, que incluye impulsos agresivos congénitos y una necesidad de dominar, controlar y gobernar a los demás y a su entorno. Entonces, la cultura es la encargada de revestir de 
“civilización" las raíces biológicas de la conducta humana, por lo que se piensan y determinan las normas culturales que sirven para enseñar a refrenar la agresividad y contener los impulsos. De ahí aparece la necesidad de entender la dificultad de transformar esas normas, ya que el mismo proceso de cambio puede generar un período de inestabilidad durante el cual puede ser experimentado el temor de perder el control, a tal punto que es factible que exista una tendencia a aferrarse a las presunciones culturales que se poseen, incluso cuando existan mejores presunciones desde el punto de vista objetivo.

\section{XII.3.4. Intimidad, amistad y amor}

Todo grupo incipiente tiene la tarea de decidir en simultáneo cómo solucionar los problemas de autoridad y cómo establecer la relación entre iguales. Así, mientras los temas relativos a la autoridad se originan en la necesidad de enfrentar los sentimientos de agresividad, las cuestiones de la relación entre iguales y la intimidad se desprenden de la necesidad de hacer frente a los sentimientos de afecto, amor y sexualidad.

\section{XII.3.5. Premios y castigos}

Los grupos para funcionar correctamente deben desarrollar un sistema de sanciones para la obediencia o desobediencia de las reglas. El sistema de recompensas de premios y castigos es parte de las características culturales principales de las organizaciones, donde las recompensas obtenidas pueden ser consideradas como una "propiedad" social adquirida. Son ejemplos, el caso de la paga extra, del reconocimiento por parte del superior, de la promoción formal o de la obtención de una jerarquía. De allí radica la importancia de comprender las reglas por las que se adquiere y mantiene una jerarquía.

El sistema de recompensas, entendido como un proceso dinámico, comprende horizontes temporales de corto y de largo alcance. Muchos de los aspectos de corto alcance involucran el rendimiento de la organización en su entorno externo (como la obtención de un producto o la disminución de los precios), por lo que el rendimiento de la empresa se trasladada al rendimiento individual de las personas en el desempeño de sus trabajos. El sistema de incentivos y recompensas de corto alcance se introduce normalmente con el propósito de aumentar lo máximo posible de rendimiento de cada actor. Los aspectos de largo alcance se vinculan con la trayectoria, con la capacidad y con otros aspectos beneficiosos que se consideran resultantes de un rendimiento permanentemente alto.

Siendo de este modo, si se desea investigar la cultura de una empresa, es menester analizar el sistema de recompensas porque revela en poco tiempo algunas reglas y presunciones subyacentes de esa cultura. Por lo tanto, una vez que han sido descubiertas cuáles son las 
conductas heroicas y cuáles las pecaminosas, se podrán deducir las creencias y presunciones que están tras esas evaluaciones.

\section{XII.3.6. Ideología y religión}

Forma parte del consenso sobre la forma de gobernar lo ingobernable y de explicar lo inexplicable. Todo grupo en algún momento afronta ciertas cuestiones que no pueden ser controladas y hechos misteriosos e impredecibles que son generadores de miedos. Una cultura relacionada estrechamente a la razón y a la ciencia considera que todo es explicable, de modo que lo misterioso permanece sin explicación sólo momentáneamente. Sin embargo, hasta que la ciencia resuelva el suceso que no se consigue gobernar o entender, resulta necesario disponer de una alternativa que posibilite situarlo en un contexto con sentido. Dicho contexto puede ser creado por la religión, la cual además es capaz de ofrecer una justificación para hechos que de otro modo podrían parecer injustos o faltos de sentido. "La religión explica lo inexplicable y da orientaciones sobre la manera de actuar en situaciones ambiguas, inciertas y amenazantes". Las mencionadas orientaciones normalmente describen y refuerzan "lo que se considera heroico y deseable, al igual que lo que se juzga pecaminoso e indeseable, con lo cual crean una ideología que abarca en un todo coherente las distintas presunciones relativas a la naturaleza del género humano, a la naturaleza de las relaciones y a la naturaleza de la misma sociedad" (Schein, 1998: 91). La ideología, a los efectos de este estudio, puede comprenderse como una serie de valores capaces de prescribir la forma en que se debe actuar, especialmente en momentos de difícil explicación y gobierno. En una sociedad donde predomina la religión, ésta generalmente se fusionará con la ideología; y en una sociedad donde predomina la razón, la lógica y la ciencia, habrá un fundamento secular de la ideología que la distinguirá de la religión.

El equivalente empresarial del mencionado proceso cultural (ya sea de la religión y/o ideología) suele desarrollarse alrededor de los hechos críticos de la historia de la organización, principalmente de los que no son fáciles de explicar pero que terminan siendo controlados. Se forjan así mitos y anécdotas sobre la fundación de la organización, sobre la época en que la organización atravesó circunstancias difíciles o sobre tiempos de transformación y cambio.

En este contexto podría decirse que la ideología de una organización puede ser muchas cosas. En ocasiones es el componente consciente de las presunciones que conforman la cultura. A veces es la racionalización sobre la conducta inexplicada o supersticiosa. Y otras son los ideales y los deseos futuros, así como las realidades cotidianas, actuando en estos casos como una guía para los miembros. La ideología generalmente posee postulados referidos a la misión central, a las metas, a los medios ideales para el cumplimiento de las mismas y las relaciones que deben lograrse entre los miembros de la compañía. 
Por ello, la ideología normalmente se encuentra parcialmente en los documentos formales como un faro que señala los valores clave de la organización. Sin embargo, "sólo cuando existan anécdotas que apoyen los valores, y cuando las presunciones subyacentes que fundan esos valores estén articuladas, se podrá precisar cuál es la verdadera esencia de la ideología" (Schein, 1998: 92). Las anécdotas y los mitos, no solo consiguen explicar la misión central y las metas fundamentales, sino que también permiten confirmar la imagen que la compañía tiene de sí misma y su teoría sobre la forma de realizar las cosas y de conducir las relaciones personales. Esto significa que, por intermedio de anécdotas, parábolas y otras formas de historia escrita u oral, una empresa transmite su ideología y sus presunciones básicas, lo que tiene especial utilidad en la formación de los recién llegados, quienes necesitan saber lo fundamental en términos abstractos y también en términos más concretos mediante ejemplos que puedan ser imitados.

\section{XII.4. La función de reducir la ansiedad}

Hasta aquí las funciones de la cultura reflejan un aprendizaje empresarial positivo, lo que significa que los grupos o las empresas al hacer frente a problemas internos y externos aprenden a enfrentarse a ellos y a dar forma a una cultura que se deriva de las respuestas obtenidas. No obstante, la cultura no sólo resuelve dichos problemas externos e internos, también tiene la función de ayudar a reducir la ansiedad ${ }^{13}$ que los humanos sienten cuando se enfrentan a situaciones que los enojan o desbordan. En otras palabras, las personas experimentarían mucha ansiedad si no lograsen distinguir del total de los estímulos los que son verdaderamente importantes; por supuesto que los individuos también cuentan con una serie de criterios para reaccionar ante los mismos.

De este modo, se pueden definir las presunciones culturales como:

(...) un conjunto de filtros o lentes que nos permiten identificar y percibir los aspectos propios de nuestro entorno. De no contar con esos filtros y esas lentes, nos sentiríamos ofuscados y desbordados. Así, desde que contamos con soluciones culturales, cabe que nos sintamos hasta cierto punto tranquilos; precisamente, una de las razones que hace que nos resistamos al cambio cultural, estriba en que de por si provoca ansiedad tener que romper con las presunciones que estabilizan nuestro mundo, aun cuando haya en perspectiva otras presunciones más funcionales. En otras palabras, la cultura no sirve únicamente para resolver los problemas de supervivencia externa e integración interna, sino que, una vez adquirida, reduce además la ansiedad inherente a cualquier situación nueva o inestable. (Schein, 1998: 94).

En este sentido, lo que posibilita a los individuos actuar adecuadamente y enfocarse en su trabajo principal es la existencia de un gran consenso sobre la conducción de los aspectos fundamentales. Si los problemas internos no están resueltos, como por ejemplo si la gente está

\footnotetext{
${ }^{13}$ El concepto de ansiedad será explicado en el capítulo XIV.
} 
preocupada por su posición e identidad, si los sujetos se sienten inseguros o si no conocen (o no están claras) las reglas del juego, lo que conduce a la incertidumbre y en consecuencia a la falta de predecibilidad, no podrán concentrarse en los aspectos importantes de supervivencia que, probablemente, deba enfrentar la empresa.

Las presunciones culturales se manifiestan a través de diversas categorías teóricas que fueron mencionadas a lo largo del trabajo y que colaboran para que el observador sepa hacia donde orientar las observaciones. Por ejemplo, un tercero que llega a un grupo comienza a experimentar su cultura tropezándose con sorpresas, esto es, las cosas que no responden a lo que el tercero esperaba. Tal es el caso de un elevado grado de conflicto en una organización que un observador percibe, aspecto que demuestra ser un importante síntoma o artefacto. También son considerados artefactos, u otras fuentes de datos culturales, la estructura de la organización, sus sistemas de información y control, y sus metas proclamadas, sus estatutos, las declaraciones sobre su misión, sus mitos, leyendas y anécdotas.

Haciendo foco en la estructura empresarial, se observa que dado que los humanos no pueden soportar demasiado la ambigüedad y la incertidumbre, necesitan de una estructura empresarial que sirva para establecer las relaciones tanto de jerarquía como entre los colegas. Como consecuencia, todas las empresas desarrollan alguna clase de sistema burocrático y de estatus para posibilitar una distribución de las tareas y permitir que sus integrantes puedan hacerse una idea firme de los demás. De esta manera, la estructura reduce la ansiedad y hace que la vida empresarial sea predecible y estable. No obstante, como es difícil deducir las presunciones a partir de la estructura, se deben distinguir con precisión las presunciones reales, y evitar las proyecciones prematuras.

La estructura de una organización, al desempeñar funciones importantes se convierte en uno de los elementos principales de la cultura. No obstante, el contenido cultural (que significa aquello que la estructura realmente es en cuanto a presunciones relativas a la tarea, la gente y las relaciones), debe descubrirse cuidadosamente y no ser aceptada sin un estudio serio, ya que dos empresas con idénticas estructuras pueden tener culturas totalmente distintas.

Otra fuente de datos culturales la ofrecen los mitos, las leyendas, las anécdotas y los estatutos. Es común poder determinar cómo las anécdotas sobre los fundadores, los estatutos y los credos de las compañías refuerzan las presunciones, pero lo que no es posible deducir son esas presunciones solamente a partir de esos datos. Nada autoriza suponer que en las anécdotas y estatutos exista algo que vaya más lejos que sus valores expresos, los cuales pueden corresponder o no con las presunciones reales que estén actuando. Es conveniente tener presente ésta misma precaución con los materiales destinados a la educación de los recién llegados, como así también 
con los mitos y leyendas que aparecen en toda empresa para ayudar a recordar los valores importantes.

Las anécdotas generalmente transmiten los valores y las creencias de los fundadores o de otros individuos destacados de la empresa, cuyo desempeño se ha convertido en un modelo simbólico. Suelen ser prescriptivas, por lo que pueden transformarse en una forma directa de adoctrinamiento. Por otra parte, puede observarse que en una compañía que tenga diversas subculturas o agrupaciones en conflicto, las anécdotas suelen ser consideradas un medio para divulgar una cultura opuesta o para revelar las inconsistencias o los absurdos de la cultura principal. A veces, son empleadas con el objetivo de idealizar a los primeros líderes, aunque no sea la conducta que se idealiza la acorde para el momento presente. En este caso, el propósito de la anécdota es, además de transmitir un valor, proporcionar a los individuos un motivo de orgullo y algo con qué identificarse. Así, la declaración explícita de credos, filosofía y estatutos, logra que el mensaje antiguo sea igualmente explícito, y refleja la intención del líder de transmitir un mensaje.

En conclusión, es mejor utilizar los artefactos empresariales para verificar las hipótesis sobre las presunciones básicas que para descifrar lo que esas presunciones son, ya que no se ha hallado un método apropiado y rápido para identificar las presunciones culturales. En ocasiones, esas presunciones son evidentes desde el principio, otras veces son difíciles de descubrir, y otras veces se termina concluyendo que en la organización no existen presunciones compartidas debido a que carece de una historia común. Es por ello que conviene entender que el único enfoque seguro es la triangulación, esto es, la confrontación de cada parte de información hasta lograr que un esquema comience a revelarse por sí mismo a causa de que la cultura no se desvela con facilidad. Pese a estar indudablemente ahí, su articulación y descripción exigen enorme paciencia y esfuerzo.

\section{Capítulo XIII. La evolución del liderazgo}

\section{XIII.1. EI líder de aprendizaje}

De la misma forma que las especies biológicas, las organizaciones necesitan adaptarse para poder sobrevivir. Sin embargo, en los entornos estables, muchas terminan volviéndose sistemas muy estructurados con fuertes jerarquías verticales, tareas especializadas y sistemas formales de información y control; por lo que si el entorno comienza a presentar cambios veloces no alcanzan a conseguir buenos resultados. Debido a ello, los líderes intentan emplear un nuevo enfoque de liderazgo y se esfuerzan por transformar sus organizaciones en sistemas más flexibles, capaces de adaptarse y de aprender constantemente.

Así, la dimensión puede ser estable o caótica, lo que indica el dinamismo de los elementos del entorno que crea la necesidad de otra manera de liderar, esto sucede por ejemplo si existen 
grandes cambios de tecnología. Un entorno se considera estable si se mantiene constante durante un cierto período de tiempo (pueden ser meses o años). Aquí, las personas esperan que la historia se repita; lo que comúnmente se expresa con la fórmula: lo que funcionó ayer también funcionará mañana. En cambio, si las condiciones son caóticas, los elementos del entorno cambian violenta e impredeciblemente, obligando a los líderes a aprender a apoyar el riesgo y el aprendizaje, a crear una visión y una estrategia, a atribuir facultades e inspirar a otros y a mantener a los subordinados concentrados hacia una misma meta en el mismo camino.

La evolución del liderazgo conduce al llamado líder de aprendizaje, que es el que está predispuesto a aprender y a cambiar la conducta o el desempeño como resultado de la experiencia, y que incentiva permanentemente el crecimiento y el desarrollo no sólo de los subordinados sino también de la organización entera. Estos líderes, que suelen ser elásticos para poder crecer en un entorno caótico e incierto, consiguen influir en los demás a través de la visión, los valores y las relaciones y no por medio del poder y del control en el sentido tradicional. Ellos aprenden a enfocarse en crear una visión y en dar forma a la cultura y a los valores que ayuden a alcanzarla. Esto incluye concentrarse en convertir a sus organizaciones en verdaderas estructuras de aprendizaje de modo que puedan liberarse de prácticas y patrones anticuados y adaptarse a los nuevos retos.

\section{XIII.1.1. Estructura organizacional}

Conducir y perfilar a una organización hacia un mayor aprendizaje y cambio precisa de ciertas modificaciones en su diseño, ya que el conocimiento y la información se convierten en elementos más importantes que la maquinaria de producción. Esto significa que las organizaciones necesitan las mentes de las personas que las constituyen tanto, o probablemente más, que su mano de obra.

En un entorno velozmente cambiante corresponde rediseñar las estructuras para transformarlas en organizaciones que aprenden; aunque conviene explicar que dichas organizaciones son simplemente un ideal de lo que puede llegar a ser si todos los miembros aprenden constantemente y se preocupan por identificar y solucionar problemas. Se basan en la igualdad, en la información abierta, en la existencia de pocas jerarquías y en una cultura compartida que propicia la adaptabilidad y permite superar las crisis. También suelen otorgar facultades a los empleados y se incentiva la colaboración interna y con otras organizaciones.

Desde esta perspectiva, se puede decir utilizando palabras de Daft (Daft, 2006: 618-631) que el diseño de la organización consta de varios elementos, de los cuales aquí se explicaran los cinco fundamentales: la estructura, las tareas, los sistemas, la estrategia y la cultura. 
1) La estructura organizacional: la estructura tradicional de las organizaciones es vertical y posee una forma piramidal. Esta forma puede resultar eficiente y propiciar una gran producción, a la vez que la jerarquía puede propiciar la supervisión y el control en una organización grande y compleja. Tiene la característica de lograr un funcionamiento correcto durante tiempos estables. No obstante, en un entorno velozmente cambiante la jerarquía vertical se convierte en un problema. Normalmente, las estructuras jerárquicas verticales generan una distancia entre los jefes y los trabajadores y una distancia entre los departamentos; lo que significa que no posibilitan dar respuestas expeditas y coordinadas ya que las decisiones se acumulan y los principales líderes no tienen la capacidad para responder con la velocidad adecuada a las amenazas o a las oportunidades. Además, como la colaboración entre departamentos es escasa, no fomenta la innovación y los subordinados simplemente tratan de alcanzar las metas de sus unidades funcionales.

Por lo tanto, muchas organizaciones deciden disolver la estructura vertical, que crea una distancia entre la cima y la base de la organización, y eligen emplear estructuras horizontales. De este modo consiguen crear su estructura basándose en los flujos de trabajo y en los procesos claves, lo que permite a las personas que trabajan en una parte de un proceso específico, tener acceso también a todas las demás partes para poder coordinar sus esfuerzos y compartir conocimientos. Así, es como, en la estructura horizontal aparecen los llamados equipos autodirigidos, que son unidades fundamentales de trabajo. Estos equipos están formados por miembros que tienen diferentes habilidades y que pueden compartir o rotar sus tareas para realizar un producto o servicio completo, lo que implica que los límites entre los departamentos disminuyan o desaparezcan.

Las organizaciones que aprenden también tratan de eliminar o de reducir al máximo la distancia que las separan de las demás, para poder compartir recursos y explotar oportunidades. De ahí, que las formas de organización como la organización de redes, son consideradas equipos horizontales de sistemas, más que equipos de personas. En una estructura de redes, una compañía mantiene las funciones fundamentales en su interior, pero subcontrata otras, como por ejemplo las ventas, la contabilidad o la producción, a organizaciones o personas asociadas a la red. Por supuesto, la mayoría de las organizaciones se encuentran en algún punto intermedio entre la estructura vertical y la horizontal.

2) Las tareas y los roles: En los entornos cambiantes, la tendencia es que la estructura formal y de control del trabajo de los subordinados sea manejada en la mayor medida posible por ellos mismos. En un entorno estable, las tareas suelen estar definidas rígidamente, por lo que las personas no tienen la posibilidad de definir cómo realizan su tarea. En cambio, en los entornos 
cambiantes, los individuos requieren mayor libertad y responsabilidad para decidir y reaccionar en el menor tiempo posible a medida que las condiciones van modificándose.

Una manera de comprender la diferencia entre las organizaciones diseñadas para el desempeño de tareas y las diseñadas para el aprendizaje es comparar el concepto de los procesos laborales mecanicistas con los orgánicos. Estos términos se utilizan con el propósito de explicar las respuestas de la organización al entorno externo. Si el entorno es estable, las tareas suelen ser mecanicistas; lo que significa básicamente que las reglas son extremadamente rígidas, los procedimientos formales y la jerarquía es de una marcada autoridad. "Las tareas están estrictamente definidas y se descomponen en partes especializadas y separadas, como en una máquina." (Daft, 2006: 623). Las decisiones, el conocimiento y el control de las tareas se reúnen en la cima de la organización, y se espera que todos los miembros cumplan lo que se les ordena y que no tomen decisiones. Sin embargo, en los entornos de rápidos cambios, las tareas tienden a ser más libres, fluidas y adaptables, por lo que algunos autores utilizan el término orgánico para describir esta clase de organización. Aquí, los líderes delegan la autoridad y la responsabilidad a los empleados de niveles inferiores, y tratan de estimularlos para que encuentren la solución de los problemas trabajando con los demás. El trabajo en equipo es entonces muy deseable y existen contadas reglas y procedimientos para la forma en que se deben hacer las cosas. De este modo, la organización adquiere mayor capacidad de adaptación a los cambios del entorno.

Las labores mecanicistas son rasgos que tiene la organización para conseguir un desempeño eficiente. Un caso característico de este tipo de tareas sería la línea de montaje de la producción en masa, en la cual se divide el trabajo en estructuras de pequeñas funciones especializadas y estandarizadas, de forma similar a compartimentos estancos, que están gobernados por reglas y procedimientos formales. Por ejemplo, en una fábrica de pantalones, algunas personas cortarían la tela, otras coserían las costuras, otros bordarían los bolsillos, etcétera; lo que demuestra que los empleados al repetir continuamente el mismo trabajo requieren de poca experiencia y estudios, por lo que no se pretende tampoco de ellos que piensen ni que decidan cómo efectuar sus tareas. No obstante, la estructuración del trabajo en tareas menores y especializadas tenía sentido en la era de la producción en masa porque se trataba de una forma eficiente y confiable de hacer las cosas; incluso, a pesar de saber que las actividades rutinarias no producen satisfacción a los empleados.

En contrapartida, las organizaciones que aprenden se inclinan por la utilización de la forma orgánica, debido a que emplean una arquitectura de organización que es adaptable al contexto. Los trabajadores cumplen un rol, y los roles se ajustan o redefinen en función de la interacción de los empleados dentro del grupo como así también con otros grupos. Existen menos reglas y 
procedimientos, y el conocimiento y el control de las tareas pertenece a los trabajadores. Se alienta a que todos aprendan y a solucionen sus problemas dentro del equipo.

Es importante aclarar que al concepto de motivar a los miembros de una empresa a participar en la organización se lo conoce como atribución de facultades. Este término significa distribuir el poder con todos los integrantes de la compañía, estimulando el aprendizaje para que puedan desenvolverse con un mayor grado de libertad en la realización de sus funciones. Gran cantidad de las organizaciones actuales se apoyan en los trabajos basados en el conocimiento y en la información (más que en las máquinas), consiguiendo el armado de proyectos de equipo y el desarrollo de la colaboración interfuncional. En estas organizaciones, los empleados cada vez tienen más estudios y están más dispuestos a cuestionar a sus líderes, lo cual contrasta notablemente con la autoridad formal.

Entonces, si los empleados disponen de plenas facultades, asumen los roles con mayor autoridad generando beneficios al momento de tomar decisiones, de controlar cómo desarrollarán su tarea y de influir y transformar cuestiones como las metas, las estructuras y los sistemas de la organización.

3) Sistemas de información: En las organizaciones nuevas o pequeñas, la forma de comunicación tiende a ser informal y cara a cara debido a que todos pueden saber qué está ocurriendo con facilidad. También, los sistemas formales de control y de información son mínimos porque los líderes trabajan de cerca con seguidores. Pero, en la medida que las organizaciones crecen, agregan progresivamente sistemas formales para manejar la cantidad de información compleja que se va incrementado.

En las organizaciones que aprenden, se intenta que los sistemas formales destinados a establecer cómo se lleva a cabo el trabajo sean los menos posibles, ya que ésta clase de sistemas contienen diversos peligros, como por ejemplo, el hecho de que la información llegado el momento deja de circular hacia quienes están en la línea de frente y que podrían utilizarla para mejorar su rendimiento. Es por tal razón que la organización que aprende se esfuerza por mantener la condición de organización joven para tratar de que todos dispongan de la información adecuada a fin de poder identificar los problemas y actuar tan rápido como sea posible. Así, en lugar de que los encargados controlen la mayor parte de la información se la comparte a través de las redes informales personales que la difunden por toda la empresa. Los individuos trabajan en equipos y hablan con cualquiera que disponga de la información que precisan, siendo todos responsables de formar la red. De esta forma, los actores sociales que prosperan son los que crean amplias redes de relaciones personales y organizacionales. La clave es que los datos fluyan libremente superando las barreras jerárquicas y funcionales. 
4) Elección de la estrategia (competencia o colaboración): En las organizaciones tradicionales, los que deciden la estrategia a poner en práctica son los líderes. Éstos se encargan de elegir cuál es la vía ideal para usar eficazmente los recursos disponibles y enfrentar los cambios del entorno.

En las organizaciones que aprenden, la estrategia puede surgir de abajo hacia arriba o de arriba hacia abajo. La clave para ello es tener una fuerte visión compartida a la que suscriban todos los individuos para que sus actos conduzcan al desarrollo de la estrategia en la organización. Esto se debe a que muchos de ellos, al estar en contacto con los clientes, los proveedores y las tecnologías, comprenden las necesidades y descubren las soluciones, colaborando en la formulación de la estrategia.

La estrategia también puede nacer de asociaciones de colaboración con los proveedores, los clientes e incluso los competidores. Por ejemplo, ciertas empresas, aunque mantengan sus propios negocios, forman alianzas y formulan estrategias en conjunto, cuando presentan cotizaciones para proyectos mayores que no podrían cotizar individualmente, o cuando solicitan a los asociados que brinden servicios que ellas no pueden dar.

5) Cultura rígida o adaptable: para conseguir el funcionamiento exitoso de una organización, la cultura tiene que favorecer la adaptación al entorno externo. Cuando esto sucede, se institucionalizan los valores, las ideas y las prácticas que han ayudado a obtener dicho éxito. No obstante, como el entorno varía continuamente, esos mismos valores que llevaron a una empresa a los buenos resultados pueden llegar a ser perjudiciales para el desempeño en el futuro. Puede decirse entonces que, con frecuencia, ciertas organizaciones pueden volverse víctimas de su propio éxito al aferrarse a conductas y a valores anticuados como consecuencia de contar con culturas rígidas que no incentivan a la adaptabilidad.

De esta manera, queda claro que una de las características principales de la organización que aprende es tener una cultura fuerte y adaptable. Pero, además, esta parte de la cultura posee otras características que incluyen con frecuencia los siguientes valores:

5.1. El todo es más importante que las partes, y los límites que separan las distintas partes son mínimas. Los miembros tienen conocimiento de todo el sistema y de cómo interactúan los distintos componentes. Por lo tanto, todos saben cómo repercutirán sus actos en los otros elementos de la organización.

5.2. La igualdad y el respeto son valores clave que producen un clima de seguridad y confianza, por lo que la cultura crea un sentido de comunidad, comprensión y preocupación por los demás. Todos los miembros son valorados y a todos se les permite desarrollar su máximo 
potencial. Se eliminan las actividades o las prebendas que generan diferencias de estatus, como por ejemplo, los estacionamientos reservados o los comedores privados.

5.3. La voluntad de favorecer el cambio y correr riesgos es estimulada por la cultura. Se valora cuestionar el status quo y la forma actual de hacer las cosas. Se considera que el hecho de cuestionar los supuestos mejora la creatividad, por lo que existen premios para los creadores de ideas $\mathrm{y}$, a veces, se premia también a los que fracasan para remarcar la importancia que tiene correr riesgos.

\section{XIII.1.2. EI desafío del líder de la organización que aprende.}

Los líderes enfrentan un desafío poderoso: tener que ser eficientes y al mismo tiempo ser una organización que aprende. No es fácil superar este doble reto, apoyar la eficiencia y el aprendizaje, el orden y el cambio, la competencia y la colaboración. Es decir, los líderes propician el aprendizaje y el cambio aunque en simultáneo mantienen la disciplina y la eficiencia.

Las organizaciones tradicionales padecen el problema de contar con fronteras rígidas, lo que genera límites en el aprendizaje y en el cambio. Por tal motivo, es necesario esforzarse para lograr transformar las fronteras y hacerlas permeables, tanto horizontal como verticalmente; es preciso controlar y optimizar el uso de los recursos, pero a la vez, crear procedimientos que permitan la colaboración, el trabajo en equipo y la innovación.

La recomendación práctica es incorporar en el diseño de la organización mecanismos que colaboren para comportarse de forma orgánica y flexible para impulsar la creatividad y la iniciación de ideas nuevas, así como un modo más mecanicista de implantar eficientemente las ideas. Conviene también utilizar las nuevas tecnologías para apoyar la colaboración, el trabajo en equipo y la información compartida. El buen uso de la tecnología genera un sentimiento de comunidad entre las personas (incluso si existen individuos en ubicaciones lejanas), debido a que puede mantener en contacto a todos, por ejemplo, a través de sistemas modernos de comunicación que llevan la información inmediatamente a las personas indicadas en el momento justo. Además, la tecnología de la información pone a disposición de todos en la organización los conocimientos y estimula el aprendizaje. No hay que olvidar tampoco que compartir la información es compartir el poder, por lo que la tecnología sustenta la enorme apertura que se requiere en un entorno que presenta cambios veloces, donde también, la ventaja se deriva de ser el primero en detectar algo y de moverse más rápido que los otros. También permite crear una red de relaciones, compuesto de un intrincado entramado que vincula a todas las partes.

\section{Capítulo XIV. Cómo se crea la cultura}


Para dar respuesta al modo en que se forma la cultura es necesario analizar algunos conceptos y teorías que señalen en qué lugar hay que buscar los orígenes culturales y que expliquen el significado de la dinámica cultural.

\section{XIV.1. Teoría sociodinámica de grupos}

La teoría de la dinámica de grupos, según sintetiza Schein, manifiesta los medios interpersonales y emocionales esenciales que posibilitan explicar el significado de la frase: " $U n$ grupo de personas comparte una visión de un problema y desarrolla una solución compartida" (Schein, 1998: 156). Lo principal aquí, es determinar que se entiende en este contexto por el término "compartir", así como explicar los mecanismos de aprendizaje que existen cuando se da una solución a un problema.

Por lo tanto, es conveniente examinar primero ciertos problemas que tienen que enfrentar los grupos incipientes, como los problemas de supervivencia externa y los problemas de integración interna, debido a que nacen en el instante en que una persona ingresa en un grupo nuevo y define al instante a los restantes miembros como parte de su ambiente externo. Cada individuo debe sobrevivir y mantenerse integrado al mismo tiempo, ya que inicialmente enfrenta a otras personas que constituyen algo que al principio no es un grupo cohesionado, sino simplemente un conjunto de individuos reunidos para un fin. El punto clave es determinar "cómo cada individuo llega a sentir que es ante todo un miembro del grupo, y cómo cada miembro resuelve el conflicto vital entre su deseo de ser asimilado y fusionado en el grupo y su deseo de gozar de completa autonomía y libertad frente al grupo" (Schein, 1998: 156).

De esta manera, para comprender cuáles son las necesidades del individuo comparadas con los intereses del grupo, resulta importante distinguir las tres necesidades primarias que tiene el individuo dentro del contexto social:

1. Inclusión e identidad. Cualquier persona que ingrese en un grupo precisa saber si pertenece o no a él y si goza de un papel o identidad adecuados en el mismo. Mientras la persona no observe una correspondencia entre lo que crea que el grupo espera de ella y lo que ella misma piensa que puede dar, experimentará preocupación, ansiedad, y no prestará suficiente atención a ciertas tareas que deba realizar como resultado de gastar energía personal y concentrarse en resolver su propio problema de supervivencia dentro de la nueva situación social.

2. Control, poder e influencia. Todo sujeto que ingresa en un grupo nuevo desea disponer de cierta influencia y poder, lo que se desprende de necesidades más profundas y primitivas tendientes a controlar el entorno. Esta necesidad refleja la autonomía, la necesidad de sentirse poderoso e independiente frente a los otros manteniendo a la vez la integración en el grupo. 
3. Aceptación e intimidad. Toda persona que ingresa en un grupo nuevo necesita sentirse aceptada, aparte de su necesidad de sentirse incluida, lo que refleja la necesidad de pertenecer en un sentido más profundo, de ser asimilado por el grupo y sentirse seguro.

Estas necesidades interpersonales no sólo reflejan las necesidades humanas básicas de seguridad (inclusión), control del entorno (influencia y poder), y amor (aceptación e intimidad), sino que además las mismas actúan como poderosas fuentes dinámicas de la ansiedad y la preocupación ante el fracaso, y de la energía positiva que intenta su satisfacción. Todo integrante de un grupo nuevo se esfuerza por satisfacer sus propias necesidades en estas áreas, incluso contra cualquier acción coherente del grupo. Al principio, como el grupo nuevo no está consolidado, no es capaz de cumplir su misión, pero luego, los miembros del grupo descubren que pueden satisfacer sus necesidades personales en parte gracias a su pertenencia al grupo. Sólo entonces pueden éstos pensar al grupo como un objeto psicológico que posee una identidad y necesidades propias. Así, la primera y principal experiencia del "compartir", aparece con el descubrimiento de que todos sienten en forma similar la ansiedad y el extrañamiento.

Lógicamente, las personas ya tienen otras identidades grupales derivadas de sus anteriores relaciones (familiares, profesionales, de vecindad, etcétera). Sin embargo, en una configuración incipiente, las nuevas identidades deberán constituirse y ser recíprocamente aceptadas antes de que el nuevo grupo forme una cultura propia. De hecho, los problemas de identidad, control e intimidad de cualquier nuevo grupo surgen a raíz de que los individuos llegan con múltiples experiencias y funciones culturales previas. Si los miembros enfrentasen las nuevas situaciones con pocas funciones y con pocos conocimientos culturales previos, no experimentarían la ansiedad que se deriva de tener que decidir en las situaciones desconocidas.

\section{XIV.1.1. Cómo reaccionan los grupos}

La manera en que reaccionan los grupos depende en gran medida del tipo de cultura que desarrollen. Esta variación cultural no puede ser únicamente explicada por factores ambientales debido a que muchos grupos que se encuentran en ambientes muy similares desarrollan culturas muy distintas. Entonces, la explicación de estas variaciones, depende de una compleja interacción de las personalidades de los líderes, los miembros y las circunstancias.

\section{XIV.1.2. Cuestiones de sociodinámica en el grupo}

$\mathrm{Al}$ ir avanzando en el tema, surgen las preguntas de ¿cómo es que se vuelven explícitas las presunciones básicas, cómo llegan los integrantes a aceptar las visiones nuevas del grupo, cómo se crean las nuevas apreciaciones comunes y cómo se hacen las normas? Si se reconstruye la historia de un grupo se descubre que las respuestas a las preguntas anteriores se resuelven en torno a hechos que se experimentan en retrospectiva como críticos, en cuanto que han supuesto mucha 
emotividad y/o absolutas redefiniciones cognoscitivas. Estos eventos se recordarán posteriormente como indicadores de la historia del grupo. Un incidente o un hecho determinado, se percibe como "crítico" cuando promueve un sentimiento o una visión nueva en el grupo. Así, los mayores obstáculos, las causas de ansiedad, las amenazas, las oportunidades, y el proceder del grupo ante la situación conforman un evento crítico, en especial si la respuesta alcanza el éxito; o lo que es lo mismo, si logra reducir el problema o reducir la ansiedad.

Sin embargo, suele suceder que los integrantes del grupo tienden a olvidar en el transcurso del tiempo los eventos críticos mencionados, por lo que no son capaces de reconstruir la manera en que la organización ha llegado al estado en que se encuentra. Pero desde que el evento es recuperado por la memoria, puede ser reproducido en forma de anécdota y convertido en un elemento legitimador de la cultura, válido tanto para explicar a los empleados cómo han llegado las cosas a ser como son, como para enseñar a los nuevos miembros.

Luego, para colaborar con la estabilidad del ambiente del grupo y hacerlo más seguro para todos sus miembros, aparecen las normas y los modelos que finalmente se aceptan e implantan mediante un consenso. Estas normas y modelos resultan ser el edificio de la cultura que regirá siempre que el grupo dure lo suficiente y que posea una mínima experiencia crítica común. Los modelos se centrarán normalmente en los problemas de inclusión (límites), autoridad, intimidad y funciones.

Ahora bien, para entender cabalmente cómo se originan las normas, necesariamente hay que reconstruir la historia del grupo. Lo más frecuente es descubrir que las normas nacen como consecuencia de eventos críticos que derivan en una respuesta al dilema que afecta al grupo, es decir, que alguien promueve una postura o afirma un valor, los demás integrantes del grupo lo ratifican mediante un asentimiento claro o con silencio; a continuación la respuesta resuelve el problema. Una de las razones que conduce a que la formación de una norma sea prácticamente invisible, es que al producirse gran parte la ratificación del grupo en silencio (nadie se opone abiertamente), se asume que todos están de acuerdo, y la norma comienza el recorrido hacia su estabilización y afirmación. Posteriormente, los eventos críticos a los que se va enfrentando el grupo, ofrecen la oportunidad de verificar si la norma es efectiva, y, en caso que lo sea, de contar con una base para afirmar las presunciones subyacentes que fomentan las normas. Por esta razón, es posible llegar a una primera aproximación de la cultura del grupo gracias a la observación de esas normas.

Además, es posible observar que si un grupo posee una breve historia o una historia poco accidentada, apenas tendrá lo que se define como cultura organizacional, incluso si cada miembro posee firmes presunciones culturales basadas en sus otras identidades grupales. De allí, que en una 
empresa joven existen mayores probabilidades de hallar por un lado, una diversidad cultural más grande y, por otro, de encontrar reductos de cultura entre los que han logrado la interacción y a los que los incidentes críticos han otorgado la posibilidad de la creación de normas y la confrontación entre subgrupos.

\section{XIV.1.3. Comprensión compartida.}

Es cuando los integrantes del grupo reconocen un sentimiento, experiencia o actividad particulares como comunes. Ello supone como mínimo tener un sistema de comunicación común, que puede ser también no verbal, en el que los signos poseen el mismo significado para todos. De esta forma, a través de la existencia de un sistema de comunicación común, cualquiera de los hechos que se explican a continuación pueden dar lugar al sentimiento de compartir.

1. Angustias comunes: El descubrimiento de que otros miembros sufren las mismas angustias $\mathrm{y}$ tensiones.

2. Respuestas emocionales comunes: El descubrimiento de tener respuestas emocionales comunes ante estímulos externos en extremo irritantes. Esto se observa por ejemplo, ante las amenazas sufridas durante la guerra, que consiguen establecer fuertes vínculos como respuestas comunes a las angustias experimentadas por quienes se sienten amenazados.

3. Acción común: Actividad conjunta para responder a una situación emocionalmente irritante, donde se revelan las fronteras del grupo en el sentido en que se ve quien forma parte o no. Si esta actividad conlleva emociones, y los integrantes reconocen respuestas emocionales comunes en los otros o si los miembros deben colaborar entre sí para la acción mediante un compromiso, la experiencia del compartir se fortalece. Todo ello demuestra los poderosos efectos de las empresas físicas colectivas, y de todas aquellas actividades que exigen un esfuerzo conjunto para lograr el éxito.

4. Liberación emocional común: Son las actividades conjuntas que tienen un significado simbólico o alguna manera de liberación emocional. Estas actividades involucran la liberación emocional de sentimientos frecuentemente inhibidos y en algunos casos impropios, como en el caso de un sacrifico colectivo o de un linchamiento, donde se produce un vínculo no sólo por la participación en el acto y el sentimiento del momento, sino por el sentimiento posterior de culpabilidad y vergüenza. Del mismo modo, aunque los sentimientos sean menos intensos, la experiencia colectiva por el simple hecho de ganarle a un competidor en una venta, o por el de triunfar en un negocio de riesgo, resulta funcionalmente equivalente.

5. Regresión emocional común: Es la liberación emocional colectiva que se produce en actividades tales como fiestas, bailes, canto, juegos y competencias deportivas. Estas actividades, incrementan el sentimiento de compartir porque liberan colectivamente las trabas sociales, y 
porque suponen una regresión generalmente aceptada a sentimientos primitivos y más intensos, derivando en una expresión sincera y vulnerable entre las personas.

Es por lo mencionado previamente que cuando se llega a definir a un elemento cultural como un acuerdo compartido respecto a un tema determinado, se piensa en una extensa e intensa historia de eventos y no en un acuerdo superficial. Cuando se registra una interacción entre individuos que viven las relaciones personales de distinta manera y que poseen diferentes formas cognoscitivas, los mismos no conseguirán elaborar significados compartidos fuera de la interacción inmediata. Se necesita entonces tiempo y una experiencia común para crear un sistema de comunicación en el que todos alcancen iguales criterios sobre el significado de los hechos.

\section{XIV.2. Teoría del liderazgo}

Esta teoría señala que los estudios enfocados en descubrir la relación del líder con el grupo, y el efecto que la personalidad y el estilo del primero tienen sobre la formación del segundo, son adecuados para comprender la formación y la evolución de las culturas.

\section{XIV.2.1. Liderazgo y tareas grupales}

La mayoría de las teorías de grupo y de liderazgo elaboran distinciones parecidas a las explicadas referidas a los problemas internos y externos del grupo. Es decir, que distinguen al liderazgo por sus funciones externas y orientadas hacia las tareas, y sus funciones internas y orientadas hacia el grupo. Por ejemplo, en los estudios de liderazgo se destaca el modelo de red empresarial de Blake de dos dimensiones (la preocupación por la producción y la preocupación por las personas), donde además, un líder determinado puede analizarse por su cuenta a fin de conocer en qué parte de la grilla se encuentra.

En definitiva, esto significa que no es posible separar el proceso del liderazgo del proceso de formación de la cultura, porque los temas que se identifican como los problemas alrededor de los cuales la cultura se desarrolla o aprende, son los mismos temas que la mayoría de las teorías identifican como funciones del liderazgo. "Puede incluso llegarse a afirmar que la función única del "liderazgo", a diferencia de la "dirección” o "administración”, consiste en crear y manejar la cultura" (Schein, 1998: 156). Además, todos los líderes y sin excepción, están determinados por su propio aprendizaje cultural (tanto por el previo como por el actual); y más aún, los líderes que ya han creado la cultura, pueden encontrarse limitados por esa misma cultura, descubriendo que ya no pueden conducir al grupo por nuevos caminos.

\section{XIV.2.2. Liderazgo y estilo grupal}


La cultura que nace de la formación de un grupo se ve configurada por la personalidad del fundador de ese grupo. Incluso, las presunciones de los líderes o fundadores de un grupo, las relaciones de autoridad generadas en el mismo, y la forma en que los líderes y los miembros se desenvuelven a nivel emocional, establecerán tanto las etapas evolutivas del grupo como el estilo cultural.

\section{XIV.3. La ansiedad y los tipos de ansiedad}

Antes de entrar en la tarea de definir la ansiedad y los tipos en que se deriva, se hará una observación preventiva. El fenómeno que se va a definir es muy complejo, por consiguiente la exactitud de los criterios dados en las definiciones son modestas, ya que como es sabido, existe una extensa literatura sobre esta clase de fenómenos psicológicos, y las delimitaciones precisas de estos conceptos han sido objeto de considerables discusiones. Lógicamente no es posible esperar mejorar la comprensión de procesos psicológicos que fueron brindados por especialistas en psicología y psiquiatría, pero resulta necesario para comprender plenamente el liderazgo analizar los procesos que le influyen. Es así que la ansiedad, al igual que otros estados emocionales, influye en las percepciones y en definitiva en la cultura. Por lo tanto, de la diversidad de conceptos existentes, considero que las definiciones dadas por Schein (Schein, 1988: 182-185) son las más adecuadas para el objeto del presente trabajo.

\section{XIV.3.1. Ansiedad existencial primaria}

Es importante observar que lo que transforma a la cultura en un sistema estable de conocimientos, sentimientos y conductas, es la extrema necesidad de proteger a los humanos del exceso, la ambigüedad y la incertidumbre. Tanto es así, que todos los integrantes descubren en el grupo que detrás de su lenguaje común existen presunciones muy distintas sobre el mundo y la manera de moverse en él, lo que genera ansiedad. No obstante, con el paso del tiempo y a medida que los miembros nuevos de un grupo vayan aprendiendo nuevas categorías de lenguaje que reflejen su propia experiencia, podrán simultáneamente ir reduciendo la ansiedad.

La ansiedad existencial básica aparece alrededor de los problemas de supervivencia externa y alrededor de los problemas internos de supervivencia social; es decir, que se trata de saber si una persona pertenece o no al grupo, y cómo cada uno equilibra el compromiso que mantiene con el grupo y consigo mismo. Dicha ansiedad social depende de los sentimientos que se llevan desde la infancia y del grupo familiar donde se aprendieron las reglas para ser aceptado, incluido y querido. El conflicto entre el interés propio y la lealtad al grupo es parte de la condición humana, y todos deben aprender la forma de "poder ser individualistas sin perjudicar al grupo". Así, cada grupo desarrolla presunciones propias sobre la mejor forma de dar respuesta a este problema; pero, desde 
el instante en que esas reglas ya no logren solucionarlo, se liberará una ansiedad social básica y primitiva.

De este modo, la ansiedad normalmente aparece cuando los impulsos instintivos de cada individuo amenazan a empujarlo a hacer cosas que suponen peligro para él mismo y para los demás. La estabilidad de las reglas referidas al control de los impulsos y sentimientos propios, brindan la oportunidad de adoptar la fuerza de la sociedad mediante sus reglas compartidas. La cultura colabora entonces ofreciendo una defensa contra los peligrosos y poderosos impulsos internos que intentan vencerlo.

\section{XIV.3.2. Ansiedad secundaria derivada de las funciones y tareas}

Muchas de las funciones y tareas que se realizan en las sociedades y organizaciones involucran riesgo y peligro físico por lo que pueden ser causantes de una ansiedad secundaria, como por ejemplo, las relacionadas con el mundo aeronáutico. Podría decirse que existen fuentes de ansiedad derivadas de la función en la mayor parte de los oficios, aunque no siempre pueden distinguirse claramente de las ansiedades primarias en razón de que ciertos peligros pueden igualmente generar temores inconscientes. No obstante, los miembros de una organización podrán analizar las ansiedades secundarias y comprobar el riesgo o peligro que tienen, debido a que si los peligros son conocidos pueden ser compensados y minimizados. En cambio, la ansiedad primaria no puede ser reducida si no es a través de soluciones culturales.

\section{XIV.3.3. Ansiedad terciaria}

La ansiedad terciaria es provocada por los mismos mecanismos que se utilizan para evitar la ansiedad primaria y secundaria. Dicha ansiedad terciaria termina siendo una fuente de motivación para el cambio cultural que, a la vez, se encuentra limitada por la resistencia defensiva que genera la ansiedad primaria. Para comprender mejor el concepto, conviene pensar lo que sucede en el caso del estudio dedicado a las enfermeras y su tendencia a comportarse de manera distante y burocrática con los pacientes, así como al hecho de que aquéllas están en constante rotación. Se observó que ni a los pacientes ni a las enfermeras les gustaba el sistema de trabajo; había gran cantidad de quejas en contra del sistema burocrático y rotativo, por entender que éste repercutía negativamente sobre la calidad del servicio prestado por las enfermeras. Pese a ello, los esfuerzos por modificar el sistema fracasaban repetidamente. La atenta observación y la entrevista indicaron que las reglas de impersonalidad se habían desarrollado como una defensa contra la ansiedad que se desataría sí las enfermeras estrecharan vínculos o sentimientos con pacientes gravemente enfermos. Los usos aparentemente arbitrarios, inhumanos y en ocasiones ineficaces de las enfermeras, eran necesarios para el funcionamiento de los hospitales. La cultura del servicio de 
enfermeras funcionaba como una defensa social contra la ansiedad, representando para el grupo el equivalente a los mecanismos de defensa individual que representan para el individuo.

Pero, si bien la continua rotación de las enfermeras por distintos servicios impide que se elaboren relaciones estrechas con los pacientes, esa misma rotación no permite que las enfermeras sean competentes en el ejercicio de su trabajo. Ellas nunca estaban el tiempo adecuado en una sección como para perfeccionar su rendimiento, y se sentían además culpables por el trato impersonal que daban a los pacientes ya que iban en contra de algunos de sus ideales profesionales. Sin embargo, si se les proponía mayor tiempo con determinados pacientes, se estimulaban las ansiedades primarias cuya consecuencia era una situación paradójica en la cual hicieran lo que hicieran se sentían ansiosas.

En conclusión, se puede decir que la capacidad de centrarse en la tarea dependerá de que los miembros del grupo puedan reducir y evitar sus ansiedades. Tales ansiedades son más notorias cuando el grupo es joven o cuando todavía no han creado presunciones culturales para controlar la ansiedad, por lo que la energía disponible para trabajar, es menor en las primeras etapas de formación del grupo. Lo más importante es resaltar que la dedicación al trabajo no produce necesariamente buenos resultados si la energía y la atención de los miembros son absorbidas por los "problemas personales".

\section{XIV.4. El cambio}

Schein (Schein, 1988: 206) introduce al tema, diciendo que es una paradoja de la evolución o el desarrollo el hecho de que cuanto más se aprende sobre el modo de hacer las cosas y la forma de estabilizar lo aprendido, más reacias o incapaces se vuelven las personas ante la adaptación, el cambio o la elaboración de nuevos esquemas, incluso cuando el entorno velozmente cambiante exige nuevos esquemas.

Por su parte, Daft (Daft, 2006: 652-658) da continuidad al estudio haciendo notar que los líderes de muchas organizaciones (sin importar la diversidad de las mismas), coinciden en modificar varios aspectos de su manera de desempeñarse con el propósito de satisfacer las necesidades cambiantes de quienes resulten demandantes, de lograr que sus seguidores estén motivados, y de mantener la competitividad en un complejo entorno global. La velocidad de los cambios tecnológicos, económicos y sociales del mundo actual lleva a las organizaciones a ir adaptándose para no quedar relegadas; se observa que los modelos de comportamiento que alguna vez tuvieron éxito van dejando de servir, por lo que van apareciendo otros patrones sin que exista alguna garantía de que alcancen el éxito. De ahí que los líderes tienen la tarea de guiar el cambio y la transformación, siendo responsables de que seguidores puedan superar la inquietud y el 
trastorno que produce un cambio mayor. En consecuencia, es posible decir que el liderazgo es más una cuestión de cambio que de estabilidad.

\section{XIV.4.1. Los cambios internos}

Debido a los permanentes cambios que sufre el entorno externo, es necesario que los cambios internos en las organizaciones sigan el mismo ritmo. Sin embargo, esta tarea no es fácil, por lo que el gran problema se traduce en la incapacidad para adaptarse a todos estos cambios del entorno. Esta cuestión puede deberse a muchas explicaciones, aunque puede señalarse que una solución básica es cambiar de liderazgo. Un liderazgo fuerte y comprometido es clave para que el cambio tenga éxito, razón por la cual, se han efectuado investigaciones que identificaron algunas características básicas que tienen los líderes que fueron capaces de realizar los proyectos adecuadamente.

- No quieren conservar el status quo.

- Exhiben valor.

- Confían en la capacidad de los individuos para asumir responsabilidades.

- Estimulan los valores que propician la adaptabilidad.

- Reconocen sus errores y aprenden de ellos.

- Manejan la dificultad, la incertidumbre y la ambigüedad.

- Son hábiles para describir su visión del futuro en términos muy vívidos.

\section{XIV.4.2. Los cambios mayores}

Crear un cambio no es sencillo, pero los líderes pueden facilitar el cambio y colaborar para que la organización se acomode a las amenazas externas y a las nuevas oportunidades. Cuando los líderes inician un proyecto para generar y guiar un "cambio mayor" es preciso reconocer no solo que el proceso de cambio transita por varias etapas, donde todas son importantes, sino que también requieren de una cantidad sustantiva de tiempo.

De la extensa cantidad de estudios realizados, se explicará a continuación un modelo que simplifica el cambio planeado en ocho etapas. Para llegar al cambio de una forma correcta, hay que prestar especial atención a cada una de las etapas, ya que si se saltea una o si se comete un error crítico en alguna de ellas, entonces el proceso de cambio fracasará.

Etapa 1: los líderes consiguen imprimir un sentido de urgencia argumentando que el cambio es realmente necesario: por ejemplo, las crisis o las amenazas eliminan la resistencia al cambio. Sin embargo, en muchas ocasiones, al no haber una crisis evidente los líderes deben convencer de que el cambio es necesario. Ellos estudian tanto el entorno externo como el interno y, cuando han identificado los posibles problemas, encuentran la forma adecuada de comunicar la información. 
Etapa 2: consiste en formar una alianza muy fuerte que tenga el poder para, en primer lugar, regir el proceso de cambio y, en segundo lugar, desarrollar un sentimiento de trabajo en equipo en el grupo. Además, para que el proceso de cambio sea exitoso, debe existir tanto un compromiso compartido de que la organización requiere una transformación como una elevada probabilidad para cumplirla.

Etapa 3: requiere que los líderes formulen y articulen una visión atractiva que rija el esfuerzo por cambiar, y una estrategia convincente que permita alcanzar esa visión. Es sabido que una imagen de un futuro muy deseable estimula a las personas a esforzarse por el cambio.

Etapa 4: consiste en la utilización de todos los medios disponibles para comunicar la visión a todas las personas. Los encargados del cambio deben concentrarse en dar el ejemplo y en moldear los nuevos comportamientos que requieren de sus subordinados. La transformación sólo será posible si la mayor parte de los miembros de la organización está comprometida y dispuesta a colaborar, muchas veces incluso hasta el extremo de hacer sacrificios personales.

Etapa 5: se trata de distribuir facultades entre todas las personas de la organización para que se comporten en consonancia con la visión. Esto favorece a la desaparición de los obstáculos que impiden el cambio y puede necesitar también la revisión de los sistemas, las estructuras o los procedimientos que interfieran en el esfuerzo por cambiar. Las personas disponen de facultades y cuentan con los conocimientos, los recursos y la libertad necesaria para tomar las decisiones que conduzca al cumplimiento de las tareas.

Etapa 6: los líderes se las ingenian para lograr triunfos a corto plazo. Por lo cual, piensan mejoras visibles en el desempeño, hacen que éstas ocurran y felicitan a los miembros que participaron. El motivo se debe a que un cambio mayor lleva tiempo, y el esfuerzo de transformación va perdiendo fuerza si los empleados no tienen logros a corto plazo para reconocer y festejar. Un logro muy visible a corto plazo renueva la credibilidad del proceso de cambio y refuerza el compromiso y el entusiasmo.

Etapa 7: hace uso de los triunfos conseguidos a corto plazo para consolidar los avances del cambio mayor. Los líderes aprovechan el momento con el propósito de modificar los sistemas, las estructuras y las políticas que no se ajustan a la visión y que todavía no han sido tocados. Además, se renueva el proceso con una nueva serie de proyectos para el cambio.

Etapa 8: el objetivo es intentar institucionalizar los cambios en la cultura de la organización; es decir, trata que los cambios perduren en el tiempo. Los antiguos hábitos, los valores, las tradiciones y mentalidades son reemplazados por otros nuevos, que son infundidos en la cultura, de forma tal que los subordinados no vean el cambio como algo nuevo, sino como algo normal de la forma de operar de la organización. Esta etapa también requiere que exista una forma de 
asegurar la sucesión, de modo que los valores y los comportamientos nuevos sean trasladados a la siguiente generación.

Cuando se trata de manejar un cambio mayor, el proceso de cambio de las ocho etapas proporciona una base sólida. Sin embargo, debe ser señalado que las etapas del proceso de cambio en general se imbrican, aunque todas sean fundamentales para lograr el cambio. Además, en ocasiones, si bien los cambios profundos pueden iniciarse en todas las áreas de la organización al mismo tiempo, los líderes también pueden iniciarlos de forma gradual.

\section{XIV.4.3. Cambio diario}

En determinadas ocasiones puede suceder que aunque el líder comprenda que es necesario efectuar cambios significativos, ciertas circunstancias no le permitan iniciar cambios mayores, por ejemplo, si reconocen que las modificaciones bruscas podrían provocar una resistencia muy fuerte. Por tal razón, muchos deciden trabajar para ir cambiando gradualmente (día a día) las actitudes, los supuestos y los comportamientos. Cuando cada líder se involucra en las actividades diarias de cambio, conseguirá un potente efecto acumulado.

\section{XIV.5. Resistencia al cambio}

La gran mayoría de los cambios, sin importar si son grandes o pequeños, encuentran cierto grado de resistencia, ya que muchas personas ven el cambio como algo doloroso que destruye el orden establecido. Por lo tanto, al conducir personas, es clave entender que la resistencia al cambio es algo natural y que con frecuencia tiene razones fundadas.

El motivo principal que explica la razón por la cual los subordinados ofrecen resistencia al cambio se debe a lo que se denomina violación del pacto personal entre los seguidores y el líder. “Los pactos personales son las obligaciones y los compromisos recíprocos que definen la relación (...)" (Daft, 2006: 662). También incluye elementos como la dependencia y la confianza recíprocas, así como los valores compartidos. En general, los aspectos del pacto tienden a estar bien definidos y pueden tener forma escrita, aunque existen otros que no están tan claros. Así, los integrantes de la organización, suelen percibir que el cambio infringe el pacto personal, principalmente por las siguientes razones (Daft, 2006: 662-664).

- Interés personal. Los individuos generalmente se resisten al cambio si entienden que les quitará algo de valor. Por ejemplo, los cambios de la estructura o de la tecnología del puesto pueden generar la posibilidad de perder poder, prestigio, entre otros. El temor a sufrir una pérdida personal es el mayor obstáculo para el cambio en la organización. 
- Incertidumbre. Se entiende por incertidumbre a la ausencia de información sobre los hechos futuros; lo que se ve reflejado a través de un comportamiento de miedo a lo desconocido. Los sujetos, al no entender cómo el cambio propuesto modificará su vida, se aferran a lo conocido, incluso si es desagradable y lleva al fracaso indudablemente, porque se sienten más seguros. En la esfera de las organizaciones, los individuos sentirán miedo por cómo afectará el cambio su rutina diaria o sus amistades en la organización. También puede suceder que tengan miedo de no tener la capacidad para poder cumplir los requerimientos de la nueva función, procedimiento o tecnología.

- Diferentes valoraciones en las metas. Este caso aparece en ocasiones, ya que los miembros, si bien se dan cuenta que sufrirán una alteración por la innovación, podrían no medir la situación de la misma manera que los líderes incluso si estos se expresan legítimamente respecto a los beneficios que traería cierto cambio. Además, las personas pueden perseguir metas distintas y un cambio puede afectar el desempeño de algunos y alejarlos de la posibilidad de alcanzarlas.

De esta forma, puede decirse que las razones explicadas de resistencia al cambio son legítimas, por lo cual quienes van a introducir un cambio no las deben pasar por alto, ya que pueden tranquilamente diagnosticar sus razones y descubrir el camino para lograr que las personas lo acepten sin problemas.

\section{XIV.5.1. Cómo superar la resistencia al cambio}

Por intermedio del modelo de las ocho etapas (Daft, 2006: 666) los encargados del cambio pueden incrementar las probabilidades de llegar a un resultado exitoso. Aunque, a fin de convencer a las personas de la conveniencia de los cambios propuestos, los líderes pueden además usar herramientas como los relatos, las metáforas, el humor, más lo que consideren de acuerdo a su personalidad para acceder a los individuos en el plano emocional. Los elementos emocionales son esenciales para persuadir a otros y para influir en ellos, por lo que no deben ser subestimados si se quiere vencer la resistencia al cambio.

Los líderes también tienen a su disposición una serie de técnicas especiales que ayudan en la amortiguación del proceso de cambio.

- Comunicación y capacitación. La comunicación abierta y honrada es una de las formas aisladas principales para superar la resistencia al cambio debido a que reduce la incertidumbre, ofrece la sensación de que todo está bajo control, explica correctamente lo bueno que traerá el cambio e inspira confianza. Es importante tener una buena comunicación frente a frente y no recurrir exclusivamente a los boletines, los memorandos o la comunicación electrónica.

Las personas también tienen que ser capacitados para adquirir habilidades que requiere el rol que desempeñarán, ya sea en el proceso de cambio o en sus nuevas responsabilidades. 
- $\quad$ Participación y dedicación. Aunque el enfoque de la participación lleva su tiempo, motiva a los seguidores para que contribuyan a realizar el cambio haciéndolos sentir que lo comprenden y especialmente que lo controlan. Los subordinados llegan a comprender mejor el cambio y se comprometen para que su implementación sea exitosa.

- $\quad$ Creatividad. Un buen camino para que los líderes faciliten el cambio es crear un entorno que fomente la creatividad y que ayude la organización a ser más innovadora, lo que quiere decir conseguir generar ideas nuevas que den por resultado una organización más eficaz y eficiente. Las personas creativas aportan ideas que podrían satisfacer las necesidades, resolver problemas o responder a las oportunidades. Sin embargo, conviene explicar que la creatividad misma es un proceso más que un resultado, es un viaje más que un punto de destino. Un aspecto fundamental es que las personas creativas se resisten menos al cambio porque tienen una mentalidad abierta, son curiosas y están dispuestas a correr riesgos.

- Coerción. Como último recurso para superar la resistencia, los líderes amenazan a sus seguidores con la idea de que podrán ser excluidos, transferidos, etcétera. La coerción es una herramienta que puede ser necesaria, por ejemplo, en una situación de crisis cuando se necesita una respuesta inmediata; no obstante, este planteamiento para el cambio no es recomendable porque enfurece a las personas contra sus líderes pudiendo producir un sabotaje al cambio.

\section{XIV.6. La cara negativa del cambio}

La implementación de los cambios, ya sean estos grandes o pequeños, que ayuden a la organización a mejorar conviene hacerlos en forma suave. Es esencial reconocer que el cambio, si bien puede tener consecuencias positivas, también puede traer consecuencias negativas y resultar inconveniente. Incluso, cuando el cambio en principio parezca positivo tanto para los subordinados como para la organización, si no es liderado cuidadosamente también puede generar desánimo, disminuir el compromiso y reducir la confianza.

Puede suceder que aunque resulte necesario efectuar ciertos cambios para el bien de la organización, los mismos generen consecuencias negativas para los seguidores, quienes podrían experimentar elevados grados de estrés al ser obligados a aprender rápidamente tareas y formas nuevas.

\section{Capítulo XV. Configuración e implantación de la cultura}

XV.1. Cómo los fundadores de empresas logran configurar la cultura 
Las organizaciones no se crean de manera accidental o casual, sino que están orientadas hacia un propósito específico y nacen porque es sabido que a través de la acción coordinada de un grupo de personas se puede realizar lo que no se consigue mediante la acción individual.

Según Schein (Schein, 1988: 211) los fundadores son quienes comúnmente establecen el modo en que el grupo soluciona sus problemas de adaptación externa e integración interna. Lo normal es que las organizaciones posean un criterio basado en su pasado cultural y en su personalidad. Se puede decir que los fundadores no sólo imprimen la gran determinación y confianza en sí mismos que poseen, sino que además suelen tener presunciones sólidas sobre la naturaleza del mundo, el rol de las organizaciones en el mismo, la naturaleza del género humano y las relaciones. Un ejemplo claro de la aplicación de las presunciones de un fundador se da cuando éste pretende de las personas a quienes les encarga liderar que sean muy "visibles", que dominen cabalmente su trabajo, que supervisen de cerca y que, especialmente, sean capaces de dar un buen ejemplo y de enseñar a los subordinados la manera adecuada de realizar las tareas.

Además, como ya fue explicado, para que algo se convierta en parte de la cultura tiene que funcionar. Las cosas que resuelven repetidamente los problemas y que consiguen reducir la ansiedad, sobrevivirán y se transformarán en parte de la cultura de la organización; aunque resulta necesario tener presente que una serie de presunciones que funciona bajo ciertas circunstancias, puede llegar a ser disfuncional bajo circunstancias diferentes. Por ejemplo, el hecho de intentar mantener determinadas presunciones a una mayor escala en un ambiente más competitivo, puede terminar en un fracaso.

\section{XV.2. Cómo los líderes implantan y transmiten la cultura}

En general, los grupos políticos, las organizaciones, las religiones y los movimientos sociales importantes se originan por intermedio de líderes que poseen visiones nuevas y soluciones innovadoras de los problemas. Muchos de ellos también cuentan con esa extraña cualidad llamada carisma, que posee como uno de sus componentes la habilidad para hacer entender a los individuos las presunciones y los valores fundamentales de una manera gráfica y clara. En este sentido, queda claro que el proceso de formación cultural es ante todo un proceso de creación de un pequeño grupo.

Se examinará seguidamente, teniendo presente que la iniciativa tiende a caer en el fundador, el proceso de implantación atendiendo a la forma en que el poder del mismo puede ser usado para inculcar las presunciones. Los mecanismos de implantación que serán descriptos comprenderán diversas dimensiones: 1) Qué tan poderosos son sus efectos, 2) Qué tan explícitos o implícitos son los mensajes transmitidos, y 3) Qué tan intencionales son. 


\section{XV.2.1. Mecanismos primarios de implantación}

Los mecanismos a ser tratados constituyen los medios primordiales gracias a los cuales los fundadores o líderes consiguen implantar sus propias presunciones en la vida cotidiana de sus organizaciones. Incluso, es importante indicar que los conflictos y las incongruencias son igualmente transmitidos, transformándose así en parte de la cultura.

Así, en términos de Schein (Schein, 1988: 224-235), los cinco mecanismos primarios más poderosos para la implantación y el reforzamiento de la cultura están compuestos por:

1) Lo que es atendido, medido y controlado por los líderes. Uno de los mecanismos más efectivos con los que cuentan los fundadores o los líderes para comunicar lo que piensan, reside en aquellas cosas a las que prestan atención continuamente. Donde, por “prestar atención" se entiende todo lo que es objeto de interés, lo que es medido, controlado y recompensado. Incluso las observaciones casuales y los interrogantes que constantemente se plantean sobre un tema determinado, pueden convertirse en eficaces mecanismos formales de control y medición.

El hecho de prestar sistemáticamente atención a ciertas cosas pasa a constituir un sólido medio para transmitir un mensaje, especialmente (...) [si el comportamiento es] del todo constante. Por el contrario, si los líderes no son conscientes de la importancia de este proceso (...) los subordinados (...) perderán un tiempo y energía desmedidos tratando de descifrar lo que refleja realmente la conducta del líder, y hasta proyectarán motivaciones tal vez inexistentes. (Schein, 1998: 225).

Cuando los líderes interpretan que alguna presunción importante está siendo transgredida reaccionan con determinados arranques emocionales, reforzando y haciendo saber por intermedio de ciertas señales a qué cosas le prestan atención. Entonces, como a los seguidores les desagradan dichos arranques, intentan evitarlos llegando gradualmente a adoptar las presunciones del líder. Otras señales intensas que los subordinados pueden interpretar como indicios de las presunciones del líder, estriban en lo que entienden que no provoca ninguna reacción.

2) Las reacciones de los líderes cuando aparecen situaciones críticas o crisis. Cuando una organización enfrenta una crisis, el modo en que los líderes reaccionan ante ella origina normas, valores y métodos de trabajo nuevos, y revela simultáneamente las presunciones subyacentes. Las crisis son importantes tanto en la creación como en la transmisión de la cultura debido a que, al estar implicadas las emociones, se incrementa la intensidad del aprendizaje. Esto significa que si la gente comparte intensas experiencias emocionales, y aprende a afrontar situaciones en extremo emotivas de manera colectiva, aumentará la probabilidad de que recuerde lo que haya aprendido.

Lo que se define como crisis es, en parte, un asunto de percepción, ya que puede o no haber peligros reales en el ambiente externo, y lo que se considera peligroso suele ser simplemente un 
reflejo de la cultura. Por lo que involucra a este trabajo, se entiende como crisis todo lo que se percibe como crisis.

Obviamente, las crisis no son igualmente valiosas respecto a la revelación de las presunciones culturales, sino que al contrario, aquellas que surgen alrededor de los más destacados problemas de supervivencia externa e integración interna son las más importantes. En el aspecto externo, muchas empresas han hecho frente a las crisis de disminución de ventas, obsolescencia tecnológica y la consecuente necesidad de reducir costos; por lo que la manera en que la organización afronta la crisis, deja al descubierto ciertas presunciones sobre la consideración que tienen hacia las personas. Existen distintos ejemplos de organizaciones que al afrontar una crisis económica severa, optaron por reducir los días de trabajo o el sueldo de todos los empleados y directivos de manera de lograr disminuir los gastos sin tener que realizar despidos. En una de esas compañías que pudo superar la crisis financiera sin tener que despedir a nadie, se cuentan anécdotas sobre la forma en la que se resolvió la situación para demostrar a los trabajadores cuáles son los valores que imperan en la empresa.

En el aspecto interno, los conflictos de lenguaje y de comunicación, el modo de decidir lo que es verdadero, de relacionarse con la autoridad y los iguales, de resolver los problemas, son probablemente los más importantes. Esto significa que la cultura de la organización está tan vinculada a la jerarquía, la autoridad, el poder y la influencia, que resulta obligado elaborar y validar a través de un consenso los mecanismos de solución de conflictos. Se puede decir en consecuencia que un buen momento para observar a una empresa, es aquel en el que se producen dichos inconvenientes, debido a que ofrecen una inmejorable oportunidad a los líderes para enviar mensajes sobre sus propias presunciones relativas a la naturaleza humana y las relaciones.

3) Planificación intencionada de las funciones y la enseñanza. Los fundadores y los líderes nuevos de las empresas tienen que comprender que su propia conducta manifiesta posee mucho valor para la transmisión de los valores y las presunciones a los demás miembros, especialmente a los nuevos. Aunque por supuesto que existe una diferencia con los mensajes que se transmiten en marcos pensados para ese fin, como por ejemplo, cuando un presidente pronuncia un discurso a los recién llegados; y cuando un presidente transmite los mensajes al ser visto informalmente. Como ya fue señalado, los mensajes informales constituyen uno de los mecanismos más poderosos para la enseñanza.

4) Criterios utilizados para la distribución de recompensas y jerarquías. Los trabajadores de cualquier organización consiguen descubrir qué es lo que la empresa valora y qué es lo que se castiga gracias a su propia experiencia en cuanto a promociones, rendimiento y discusiones con el jefe. Entonces, tanto la conducta que se recompensa y castiga como los propios castigos y 
recompensas, son transmisores de los mensajes, por lo que los líderes de una empresa pueden expresar rápidamente sus preferencias, valores $\mathrm{y}$ presunciones asociando reiteradamente recompensas y castigos a la conducta que les corresponda juzgar. En definitiva, lo que aquí se indica, es aquello que realmente ocurre, y no lo que se expone, publica o predica.

En este sentido, si la intención de los fundadores o líderes es el de asegurar el aprendizaje de sus valores y presunciones, requerirán contar con un sistema de recompensas, promoción y jerarquía que sea congruente con esas presunciones. Así, mientras que al principio el mensaje se transmitirá a través de la conducta cotidiana del líder, a la larga éste es juzgado en función de la congruencia que exista entre la distribución de las recompensas importantes y dicha conducta diaria. En el caso de que la transmisión de este tipo de mensajes sea incongruente, podrá decirse que la cultura será muy conflictiva, o que será en su defecto, una empresa carente de cultura en todos sus niveles.

5) Criterios empleados para el reclutamiento, la selección, la promoción, la jubilación y la segregación. Uno de los medios de implantación y perpetuación de la cultura más eficaz es el de la selección inicial de los nuevos integrantes. Si un fundador posee la presunción de que "el mejor medio de construir una empresa consiste en contratar gente muy tenaz e independiente, y dejar que actúe por su cuenta, y si se da el caso que obtiene frutos contratando gente tenaz e independiente, creará entonces el tipo de cultura que presume más conveniente." (Schein, 1998: 233). Es por ello que el éxito de la cultura descansa en el éxito obtenido en el reclutamiento, y esto es tan así, que incluso sus criterios sobre la manera posterior de organizar la empresa pueden quedar desdichos cuando la selección no fue realizada adecuadamente a las presunciones elegidas.

Entonces, como la cultura se mantiene a sí misma por intermedio de un reclutamiento que se adecua a ella, resultaría difícil introducirle cambios debido a que en este caso se exigiría a los subordinados que adopten presunciones que no se adecuan a su propio bagaje cultural. Por el contrario, el cambio cultural puede efectuarse gracias a la selección de nuevos miembros que estén en consonancia con las nuevas presunciones culturales. Una estrategia de estas características generará un período de confusión pasajera, aunque los nuevos integrantes no se sentirían incómodos en la nueva cultura, siempre que hayan sido elegidos para adecuarse a la misma.

Este mecanismo de implantación cultural es sutil porque trabaja de forma inconsciente en la mayoría de las organizaciones a raíz de que tiende a contratar a quienes se asemejen con los miembros ya integrados por su estilo, presunciones, valores y creencias. Es evidente que tanto las decisiones iniciales para la selección explicada, seguidas por los criterios utilizados para la promoción, las jubilaciones anticipadas y la segregación efectiva de los miembros, son mecanismos muy fuertes tanto para la implantación de la cultura como para su continuidad, 
especialmente cuando se combinan con tácticas socializadoras pensadas para enseñar las presunciones culturales deseadas.

\section{XV.2.2. Mecanismos de articulación secundaria y reforzamiento}

Menos poderosos, más ambiguos y más difíciles de controlar resultan ser los mensajes implantados a través de los mecanismos secundarios, que tienen esta denominación debido a que para ponerse en práctica necesariamente tienen que ser congruentes con los mecanismos primarios. Cuando se da esa congruencia, se continúa con la formación de las ideologías empresariales y por consiguiente se formaliza lo que se aprendió informalmente al principio. En cambio, si no se da la congruencia, estos mecanismos secundarios podrán ser ignorados o bien podrán generar conflictos internos. Así, las presunciones culturales que operen serán normalmente el reflejo de las puestas de manifiesto por la conducta de los líderes y no las que se registran por escrito. Es por este motivo que las organizaciones se diferencian en función del grado de congruencia y claridad de sus mensajes culturales.

A pesar de todo, los mecanismos secundarios pueden ser un refuerzo poderoso de los mensajes primarios siempre que el líder sea capaz de controlarlos. Lo que importa es entender que todos estos mecanismos comunican el contenido de la cultura a los recién llegados, por lo que los líderes lo único que pueden lograr es un mayor o menor control de aquello que comunican. Ahora bien, dentro de esta categoría de mecanismos de articulación secundaria y reforzamiento, los principales son:

1) Organización y estructura de la empresa. La organización de la empresa, que comprende fundamentalmente la división de las áreas de trabajo y las responsabilidades funcionales, puede ser la expresión de una lógica no muy estricta. Esto significa que el cumplimiento de la tarea primordial depende de una organización adecuada para que la empresa pueda sobrevivir en el ambiente externo, aunque puede suceder que las exigencias de dicha tarea sean confundidas con las presunciones relativas a las relaciones internas y a la forma de trabajo, que se desprenden más bien del criterio del fundador que de un análisis real.

En este sentido, tanto la organización inicial de la empresa como las posteriores reordenaciones, ofrecen la oportunidad para que el líder pueda implantar sus más profundas presunciones respecto a las tareas y a los medios, para ajustarlas a la naturaleza de los individuos y al tipo de relaciones que se quiera incentivar entre ellos. Algunos líderes tienen la capacidad de explicar el por qué han organizado la compañía del modo como lo han hecho; pero otros, que incluso aparentan actuar racionalmente, no son conscientes de las presunciones que están fomentando. 
2) Sistemas y procedimientos. La parte más visible del funcionamiento de las organizaciones resultan ser los ciclos, ya sean diarios, mensuales o anuales de las rutinas, los informes, los registros, y todas aquellas tareas que sean realizadas frecuentemente. Los sistemas y procedimientos cumplen así una función similar a la de la estructura formal: hacen que la vida sea previsible y, en consecuencia, reducen la ambigüedad y la ansiedad.

Entonces, como las personas buscan esa forma de estabilizarse y reducir la ansiedad, los fundadores y los líderes pueden reforzar sus presunciones mediante la creación de sistemas y procedimientos. Estos, pueden formalizar por ejemplo el proceso de "prestar atención”, para reforzar el mensaje de que el líder se preocupa por determinadas cosas. Es por ello que las rutinas suelen servir para recordar a los subordinados qué es a lo que se le otorga la prioridad, porque si los líderes y los fundadores no conciben sistemas y procedimientos en calidad de mecanismos de reforzamiento, le dejan libre la entrada a incongruencias en la cultura o debilitan su propio mensaje.

3) Diseño del espacio físico, fachadas y edificios. Esta categoría comprende todas las características visibles de la organización. Los mensajes que pueden deducirse del entorno físico son, como en el caso de la estructura y los procedimientos, fiel sustento de los mensajes del líder, pero sólo si se conciben para tal fin. Si no se conciben para ello, pueden reflejar las presunciones de los arquitectos, los recursos que dispone la empresa, las normas de una comunidad u otras presunciones sub culturales.

Es por este motivo que los líderes que poseen un estilo definido, normalmente eligen incorporarlo en las manifestaciones visibles de sus empresas. Por ejemplo, se observa el estilo en la distribución de las oficinas, de forma tal que podría señalar la importancia que se le otorga a la igualdad, a la libertad de las comunicaciones y a las relaciones. Tales artefactos físicos no son casuales o fortuitos sino que reflejan las presunciones básicas sobre la forma de realizar las tareas, la de conducir las relaciones y la de arribar a la verdad. De allí que sea posible aprender de estos artefactos, siempre que se conozca cómo interpretarlos.

4) Anécdotas sobre los acontecimientos y las personas. A medida que un grupo desarrolla su historia, una parte de la misma va siendo expresada a través de anécdotas sobre las actuaciones de los líderes. Las anécdotas, que pueden ser dadas en forma de parábola, leyenda o mito, tienen como función reforzar las presunciones y educar a los nuevos miembros. No obstante, debido a que el mensaje dado en la anécdota aparece con frecuencia tamizado o de manera ambigua, ésta forma de comunicación no resulta muy fidedigna. A ello se le suma que los líderes no pueden controlar todo el tiempo lo que se dice de ellos en dichas anécdotas. Ahora bien, lo que si pueden hacer, es reforzar las anécdotas que consideren buenas, e incluso también introducir anécdotas 
portadoras de mensajes deseados. Además, los líderes tienen la opción de situarse en un lugar visible para aumentar la probabilidad de que se cuenten anécdotas sobre ellos, si bien en ocasiones, este intento de manejar el mensaje sólo consigue traer repercusiones negativas en la medida en que la anécdota muestre las incongruencias que los observadores aprecian en el líder.

5) Declaraciones formales sobre la filosofía, credos y estatutos de la empresa. La declaración formal es un recurso utilizado para enfatizar los valores y las presunciones. Estas declaraciones resaltarán únicamente una parte del conjunto de presunciones que opera en el grupo y pueden ser de utilidad para el líder como medio para señalar los puntos de especial interés para la empresa, como por ejemplo, los valores alrededor de los cuales deben unirse los miembros y las presunciones fundamentales que no deben ser soslayadas. A pesar de esto, las declaraciones formales no pueden ser entendidas como un medio para realizar una definición completa de la cultura de la empresa. Pueden abarcar simplemente una mínima porción de la "esfera pública" de la cultura, es decir, que sólo cubre aquellos aspectos que los líderes consideran conveniente publicar en calidad de ideología de la organización. En cualquier caso, la claridad no se consigue por intermedio de estas declaraciones públicas, sino más bien, por la estimación de todo el espectro de mensajes discutidos.

\section{E. Conclusión}

Del análisis hasta aquí realizado, resulta que el liderazgo es un arte, en cuanto aptitud y/o don, complejo. Es uno de los fenómenos más observados, pero al mismo tiempo, uno de los menos comprendidos como resultado de la imposibilidad de disponer de una única respuesta acerca de cuál es el estilo de liderazgo más adecuado o más eficiente o más eficaz, ya que adoptar una u otra manera de liderazgo dependerá básicamente de los seguidores (capacidad, lealtad, etc.) y del contexto.

El liderazgo necesita tener un encuadramiento de tiempo y lugar, debido a que se modifica con la evolución del hombre, de las ciencias y de las artes. Es sabido que no se lidera de igual modo a los argentinos que a los suecos o a los japoneses. Es decir que en esto, no hay sistemas ni recetas por la razón de que en el liderazgo se trabaja con elementos humanos antes que con ninguna otra cosa y, los recursos humanos, tienen características propias que se relacionan con el tiempo, con su evolución, con el lugar, con la cultura propia de los pueblos. En este sentido, por ejemplo, se observa que se lidera de manera distinta en el ámbito militar: donde el personal está educado en una disciplina jerárquica en la cual normalmente casi nadie dice que no; que en la política, donde la cuestión es distinta ya que, a pesar de que en ella hay algunos intransigentes, debe ser un juego de flexibilidad, de respeto. Solamente se debe ser intransigente en los grandes principios y luego ser tolerante hasta con la intolerancia. Por lo tanto, al líder se lo concibe como 
un hombre de acción que nunca puede ser autoritario ni intransigente porque la política puede ser definida como el arte de convivir, y, en consecuencia, la convivencia no se hace a base de intransigencia, sino de transacciones. No obstante, a fin de que la sociedad lo siga, debe saber siempre lo que quiere ya que, para convencer, lo primero que tiene que hacer es estar convencido.

Es importante señalar que el liderazgo se comprende o no, pero no se aprende, es el ejercicio del criterio que debe estar basado en una erudición suficiente, por lo que, quien no lo pone en juego y pretende reemplazarlo por la retentiva o por la memoria, nunca será un conductor. La memoria no da resultado ya que los casos concretos de la vida y de la historia del liderazgo, especialmente en la política, no se repiten; es la comprensión del problema (y de la cultura) lo que va a dar la solución. Sin embargo, estudiarlos, ofrece una gimnasia y un entrenamiento que nos hará más sabios para todas las situaciones que puedan presentarse. Ésta es una de las razones por la que liderar es difícil, porque no se trata solamente de liderar sino también de organizar, educar, enseñar, capacitar y por último conducir.

La importancia de contar con un buen liderazgo en las organizaciones, ya sean privadas o públicas, es clave a raíz de que las mismas enfrentan desafíos en forma constante. Sucede que el progreso, especialmente el tecnológico a través de la comunicación, y las incertidumbres en un mundo muy cambiante obligan a tener un líder fuerte, que aprenda y evolucione permanentemente, es decir, que logre adaptarse a las situaciones. Tal es así, que las organizaciones que han permanecido estáticas y que no han sabido adaptarse a los veloces cambios de la sociedad, han sufrido consecuencias tales como la desaparición o la merma en sus posibilidades debido a que las mismas se encuentran necesariamente en una lucha constante por ser cada vez más competitivas. En este sentido, queda claro que un líder capaz, fuerte y comprometido puede guiar mucho mejor a su equipo, empresa o nación hacia el éxito, ya que logra atraer a la sociedad hacia las metas en lugar de empujarlas hacia ellas. No obstante, debemos reconocer que el liderazgo trae otro tipo de consecuencias, como por ejemplo, el desgaste que sufren los líderes porque son vulnerables, corren riesgos e inician el cambio que, generalmente, ofrece resistencia.

Esto también significa que es necesario formar personas capaces de decir y de hacer, aunque, en lo posible, se trata de formar el mayor número de personas capaces de hacer debido a que, por un lado, en nuestro país generalmente se forman individuos en la parte de "decir" -que es la más fácil de la conducción- y que, por el otro, siendo que lo difícil es liderar, -ya que el liderazgo es un arte principalmente de acción- los líderes tienen que ser capaces de tomar una resolución y ejecutarla. De esta manera, dentro de los grandes principios desarrollados que resultan el esqueleto de todo el liderazgo -traducido en conducción- resulta necesario destacar la importancia de que se capacite sobre todo en la esfera de la moral, es decir, que tenga los 
lineamientos de una ética sin la cual la política (o el sector privado) resulta un oficio oscuro y muchas veces perjudicial.

Particularmente, en cuanto a las organizaciones, se puede observar que no se generan de manera accidental o casual, sino que están orientadas hacia un propósito específico y nacen porque es sabido que, a través de la acción coordinada de un grupo de personas se puede realizar lo que no se consigue mediante la acción individual. Entonces, como el liderazgo es fundamental, toma relevancia en las empresas la formación de líderes; para lo cual se necesitan maestros, entrenadores (coach) o capacitadores, siendo lo más conveniente que éste rol sea ejercido por otros líderes, es decir, que es conveniente conseguir líderes de líderes. De ello se deriva que, cuando se habla de desarrollo de líderes, inevitablemente se hace referencia al crecimiento interior y a la transformación individual de una persona que tiene la voluntad de convertirse en un buen líder. Lógicamente el aprendizaje y la evolución también son generados mediante otras fuentes, como es el caso del aprendizaje individual y el que deriva del entorno organizacional o social.

En resumen, y luego del análisis efectuado, ratificamos la hipótesis propuesta en el presente trabajo, quedando en evidencia no sólo que las organizaciones exitosas poseen grandes líderes, sino también que resulta de suma importancia que las instituciones que quieran mejorar el rendimiento, deben invertir en la capacitación, formación y participación de aquellos que serán los encargados de conducir el destino de la sociedad toda.

\section{F. Bibliografía}

\section{De Metodología}

- Eco, Umberto (2002): Cómo se hace una tesis, Barcelona: Editorial Gedisa.

- Hernández Sampieri, Roberto, Fernández Collado, Carlos y Baptista Lucio, Pilar (1997): Metodología de la investigación, Santafé de Bogotá: McGraw-Hill.

- Hughes, John y Sharrock, Wes (1999): La filosofia de la investigación social, México D.F.: Fondo de Cultura Económica.

- Khun, Thomas (1971): La estructura de las Revoluciones Cientificas, México D.F.: Fondo de Cultura Económica.

- Marradi, Alberto, Archenti, Nélida y Piovani, Juan Ignacio (2007): Metodología de las Ciencias Sociales, Buenos Aires: Emecé.

- Página Web de la Universidad Nacional de Río Cuarto, Facultad de Economía (www.eco.unrc.edu.ar), materia Metodología de la ciencia 1: www.eco.unrc.edu.ar/wp-content/uploads/2011/03/unidad3MC.doc

En esta materia se cita entre otros a: Gianella, Alicia (2000): Introducción a la Epistemología y a la Metodología de la Ciencia, La Plata: Editorial de la Universidad Nacional.

- Popper, Karl (1962): La lógica de la investigación científica, Madrid: Tecnos.

\section{Específica}

- Arendt, Hannah (2012): La condición humana, Buenos Aires: Paidós. 
- Aristóteles (2005): Política, Buenos Aires: Losada.

- Balandier, Georges (1994): El poder en escena: De la representación del poder al poder de la representación, Barcelona: Paidós.

- Bay, Christian (1961): La estructura de la libertad, Madrid: Editorial Tecnos S.A..

- Berger, Peter y Luckmann, Thomas (1994): La construcción social de la realidad, Buenos Aires: Amorrortu.

- Beattie, John (1972): Otras culturas, México: F.C.E..

- Bobbio, Norberto, Matteucci, Nicola y Pasquino, Gianfranco (2008): Diccionario de politica. Volumen I y Volumen II, México: Siglo XXI Editores.

- Bobbio, Norberto (1986): “¿Gobierno de los hombres o gobierno de las leyes?”, en El futuro de la democracia, México D.F., FCE, p. 120-136.

- Boivin, Mauricio, Rosato, Ana y Arribas, Victoria (1998): Constructores de otredad: Una introducción a la Antropología Social y Cultural, Buenos Aires: Eudeba.

- Bourdieu, Pierre (2002): “La economía de los bienes simbólicos”, en Razones prácticas, Barcelona: Anagrama, p. 159-201.

- Castaño Sánchez, Rafael (2013): Un nuevo modelo de liderazgo por valores, Madrid: Universidad de Alcalá. Departamento de Economía y Dirección de Empresas. (Fuente: http://dspace.uah.es/dspace/handle/10017/20002)

- Contreras, Manuel (2004): El liderazgo en la gestión politica: del postulado a la complejidad de su implementación, Madrid: IX Congreso internacional del CLAD sobre la reforma del Estado y de la Administración pública,.

- Daft, Richard (2006): La experiencia del liderazgo, México D.F.: International Thomson Editores.

- Durham, Eunice (1984): “Cultura e ideología”, Río de Janeiro: Dados, Revista de Ciencias Sociales 27.

- Felcman, Isidoro (2001): Marco conceptual y referencial para el análisis de la cultura organizacional de la administración pública argentina, Buenos Aires, 5-9 Noviembre: VI Congreso internacional del CLAD sobre la reforma del Estado y de la Administración Pública.

- Freund, Julien (1968): La esencia de lo politico, Madrid: Editora Nacional.

- García Canclini, Néstor (1995): Ideología, Cultura y Poder, Buenos Aires: Facultad de Filosofía y Letras UBA, Serie Cursos y Conferencias $\mathrm{N}^{\circ} 5$.

- Geertz, Clifford (1973): La interpretación de las culturas, Buenos Aires: Gedisa Editorial.

- Giddens, Anthony (1993): Emile Durkheim. Escritos selectos, Buenos Aires: Nueva visión.

- Goleman, Daniel (2000): La inteligencia emocional, Buenos Aires: Vergara.

- Heifetz, Ronald (1997): Liderazgo sin respuestas fáciles, Barcelona: Paidos.

- Hobbes, Thomas (2004): Leviatán: Tomos I y II, Buenos Aires: Losada.

- Janowitz, Morris (1990): El Soldado Profesional, Madrid: Ministerio de Defensa de España. Y Gil Muñoz, Carlos. Introducción a la edición española, Madrid: Ministerio de Defensa de España.

- Kant, Immanuel (2002): Fundamentación para una metafísica de las costumbres, Madrid: Alianza Editorial.

- Koontz, Harold y Weihrich, Heinz (1998): Administración. Una perspectiva global, México D.F.: McGraw-Hill.

- Losada i Marrodán, Carlos edtr. (1999): ¿De burócratas a gerentes? Las ciencias de la gestión aplicadas a la administración del Estado, Washington, D.C.: Banco Interamericano de Desarrollo.

- Maquiavelo, Nicolás (2003): El príncipe, Buenos Aires: Longseller.

- Platón (2008): República, Avellaneda, Buenos Aires: Eudeba.

- Puglisi, Alfio (1999): Conducir, Buenos Aires: Instituto de Publicaciones Navales. 
- Regatky, Ariel (2001): Investigación exploratoria sobre culturas organizacionales privadas. El caso de las medianas y grandes empresas de Capital Federal y Gran Buenos Aires: comparación con las organizaciones públicas, Buenos Aires: VI Congreso Internacional del CLAD sobre la reforma del Estado y de la Administración Pública.

- Schein, Edgar (1988): La cultura empresarial y el liderazgo, Barcelona: Plaza y Janes Editores S.A..

- Schmitt, Carl (1991): El concepto de lo político, Madrid: Alianza.

- Serrano Gómez, Enrique (2002): Consenso y Conflicto. Schmitt y Arendt: la definición de lo político, Medellín: Editorial Universidad de Antioquia. Instituto de Estudios Políticos de la Universidad de Antioquia.

-Thompson, John (1998): Ideología y cultura moderna, México D.F.: Universidad Autónoma Metropolitana.

- Tomás de Aquino (2002): La monarquía, Madrid: Tecnos.

- Weber, Max (1964): Economía y sociedad, México D.F.: Fondo de cultura económica.

- Weber, Max (2009): El político y el cientifico, Buenos Aires: Prometeo.

\section{De contexto}

- Abeles, Marc (1997): “Antropología política: nuevos enfoques”, Revista Internacional de Ciencias Sociales, p.153.

- Aron, Raymond (1967): El opio de los intelectuales, Buenos Aires: Ediciones Siglo Veinte.

- Auyero, Javier (2001): La política de los pobres, Buenos Aires: Manantial.

- Ayuso, Emilio (2006): Las acciones positivas en la Constitución Nacional: Debates de actualidad, Año XXI, N ${ }^{\circ}$ 196.

- Bidart Campos, German (1989): Teoría general de los Derechos Humanos, México: Universidad Nacional Autónoma de México.

- Bauman, Zygmunt (1996): Racismo, antirracismo y progreso moral: El genocidio ante la historia, Buenos Aires: Eudeba.

- Benedict, Anderson (1993): Comunidades imaginada: Reflexiones sobre el origen y la difusión del nacionalismo, México D.F.: Fondo de Cultura Económica.

- Cohen, Abner (1979): “El análisis del simbolismo en las relaciones de poder", en Llobera, José comp., Antropología política, Barcelona: Anagrama.

- Cohen, Ronald (1979): “El sistema politico”, en Llobera, José comp., Antropología política, Barcelona: Anagrama.

- Collo, Paolo y Sessi, Frediano (2001): Diccionario de la tolerancia: ver apartado de Norberto Bobbio: Iguales y Diversos, Bogotá: Editorial Norma.

- Colson, Elizabeth (1979): "Antropología política”, en Llobera, José comp., Antropología política, Barcelona: Anagrama.

- Durant, Will (1961): Historia de la filosofia. De Sócrates a Jhon Dewey, Buenos Aires: Joaquín Gil Editor.

- Foucault, Michel (2006): Seguridad, Territorio y Población. Curso en el College de France (1977 - 1978), México D.F.: Fondo de Cultura Económica.

- Freud, Sigmund (1921): Psicología de las masas y análisis del yo, Buenos Aires: Amorrourtu.

- Ferrero, Guglielmo (1943): El Poder. Los genios invisibles de la ciudad, Buenos Aires: Editorial Interamericana.

- Gargarella, Roberto (1999): Las teorías de la justicia después de Rawls: Un breve manual de filosofía política, Barcelona: Paidós.

- Habermas, Jürgen (1985): Conciencia moral y acción comunicativa, Barcelona: Homo sociologicus ediciones península. 
- Linchetta, María Cristina (2013): Legitimidad y Legitimación en la Argentina 1853-1930. Una relación dialéctica que no siempre resulta condición veritativa, La Plata: Tesis de Doctorado. En página Web: sedici.unlp.edu.ar/handle/1095/38112

- Lins Ribeiro, Gustavo (1989): “Descotidianizar: extrañamiento y conciencia práctica, un ensayo sobre la perspectiva antropológica", en Cuadernos de Antropología Social, Sección Antropología Social, Instituto de Ciencias Antropológicas, Facultad de Filosofía y Letras-UBA, v2, nro. 1.

- Lutero, Martín (1990): Escritos políticos, Madrid: Tecnos.

- Nino, Carlos (1992): Fundamentos de derecho constitucional, Buenos Aires: Astrea.

- Poulantzas, Nicos (1985): Poder politico y clases sociales en el estado capitalista, México: Siglo XXI Editores.

- Puccinelli, Oscar. El principio de igualdad en occidente. Alcances y perspectivas. E.D. (t.142) 903.

- Quiroga Lavié, Humberto, Benedetti, Miguel y Cenicacelaya, María de las Nieves (2001): Derecho constitucional argentinto. Tomo II, en Rubinzal - Culzoni edtrs.

- Saskia, Sassen (2007): Una sociología de la globalización, Buenos Aires: Editorial Katz.

- Sun Tzu (2002): El arte de la guerra, Buenos Aires: Longseller.

- Von Clausewitz, Karl (2005): De la guerra, Buenos Aires: Agebe 